\title{
Analytical Evaluations of Buckling Behavior of Wood Composite I- Joist with Sinusoidal Web
}

Pengcheng Jiao

West Virginia University

Follow this and additional works at: https://researchrepository.wvu.edu/etd

\section{Recommended Citation}

Jiao, Pengcheng, "Analytical Evaluations of Buckling Behavior of Wood Composite I-Joist with Sinusoidal Web" (2012). Graduate Theses, Dissertations, and Problem Reports. 139.

https://researchrepository.wvu.edu/etd/139

This Thesis is protected by copyright and/or related rights. It has been brought to you by the The Research Repository @ WVU with permission from the rights-holder(s). You are free to use this Thesis in any way that is permitted by the copyright and related rights legislation that applies to your use. For other uses you must obtain permission from the rights-holder(s) directly, unless additional rights are indicated by a Creative Commons license in the record and/ or on the work itself. This Thesis has been accepted for inclusion in WVU Graduate Theses, Dissertations, and Problem Reports collection by an authorized administrator of The Research Repository @ WVU. For more information, please contact researchrepository@mail.wvu.edu. 


\title{
Analytical Evaluations of Buckling Behavior of Wood Composite I-Joist with Sinusoidal Web
}

\author{
Pengcheng Jiao \\ Thesis submitted to the \\ College of Engineering and Mineral Resources \\ at West Virginia University \\ in partial fulfillment of the requirements \\ for the degree of \\ Master of Science \\ in \\ Civil Engineering \\ Indrajit Ray, Ph.D., Chair \\ An Chen, Ph.D., Co-Chair \\ Radhey Sharma, Ph.D. \\ Department of Civil and Environmental Engineering \\ WEST VIRGINIA UNIVERSITY \\ Morgantown, West Virginia \\ May 2012
}

Keywords: Lateral-Torsional Buckling, Local Buckling, Analytical Evaluations, Finite Element (FE) Simulation, Experiment

Copyright @ 2012 Pengcheng Jiao 


\section{ABSTRACT \\ Analytical Evaluations of Buckling Behavior of Wood Composite I-Joist with Sinusoidal Web}

\section{Pengcheng Jiao}

Flexural-torsional buckling or lateral torsional buckling is an important limit state for wood composite I-joist because the in-plane bending stiffness is typically greater than torsional lateral bending stiffness. Web local buckling is another important limit state because of the thin-walled web configuration. To increase the buckling capacities of wood composite I-joist, a new structural wood composite I-joist with sinusoidal web has been developed at West Virginia University. Extensive experimental investigations have been conducted in a companion study (McGraw, 2012). This study presents analytical evaluations of buckling behavior, including flexural-torsional buckling of simply-supported beam and cantilever beam, and local buckling of web panel under compression.

Critical buckling loads are predicted using energy method. The analytical results are verified against the experimental results from McGraw (2012) and Finite Element analysis, where good agreement can be observed. The analytical models are further employed to conduct a parametric study to evaluate the effects of the length and height of the I-joist on global flexural-torsional buckling and elastic restraint at the flange-web joint on local compressive buckling of the web panel.

The analytical solutions developed in this study can be extended to determine the buckling capacities of I-joist with different web geometries. 
To my beloved parents, Hongqi Jiao and Ying Zhang, who have been wholeheartedly supporting me in all my endeavors. 


\section{ACKNOWLEDGEMENTS}

First of all, I would like to express my sincere gratitude and appreciation towards my advisor Dr. Julio F. Davalos for providing me with the opportunity to embark upon graduate study. His support, vast knowledge, and encouragement are greatly acknowledged.

I would like to give my sincerely grateful to my co-advisor Dr. An Chen. I would not have been able to complete this work successfully without his expertise guidance and constructive suggestions over the past three years. I would also like to appreciate the help from my co-advisor Dr. Indrajit Ray, the Chair of my thesis committee, who brought a friendly research environment and valuable assistance to me in many ways. Meanwhile, I must thank Dr. Sharma for his support during the past half of a year and willingness to serve as one of my committee members.

I greatly appreciate Dr. David B. DeVallance for allowing me to use the INSTRON machine in Forestry department. I also acknowledge Mr. David Turner for his immense technical assistance in the concrete laboratory.

I would like to thank Bradley McGraw, Mehrzad Zahabi, Manish Roy, John Wattick, Arkamitra Kar, and Subhadeep Ghosh for helping me in associate tasks. I would also like to thank other members of B-11 and friends for making the graduate life at WVU more memorable.

I am grateful to other family members and friends back in China for taking care of my parents in my absence. 


\section{TABLE OF CONTENTS}

ABSTRACT

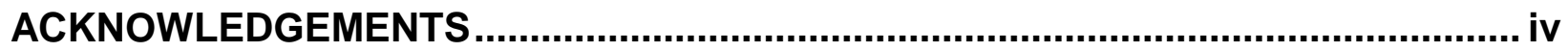

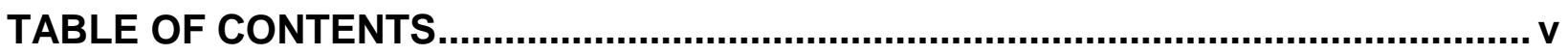

LIST OF FIGURES................................................................................................. viii

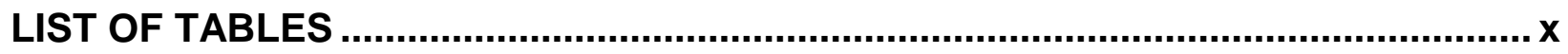

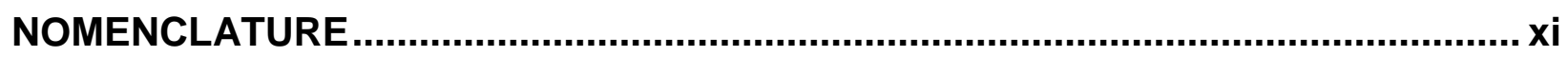

CHAPTER

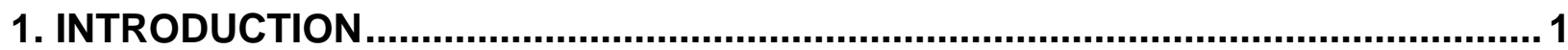

1.1 Problem Statement and Research Significance ............................................. 2

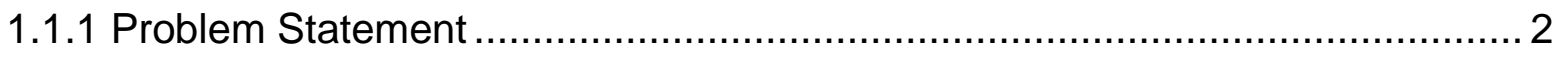

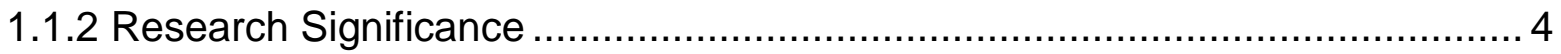

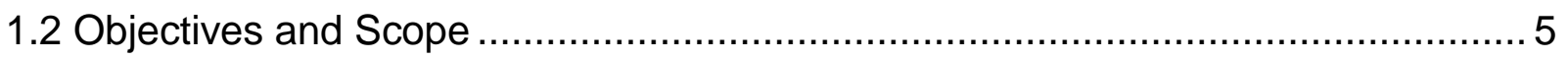

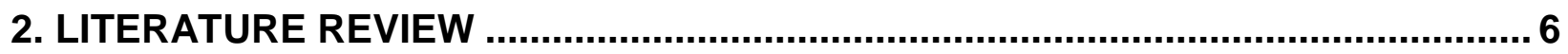

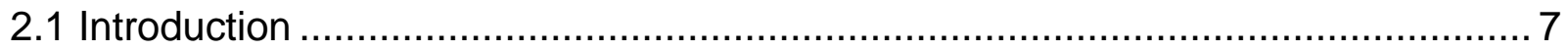

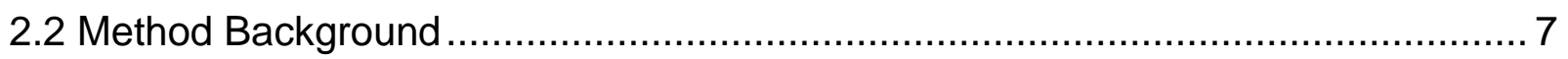

2.3 Influence of Flanges to I-Beam Buckling Capacities .......................................... 8

2.4 Influence of Webs to I-Beam Buckling Capacities.............................................. 10

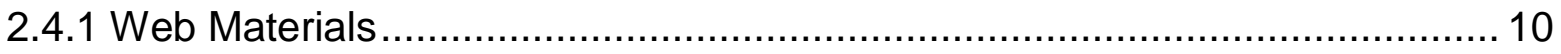

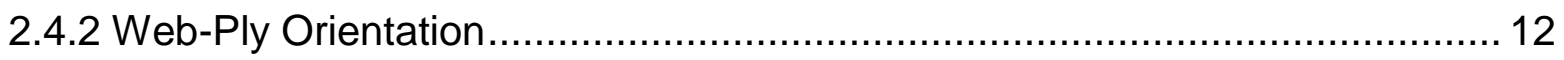

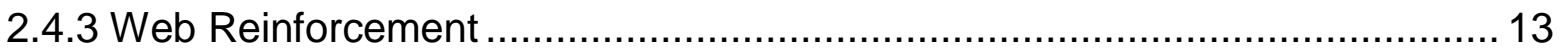

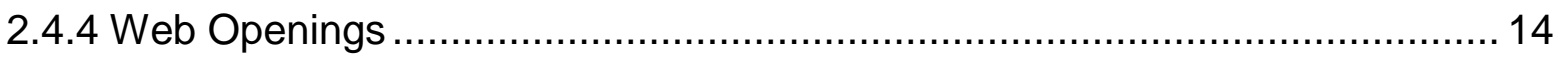

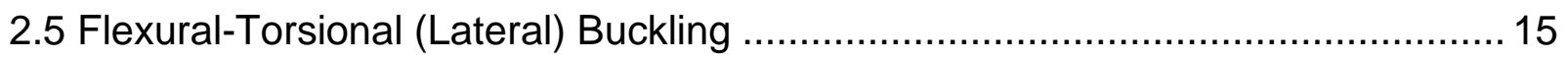

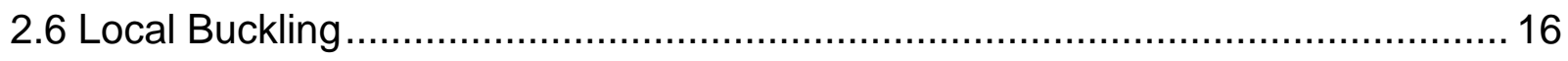




\section{FLEXURAL-TORSIONAL BUCKLING OF I-BEAMS WITH SINUSOIDAL WEB}

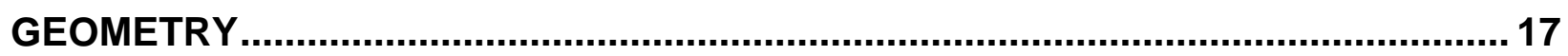

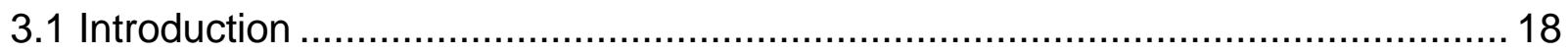

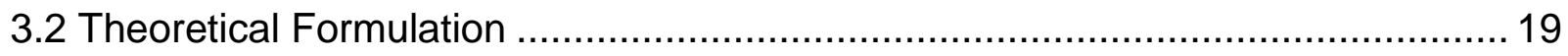

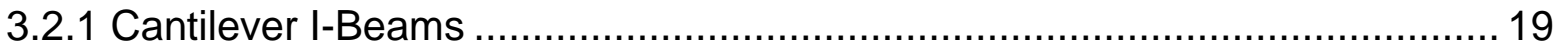

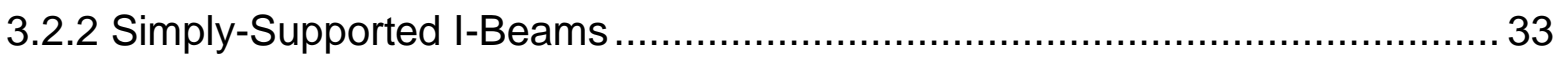

3.3 Verification with Existing Solutions of Flat Web I-Beams ................................. 42

3.4 Verification with Experimental Investigation of Sinusoidal Web I-Beams............. 46

3.5 Verification with Finite Element Simulation of Sinusoidal Web I-Beams .............. 48

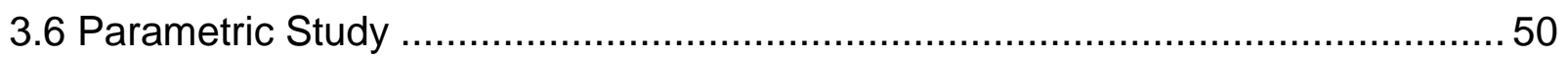

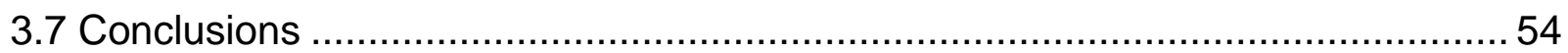

\section{LOCAL BUCKLING CAPACITIES OF SINUSOIDAL WEB I-BEAMS UNDER}

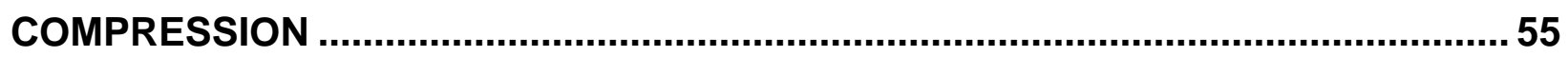

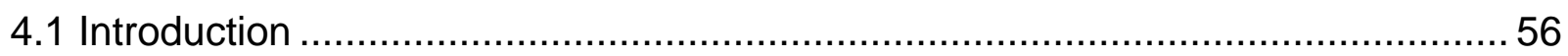

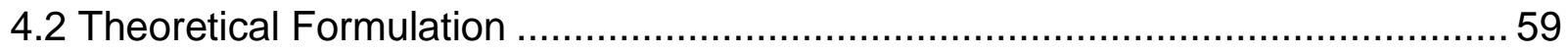

4.3 Verification with Finite Element Simulation .................................................. 67

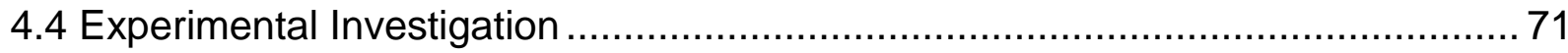

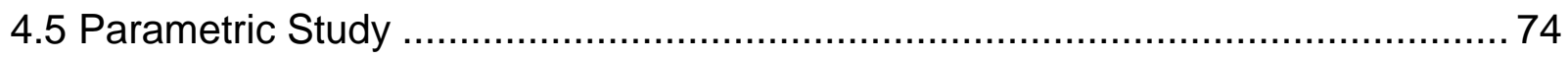

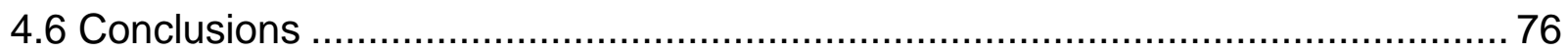

5. CONCLUSIONS AND RECOMMENDATIONS ...................................................... 77

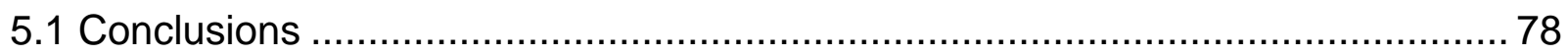

5.1.1 Flexural-Torsional Buckling of Composite I-Beams with Sinusoidal Web ...... 78

5.1.2 Local Buckling of Sinusoidal Web I-Beams............................................. 78

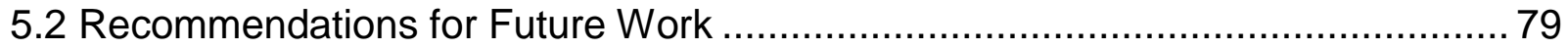




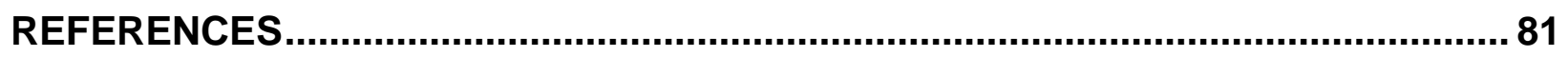

APPENDIX

BRIEF INTRODUCTION OF ENERGY METHOD....................................................90

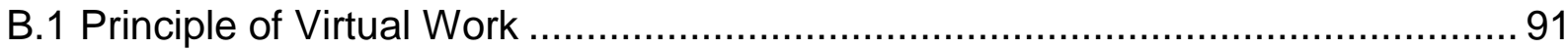

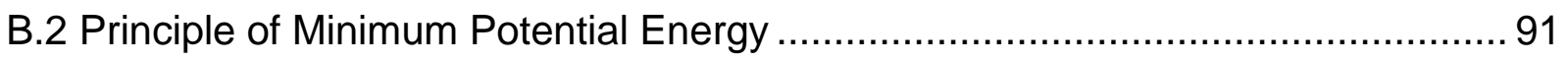

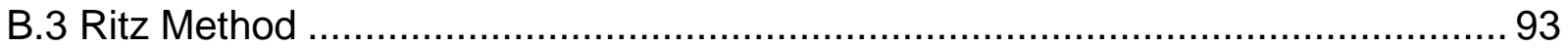




\section{LIST OF FIGURES}

Figure 1.1 a\&b Flexural-Torsional and Lateral-Distortional Buckling ..................... 2,3

Figure 1.2 Composite I-Beams with Sinusoidal Web Geometry .............................. 4

Figure 3.1 Cantilever I-Beam under Tip Load $P$............................................ 20

Figure 3.2 Cross-Sectional Geometry of Wood I-Beam .......................................2 20

Figure 3.3 Top Flange Deflections under Tip Load $P$....................................... 21

Figure 3.4 Deformed Shape of Sinusoidal Web ……............................................. 25

Figure 3.5 Membrane Forces of the Sinusoidal Web in $x-y$ Plane .......................... 28

Figure 3.6 Simply-Supported I-Beam under Centric Load $P$.............................. 33

Figure 3.7 Coordinate System and Geometry of Flat Web I-Beam ........................ 43

Figure 3.8 Flat Web I-Beam Buckled I3x6 Beam ............................................ 43

Figure 3.9 Composite Wood I-Beam Samples with Flat Web................................. 44

Figure 3.10 a\&b Composite Wood I-Beam Samples with Sinusoidal Web .............. 47

Figure 3.11 Deformed Shape of Sinusoidal Web I-Beam with Cantilever Boundary Conditions for Flexural-Torsional Buckling ....................................................... 49

Figure 3.12 Deformed Shape of Flat Web I-Beam with Cantilever Boundary Conditions for Flexural-Torsional Buckling ......................................................... 49

Figure 3.13 Cross-Sectional Geometry of Simply-Supported I-Beam ......................50

Figure 3.14 Sinusoidal Web Critical Buckling Load vs. Web Height.........................53

Figure 3.15 Critical Buckling Load $P_{c r}$ Comparisons between Sinusoidal Web and Flat

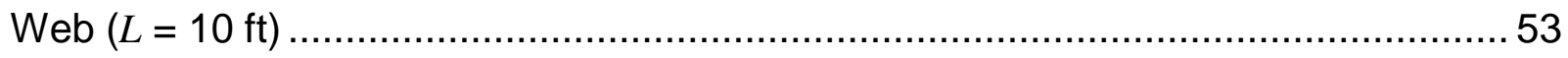


Figure 3.16 Critical Buckling Load $P_{c r}$ Comparisons between Sinusoidal Web and Flat

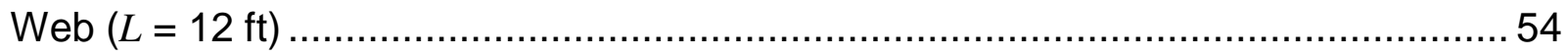

Figure 4.1 Composite I-Beams with Sinusoidal Web …...................................... 57

Figure 4.2 Mid-Surface of Sinusoidal Web in $x-y$ Plane ........................................ 59

Figure 4.3 Sinusoidal Panel under Axial Compression ........................................ 60

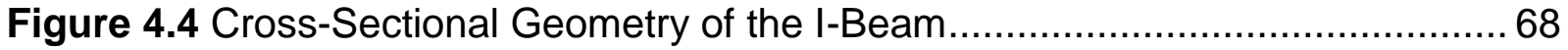

Figure 4.5 First Buckling Mode for 10" Sinusoidal Web I-Beam ............................... 69

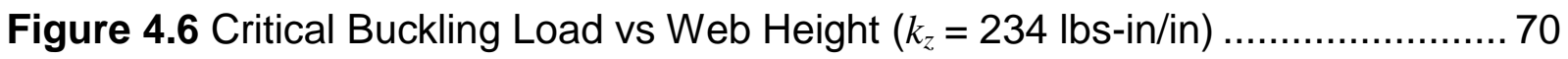

Figure 4.7 Buckling Load vs Spring Stiffness Coefficient for Elastic Restraints ........ 71

Figure 4.8 Sinusoidal I-Beam Compression Test .................................................. 72

Figure 4.9 Critical Buckling Load vs Spring Stiffness for Various Heights................. 75

Figure 4.10 Critical Buckling Load vs Web Height for Various Rotational Restraint

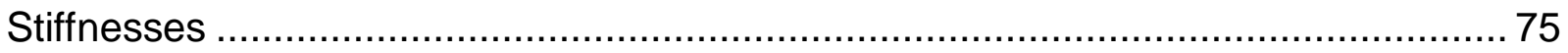




\section{LIST OF TABLES}

Table 3.1 Material Properties of I-Beams 45

Table 3.2 Comparison of Critical Buckling Loads $P_{c r}$ between Existing Results and

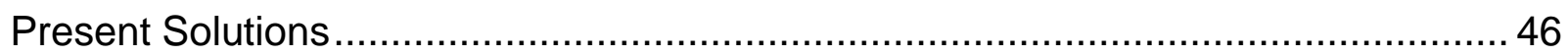

Table 3.3 Comparison of Critical Buckling Loads $P_{c r}$ between Analytical and

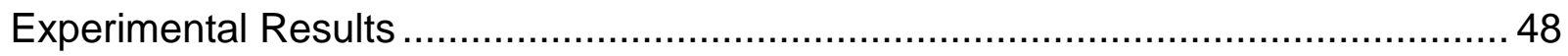

Table 3.4 Comparison of Critical Buckling Loads $P_{c r}$ between Analytical and

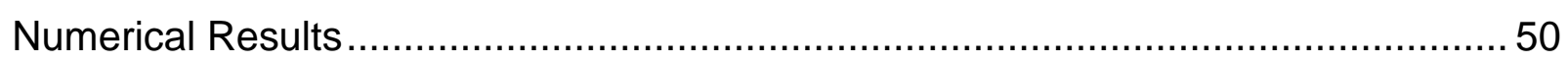

Table 3.5 Comparison of Critical Buckling Loads $P_{c r}$ with Different Heights I ...........51

Table 3.6 Comparison of Critical Buckling Loads $P_{c r}$ with Different Heights II...........51

Table 3.7 Comparison of Critical Buckling Loads $P_{c r}$ with Different Web Geometries I 52

Table 3.8 Comparison of Critical Buckling Loads $P_{c r}$ with Different Web Geometries II 52

Table 4.1 Material Properties of Composite I-Beams 68

Table 4.2 Estimated Value of Buckling Load for Compression Tests, FE Analysis, and Theoretical Formulation 73 


\section{NOMENCLATURE}

\section{$\underline{\text { SYMBOL }}$}

a

A

$A_{i j}, D_{i j}$

$b$

$C_{i}$

E

G

h

I

$K_{z}$

$L$

$M_{x}, M_{y}, M_{x y}$

$N_{x}, N_{y}, N_{x y}$

$P$

$P_{c r}$

$q_{2}$

$R$

s

$t$

$u$

$U$

$U_{b}$

$U^{c b}$

$U^{c t}$

$U^{c w}$

$U_{m}$

$U^{s b}$
DESCRIPTION

sinusoidal web wavelength

sinusoidal web amplitude

orthotropic stiffness matrices

flange width

differential equation constants

Young's modulus

shear modulus

height

moment of inertia

elastic rotational restraint stiffness

beam length

bending and twisting moments

membrane forces

applied concentrated load

critical buckling load

compression force

curvature radius of shell mid-surface

shell length

thickness

displacement in $x$ direction

total strain energy

out-of-plane bending strain energy

bottom flange strain energy of cantilever I-beam

top flange strain energy of cantilever I-beam

web strain energy of cantilever I-beam

membrane strain energy

bottom flange strain energy of simply-supported I-beam 


$\begin{array}{ll}U^{s t} & \text { top flange strain energy of simply-supported I-beam } \\ U^{s w} & \text { web strain energy of simply-supported I-beam } \\ v & \text { displacement in } z \text { direction } \\ w & \text { displacement in } y \text { direction } \\ W & \text { pre-buckling work } \\ w(z) & \text { buckling displacement function } \\ v & \text { Poisson's ratio } \\ \omega & \text { weight constant } \\ \Pi & \text { total potential energy } \\ \delta \Omega & \text { increment in potential of external load } \\ \delta U & \text { change of shell strain energy during buckling } \\ \delta U^{b} & \text { bending strain energy } \\ \delta U^{\Gamma} & \text { elastic restrain } \\ \delta U^{m} & \text { membrane strain energy } \\ \varepsilon_{x}, \varepsilon_{y}, \gamma_{x y} & \text { mid-surface in-plane strains } \\ \kappa_{x}, \kappa_{y}, \kappa_{x y} & \text { mid-surface curvatures } \\ \chi_{x}, \chi_{y}, \chi_{x y} & \text { changes of mid-surface curvature }\end{array}$


CHAPTER ONE INTRODUCTION 


\subsection{Problem Statement and Research Significance}

\subsubsection{Problem Statement}

As one of the two major categories leading to the failure of a mechanical component, structural instability is often called buckling. The I-beams can buckle in various modes depending on the geometry of the cross-section, the material properties, and the boundary and loading conditions, with flexural-torsional and lateral-distortional buckling to be the most common types under bending loads. A long slender beam under bending loads about the strong axis may buckle by combined lateral bending and twisting of the cross section, leading to significant out-of-plane bending and twisting instability. This phenomenon is known as flexural-torsional (lateral) buckling (Figure 1.1 a\&b). For intermediate span beams, a combination of lateral and local buckling may result in lateral-distortional buckling of the section. Lateral-distortional buckling involves out-of-plane bending as well as localized buckling. There are typically two ways to increase the buckling capacity of composite I-beams: either using high quality materials and increased dimensions, or improving the design.

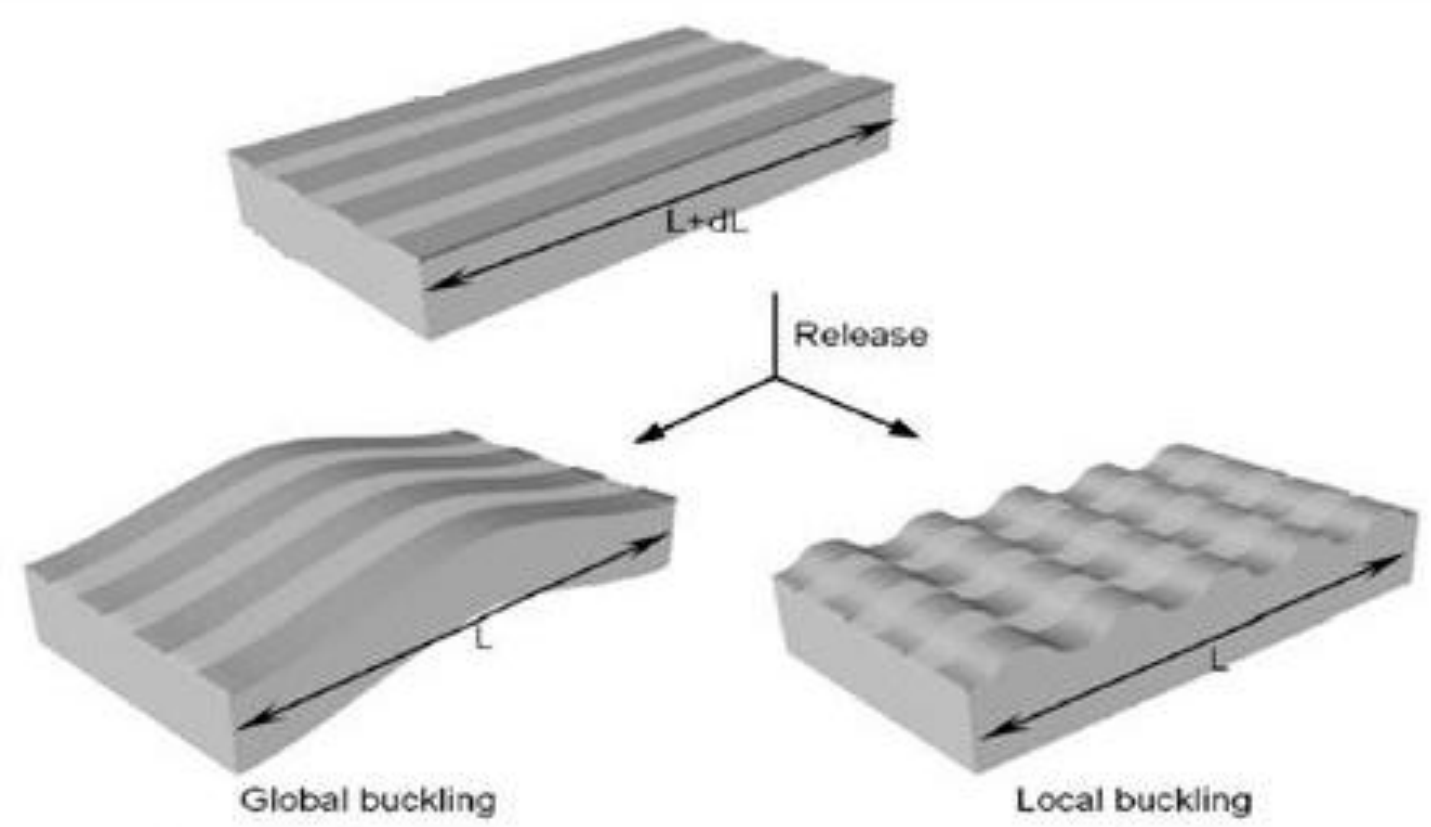




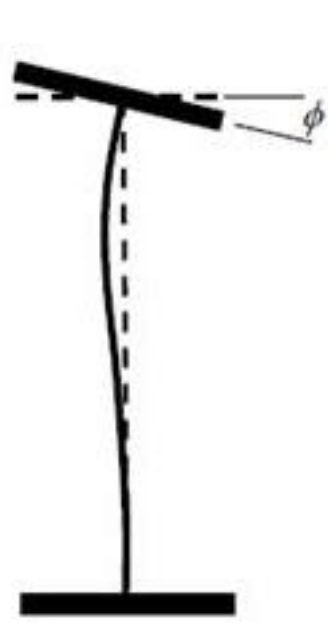

Local buckling

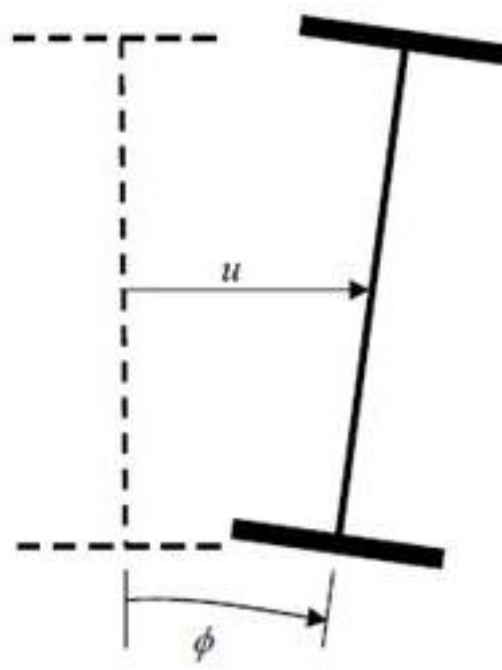

Flexural-torsional buckling

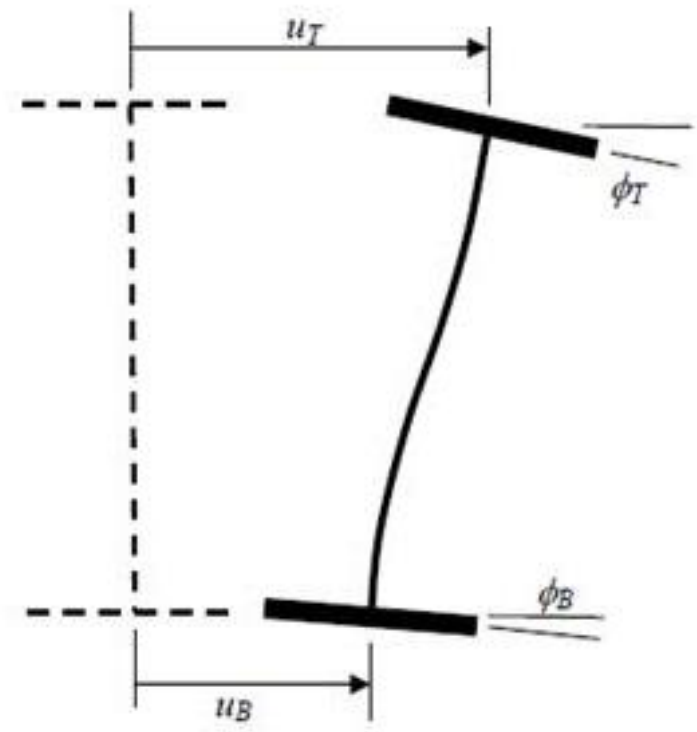

Lateral-distortional buckling

Figure 1.1 a\&b Flexural-Torsional and Lateral-Distortional Buckling

Due to the excellent stiffness and weight characteristics, composite materials have been receiving more attention in I-beams. Therefore, according to extensively using in the form of thin-wall I-beams, theoretical models have been intensively considered by researchers under various loading and boundary conditions. Thus far, however, there is still a need to develop an analytical model for stability of composite Ibeams with various shapes of web, especially sinusoidal web geometry, as shown in Figure 1.2. 


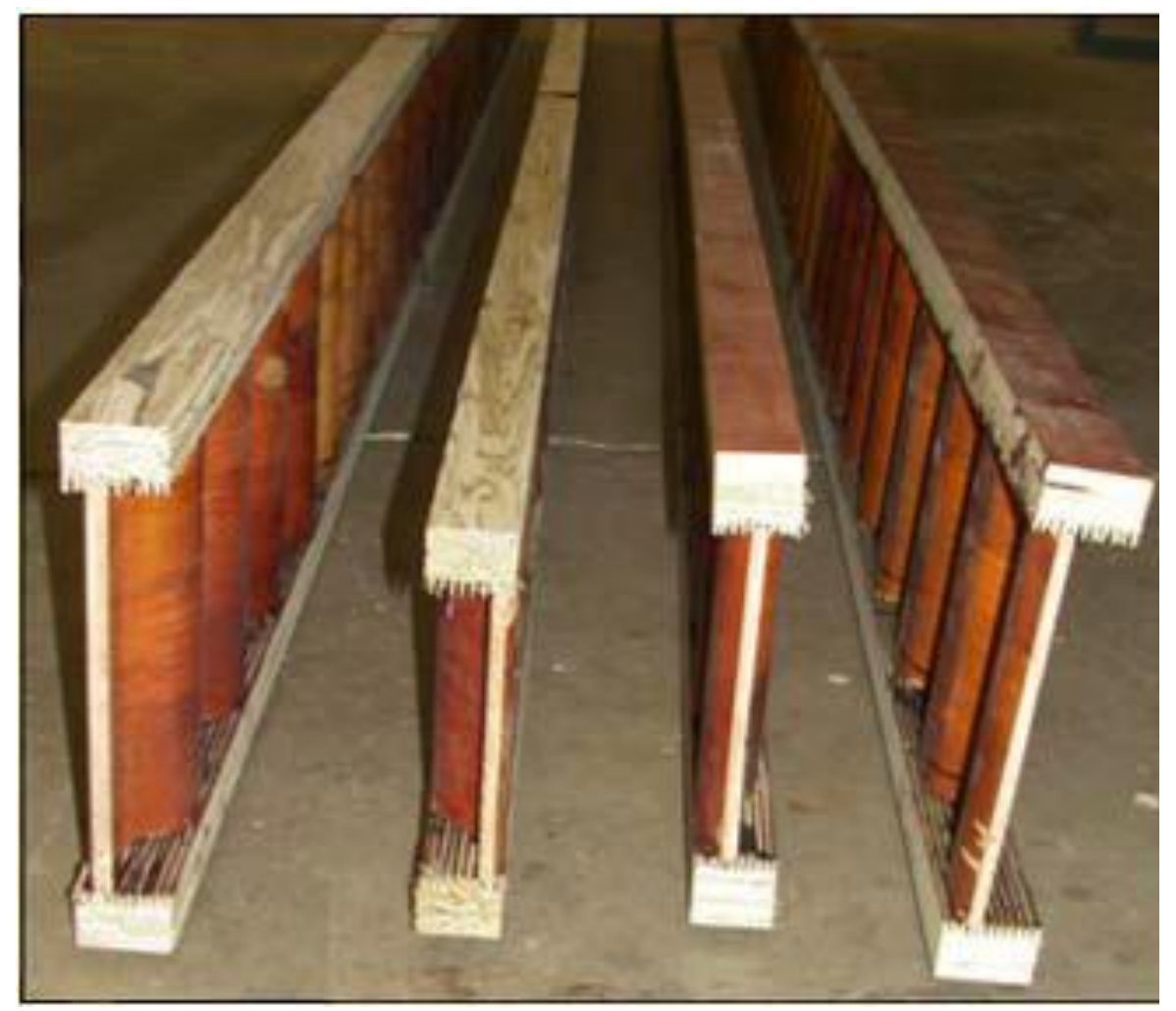

Figure 1.2 Composite I-Beams with Sinusoidal Web Geometry

\subsubsection{Research Significance}

A critical obstacle to the widespread use and applications of composite I-beams in civil engineering is the lack of simplified and practical design guidelines. Unlike standard materials (e.g., steel and concrete), composite materials are typically orthotropic or anisotropic, and their analyses are much more complex.

Because of the complexity of composite structures, common analytical and design tools developed for members of conventional materials cannot always be readily applied to composite structures. Moreover, numerical methods, such as FE method, are often difficult to use, which require specialized training, and are not always accessible to design engineers. Therefore, to expand the applications of composite wood structures, an explicit engineering design approach should be developed. To develop such explicit 
buckling for several typical stability analyses (i.e., flexural-torsional buckling and local buckling) of composite wood structures is the main goal of this thesis.

\subsection{Objectives and Scope}

The objectives of this study are, to first derive an analytical approach based on energy method to characterize flexural-torsional (lateral) buckling of cantilever and simply-supported composite I-beams with sinusoidal web geometry, and sinusoidal Ibeams under uni-axial compression with elastic restrained loaded edges. Experiment and FE simulation are carried out to evaluate the accuracy of the analytical critical buckling load presented. Moreover, the analytical solutions are verified by existing FE and experimental testing results.

Parametric studies are carried out to study the web heights and restraining stiffness effect on the buckling behaviors of composite I-beams with sinusoidal web geometry. Meanwhile, composite I-beams with flat web geometry are reduced by the present analytical model, comparing with the solutions of sinusoidal web geometry, to illustrate the advantages of sinusoidal webs in terms of the buckling capacities. 


\section{CHAPTER TWO}

\section{LITERATURE REVIEW}




\subsection{Introduction}

As stated in Chapter one, the goal of this study is to conduct a stability analysis of composite I-beams. The stability analyses considered in this study consist of two parts: flexural-torsional (Lateral) buckling of composite I-beams with sinusoidal web geometry; and local buckling of composite I-beam with sinusoidal web geometry. Many researchers have conducted different studies in these two areas, therefore it is necessary to present their work chronically and point out the uniqueness of the present study.

In this Chapter, Section 2.2 reviews the background of analytical method, especially the energy method that forms the theoretical foundation for obtaining explicit solutions. Section 2.3 reviews the influence of flanges to buckling capacities of composite I-beams. Section 2.4 reviews the influence of web geometry to buckling capacities of composite I-beams. Section 2.5 reviews the previous researches on flexural-torsional buckling of composite I-beams. Section 2.6 reviews the work on the local buckling analysis of the composite I-beams.

\subsection{Method Background}

The complete analysis of a load-carrying member by the so-called method of equilibrium involves three basic principles. These so-called three aspects of solid mechanics problems can be outlined as statics, deformations and geometry. The solutions based on this procedure must satisfy the boundary conditions. The preceding requirements will be expressed mathematically and used in problems presented.

Energy method, alternatively, is the analysis of stress and deformation can be accomplished based upon the concept of strain energy. The roles of the equilibrium and energy approaches are twofold. They can provide solutions of acceptable accuracy, where configurations of loading and member are regular, and they can be employed as a basis of numerical methods for more complex problems. Therefore, as an alternative to the equilibrium methods, the analysis of deformation and stress in an elastic body can be accomplished by employing energy methods. These two techniques are, 
respectively, the Newtonian and Lagrangian approaches to mechanics. The last is predicated upon the fact that the governing equation of a deformed elastic body is derivable by minimizing the energy associated with deformation and loading. Application of energy method is effective in situations involving irregular shapes, no-uniform loads, variable cross sections, and anisotropic materials.

\subsection{Influence of Flanges to I-Beam Buckling Capacities}

Because the web possesses a somewhat lower modulus of elasticity (MOE), tension and compression stresses are amplified in the flanges (Samson 1981, 1983). As a result, the properties of flange material are especially important. Analytical and empirical methods have been used to evaluate the contributions of the flanges on the basis of material properties, grade, and connection methods.

Because tension flange quality is a major factor in I-beam buckling load, producers utilize machine stress-rated (MSR) lumber, as well as laminated products for flange stock. Early research by Lewis et al. (1960) indicated that excessive slope of grain (1:15 in lumber) reduced I-beam strength by $30 \%$ and that compression damage induced by reverse loading reduced strength $70 \%$.

The influence of flange stiffness on the load capacity of double-webbed I-beams was investigated by Samson in 1983. Statistical analyses showed that more than $50 \%$ of the variations in load capacity of the I-beams were attributed to variation in the average MOE of the tension Range. Flanges were most efficient when the MOE of the tension flange was 1.25 times the MOE of the compression flange. Fergus (1979) also found that the performance of moment-critical beams was governed by flange stiffness and strength and those shear-critical I-beams were also sensitive to flange stiffness. The importance of flange stiffness was also noted by Hilson and Rodd (1979) whose study of the post-buckling behavior of hardboard-webbed I-beams indicated that stiffer flanges resist shape changes and carry greater shear loads after web buckling, leading to increased ultimate loads. 
When the sections of flange material are properly jointed, I-beams longer than stock length lumber can be produced. Structural joints in lumber flanges can be developed with either finger or scarf joints. Although potentially stronger than the finger joint, the scarf joint is more difficult to produce in continuous manufacturing operations. The results of experimental tests on finger-jointed lumber in bending, tension, and compression have generally shown that the stiffness of the joined wood is not affected by the presence of the joint; however, strength is reduced below that of clear wood (Jokerst 1981). This reduction is more significant in higher strength flange material. Studies have shown that the strength of joined wood is reduced about $10 \%$ in compression; however, strength can be reduced as much as $50 \%$ in bending (Jokerst 1981). Nevertheless, in lower grades of lumber the reduction in strength caused by the presence of a joint generally has less effect on flange material than a knot or knothole.

The primary alternative material to sawn-lumber flange stock is laminated veneer lumber (LVL), a unidirectional laminate of graded veneers bonded with an exterior-grade adhesive. This type of lumber has been used extensively in commercial products though some producers utilize parallel-strand lumber. Because of their durability (Laufenberg 1982), reliable mechanical properties, and long lengths, LVL and parallel-strand lumber are well suited for production of structural components without end joints. Though not common commercially, these products are as easily and reliably end-jointed as solid lumber (Youngquist et al. 1984).

Less sophisticated materials have been investigated for use in I-beam flanges. Minimally machined half-stems of lodge pole pine were tested for possible use as flange material by investigators who felt that the product could be competitive with beams using traditional flange types. Ultimate bending tests indicated that failures, evenly divided between tension and compression, occurred largely in the flanges. Several problems need to be resolved before this product is acceptable; crucial problems include establishing methods for joining the stems to produce longer sections, assigning lumber grades, and accommodating the no prismatic and geometrically variable cross sections in design. Because flange quality has a significant influence on I-beam 
performance, Solli and Lackner (1986) proposed evaluating strength properties and lumber quality of small cross-section lumber to establish alternative grading rules.

Flexural stiffness properties of I-beams with flanges molded from particle-based material were found to be comparable to that of a solid lumber beam of equivalent weight (Geimer and Lehmann 1975). However, bending strength was only half that of the lumber-flanged counterpart, and fractures were brittle in nature. The relatively poor performance was attributed to the lower tensile strength of the particle-based flanges.

The quality of flange material needed in wood I-beams is underscored by the fact that manufacturers are increasingly utilizing high quality composite structural lumber products, such as laminated veneer and parallel strand lumber.

\subsection{Influence of Webs to I-Beam Buckling Capacities}

\subsubsection{Web Materials}

Materials such as plywood, particleboard, wafer board, oriented strand board (OSB), and hardboard are characterized by high shear modulus, and shear strengths (through the thickness). Although these composite materials exhibit much lower bending strengths than solid or laminated wood used as flanges, they have higher shear properties.

The effect of shear modulus of the web material on total beam deflection was investigated by Leichti and Tang (1983) using a strain energy approach. As expected, the authors found that a lower shear modulus led to greater shear deflections. This reinforced the findings of Booth (1974), who showed that shear deflection, a major component of total deflection, cannot be ignored in design.

Experimental tests performed by Percival et al. (1977) investigated the stiffness performance of experimental I-beams, constructed with various $1 / 2$-in. web panels and nail-glued 2 by 4 flanges. Panel materials included plywood, underlayment particleboard, aspen wafer board, and mixed-hardwood particleboard. Results indicated that the wafer board-webbed I-beams were about $20 \%$ stiffer than the plywood webbed beams. The 
particleboard-webbed members were 10 percent stiffer. Though stiffness was the primary parameter investigated, Percival et al. (1977) speculated that the type of web material should affect load capacity.

Because of its relatively low variability and high shear modulus, particleboard has been studied as a web material. Johnson et al. (1975) evaluated the performance of shear critical, particleboard-webbed I-beams in flexure. Flexural rigidity and load capacity were estimated on the basis of elastic and strength properties, section geometry, and elementary beam theory. Load capacity was based on the weakest component, assumed to be the tensile strength of the particleboard web. Measured loads were greater than estimated, and failures began near the nails in the glued nailed flanges. Measured flexural rigidity was less than estimated.

The FPL evaluated the use of hardboard as a web substrate through the testing of moment-critical beams constructed with $1 / 4$-in. webs and face-glued lumber flanges (Superfesky and Ramaker 1976). Good agreement between predicted and measured deflections and stresses was reported.

In an extension of their prior study, Superfesky and Ramaker (1976) investigated the effect of web material and span length on mode of failure. TWO different types of hardboard were used as web materials, and all beams had LVL flanges face glued to the web panels. Results of tests on 6- and 12-ft-long beams showed that beam behavior was reasonably well predicted using elementary beam theory with transformed sections and material properties of the components. However, behavior of the shorter and more shear-critical beams as well as that of the longer members did not conform to the theory, even though shear deflections were considered.

In an analysis of load-deflection curves, Superfesky and Ramaker (1976) showed that hardboard-webbed I-beams exhibit linear behavior to a load level equivalent to $60 \%$ of the rail shear strength of the hardboard web. As with the other experimental hardboard-webbed beams, the 12-ft beams failed in the tension flange, with essentially no inelastic deformation before failure. In their later study, Superfesky and Ramaker (1976) included two 1/4-in. hardboards and 1/4-in. plywood as web 
substrates. Under short-term destructive loading, the strength and stiffness of plywoodwebbed beams were found to be about half that of equivalent hardboard- webbed elements.

Tests were conducted on I-beams with commercial insert-type flange-web joints and web panels oriented with the major panel axis perpendicular to the beam span (Leichti 1986). Findings indicated that web material has a statistically significant effect on I-beam stiffness and load capacity. The I-beams with OSB webs carried greater loads than those with wafer board or plywood webs, which had similar load capacities. Stiffness, as measured by load at a defined deflection, was similar for I-beams with OSB and wafer board webs but significantly lower for those with plywood webs. In subsequent studies of I-beams with webs of plywood, random wafer board, or OSB made of southern hardwoods load capacities differed significantly as a result of web material; I-beams with OSB webs carried greater ultimate loads.

\subsubsection{Web-Ply Orientation}

The influence of web material orientation with respect to the beam flexural axis has not been clearly identified. Early experimental studies at the FPL with box and Ibeam constructions (Lewis et al. 1960) concluded that box-beam webs oriented at $45^{\circ}$ were more efficient in carrying shear stresses than webs oriented at 0 or $90^{\circ}$. The studies further demonstrated that vertically and horizontally oriented panels had about the same shear strength.

More recently, the effects of web-ply orientation on the structural performance of wood composite I-beams were examined using FE analysis. The web was idealized as a stack of rectangular plate elements and the flanges as a series of truss elements. In general, the analyses indicated that web crippling performance was improved by increasing the number of web plies with grain perpendicular to the horizontal beam axis. Although this result is not supported by the earlier experimental studies (Lewis et al. 1960), most manufacturers' produce I-beams with the major axis of the web ply oriented perpendicular to the beam axis. 


\subsubsection{Web Reinforcement}

Web reinforcement, an important element of the wood I-beam, serves to prevent flange distortion, web buckling under concentrated loads, knifing of the web through the flange, and lateral sway. Also, web reinforcement can significantly reduce the bearing length required. The requirements for reinforcement vary and are a function of beam geometry and the mechanical properties of the web substrate.

Web buckling was of major concern in early studies with lightweight sections intended for aircraft structures. One study showed that I-beams with plywood webs buckled in elastically under repeated stresses of approximately two thirds the ultimate loads (Lewis et al. 1960).

Web reinforcement is prescribed in the form of either bearing or intermediate stiffeners. Bearing reinforcement is located at reaction positions; such reinforcement increases the web-to-flange bearing area and improves the buckling performance of the web. Stiffeners are designed with consideration given to compression and rolling shear requirements (APA 1982). Maley (1987) found that bearing stiffeners can transfer 80 to $90 \%$ of the reaction capacity in deep I-beams but only 10 to $20 \%$ in shallower beams because the webs of shallow beams resist buckling.

The influence of web stiffeners in hardboard-webbed I-beams was recently investigated by Norlin (1988). Using analytical and experimental methods, he identified stiffener needs according to the ratio of free web height to web thickness and presented a method for estimating optimum stiffener spacing. Specific web-reinforcement requirements are given by the APA (1982), the Wood Handbook (USDA 1987), and various I-beam product manuals.

In general, bearing reinforcement is required at reaction and concentrated load points. According to the APA (1982) intermediate stiffeners spaced 48 in or less on center will develop all or nearly all the shear strength of a beam of normal proportions. 


\subsubsection{Web Openings}

The design of wood composite I-beams must allow for the passage of electrical conduit, plumbing lines, and heating and ventilation ducts to maximize headroom in a building.

Literature devoted to the analysis of openings in the webs of wood I-beams is limited; however, a substantial body of knowledge exists for round and rectangular openings in steel thin-webbed I-sections. Closed-form mathematical solutions for plates with openings and various boundary conditions are available in classical texts on the mechanics of materials.

The effects of circular web openings in moment- and shear-critical I-beams with plywood and OSB webs were studied by Fergus (1979). The study indicated that the bending strength of moment-critical I-beams was not affected by circular openings in the web, in spite of a removal of $70 \%$ of the web height. Larger openings, however, can reduce shear capacity and decrease stiffness (Maley 1987). Although Fergus (1979) could not directly assess a performance change caused by web openings, the author noted that webs buckled around the openings in shear-critical I-beams with plywood webs but not in those with OSB webs. Square openings cause stress concentrations at corners, and large openings can lead to stress concentrations at the flange-web joint (Maley 1987).

In developing design information for round service openings in hardboard webbed I-beams, Hilson and Rodd (1979) found that the ratio of beam height to distance between web stiffeners and the web slenderness interacted with the size of the web openings. For very slender beams, the authors suggested that openings relieved diagonal compression stresses, resulting in more uniform strain distributions and reduced buckling. In general, however, as opening size increased, strength decreased.

Thus, openings in wood I-beams can have a significant effect on shear strength and stiffness, depending on their size and location. Allowable sizes and locations of web openings for commercial products are clearly specified in the product catalogs of 
manufacturers. These recommendations are determined from experimental investigation, the results of which are typically proprietary.

\subsection{Flexural-Torsional (Lateral) Buckling}

A long slender beam under bending about the strong axis may buckle by a combined twisting and lateral (sideways) bending of the cross section. This phenomenon is known as flexural-torsional (lateral) buckling. Flexural-torsional buckling is an important limit state that must be considered in structural design. Flexural-torsional buckling occurs when a structural member experiences significant out-of-plane bending and twisting. This type of failure occurs suddenly in members with a much greater inplane bending stiffness than torsional or lateral bending stiffness. For the long span composite I-beams, flexural-torsional (lateral) buckling is more likely to occur than local buckling, and the second variational total potential energy method is often used to develop the analytical solutions.

The first published discussions of flexural-torsional buckling were made by Prandtl (1899) and Michell (1899), which considered the buckling of beams with narrow rectangular cross-sections. Their work was further studied by Bleich (1952) and also by Timoshenko and Gere (1961). This research was then published into textbooks, and it was extended to include wide flange sections. They provided the classical energy equation for calculating the elastic flexural-torsional buckling load of a thin-walled beam. Galambos (1963) was an early researcher to consider inelastic flexural-torsional buckling of wide flange sections. Other research was presented by White (1956). All of this research was done using the classical approach. This approach provides exact solutions, yet it is somewhat limited because all calculations were done analytically.

In the 1960's, the amount of published research dramatically increased due to digital computers. Researchers used numerical approaches which work well with computers. Some of the numerical approaches studied include the Rayleigh-Ritz method by Wang (1994) and the finite difference method by Bleich (1952), Chajes (1993). Trahair (1968) used the finite integral method, which was also used by Anderson and Trahair (1972), and Kitipornchai and Trahair (1975). Vacharajittiphan and 
Trahair $(1973,1975)$ considered the flexural-torsional buckling of portal frames and plane frames using the finite integral method. More recent research on the theory of flexural-torsional buckling has been presented by Tong and Zhang (2003a) and (2003b) with their investigations of a new theory to clarify the inconsistencies of existing theories of the flexural-torsional buckling of thin-walled members.

The classical energy equation for calculating the elastic flexural-torsional buckling load of a thin-walled beam is usually assumed to be independent of the prebuckling deflections. The early investigations of the effects of pre-buckling were based on the solutions of the governing differential equation (Michell, 1899). Varcharajittiphan et al. (1973) used the finite integral method, and Roberts along with Azizian (1983) used the FE procedure to consider the effects of in-plane deformations on the flexuraltorsional buckling problem. $\mathrm{Pi}$ and Trahair (1992) pointed out that the FE solutions presented by Roberts and Azizian was not accurate, and they present their own FE solutions to the flexural-torsional buckling problem. A comprehensive book on the flexural-torsional buckling was published by Trahair (1993).

\subsection{Local Buckling}

For short span composite I-beams, local buckling is more likely to occur and finally leads to large deformation or material crippling. A number of researchers presented studies on local buckling analysis on composite plates and shells. Several analytical efforts were made to develop explicit analyses of local buckling of orthotropic composite plates with various boundaries and loading conditions.

The elastic critical local buckling stress at ambient temperatures has been thoroughly experimented and investigated by many researchers (Timoshenko and Gere., 1961; Thompson and Hunt, 1973). Local buckling capacity is determined using the plate slenderness and local buckling coefficient with the corresponding half-wave buckling length. 
CHAPTER THREE

FLEXURAL-TORSIONAL BUCKLING OF I-BEAMS

WITH SINUSOIDAL WEB GEOMETRY 


\subsection{Introduction}

Composite I-beams are efficient lightweight structural components. Since the Ibeams are long slender members with thin-walled webs and relatively low stiffness, they will most likely fail due to buckling before the ultimate loads capacity are reached. Therefore, a long slender beam under bending about the strong axis may buckle by a combined twisting and lateral bending of the cross section. This phenomenon is known as lateral buckling, and extensive reviews of analytical and theoretical investigation for wood composite I-beams have been presented. The effects of load position on the lateral buckling response of I-sections were investigated, and the results were correlated with an approximate formula by Nethercot and Rockey (1971) and FE eigenvalue analysis. With the use of Galerkin method to solve the equilibrium differential equation, Pandey et al (1995) presented a theoretical formulation for flexure-torsional buckling of thin-walled composite I-section beams, and simplified formulas for several different loading and boundary conditions were developed. Utilizing the assumed stress functions, the approximate lateral buckling solutions for anisotropic beams were given by Murakami and Yamakawa (1996). Using a seven degree of freedom element, a parametric study of optimal fiber direction for improving the lateral buckling response of pultruded I-beams was performed by Lin et al (1996). A FE method based on moderate rotational theory for the simulation of thin-walled composite beams was developed by Fraternali and Feo (2000). Barbero and Raftoyiannis (1994) extended the formulation of Roberts and Jhita (1983) to study the lateral and distortional buckling of simply supported composite I-beams under central concentrated loads.

Engineered wood composite I-beams with sinusoidal web have recently been developed at West Virginia University using hardwood veneer-mill residues in order to increase the buckling capacity. The analytical solutions presented in this Chapter are compared with the experiment results to characterize flexural-torsional (lateral) buckling of cantilever engineered wood I-beams. 


\subsection{Theoretical Formulation}

The analysis of flexural-torsional (lateral) buckling is presented based on energy method, and the total potential energy equations governing instability are derived using plate and shell theory. The total potential energy of the system is the sum of the strain energy and potential energy of the applied loads. Based on the criterion of buckling, in which $W$ is the pre-buckling work that the product of the applied loads and their corresponding displacements can be ignored, the total potential energy yields

$$
\Pi=U=0
$$

For an I-beam section consisting of two flanges and one sinusoidal web, the total strain energy in a buckled beam is given by

$$
U=U^{t}+U^{w}+U^{b}
$$

where the superscripts $t, w$ and $b$ refer to top flange, web and bottom flange, respectively.

\subsubsection{Cantilever I-Beams}

\subsubsection{Top Flange Consideration}

For buckling analysis of I-beams under bending, the deformation before buckling is ignored. Based on the coordinate system and cross-sectional geometry shown in Figures 3.1 and 3.2, the displacements in three directions of the top flange are expressed as follows (Davalos 1997)

$$
\left\{\begin{array}{l}
u^{c t}=u^{c t}(x, y)=-y \cdot \frac{d w}{d x} \\
v^{c t}=v^{c t}(x, y)=-y \cdot \alpha \\
w^{c t}=w^{c t}(x)
\end{array}\right.
$$




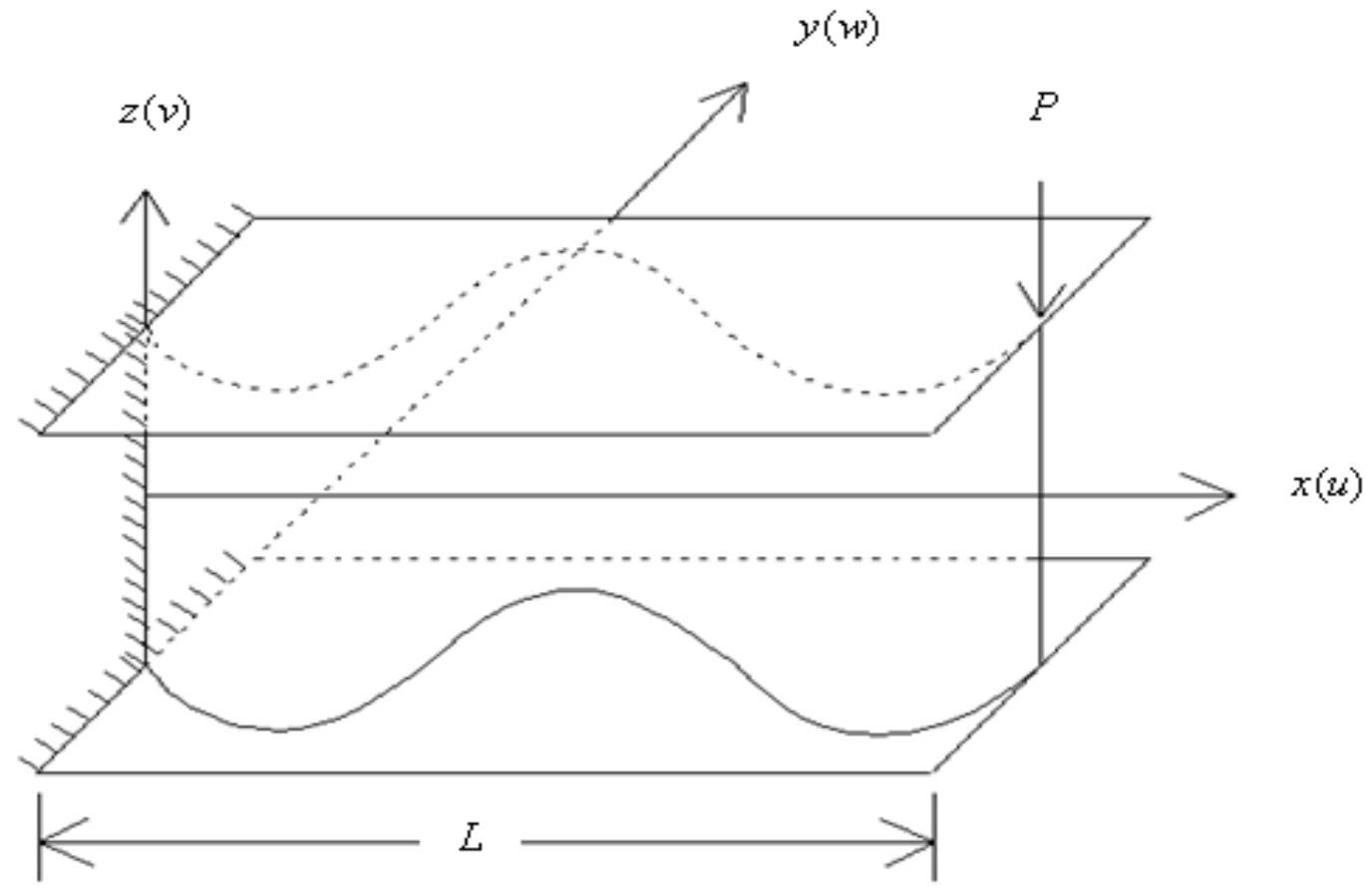

Figure 3.1 Cantilever I-Beam under Tip Load $P$

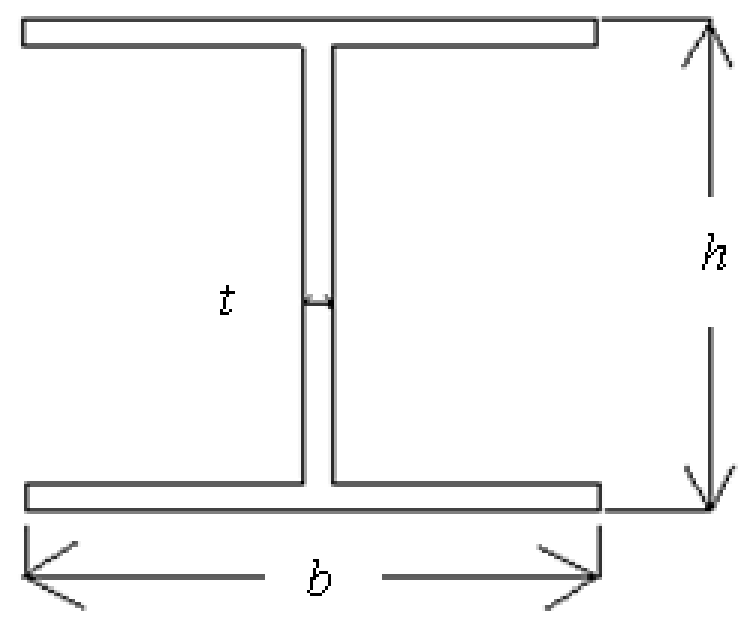

Figure 3.2 Cross-Sectional Geometry of Cantilever I-Beam 
For flexural-torsional buckling in this study, $w$ is centroidal axis lateral displacement; $\alpha$ is beam section rotation, as shown in Figure 3.3.

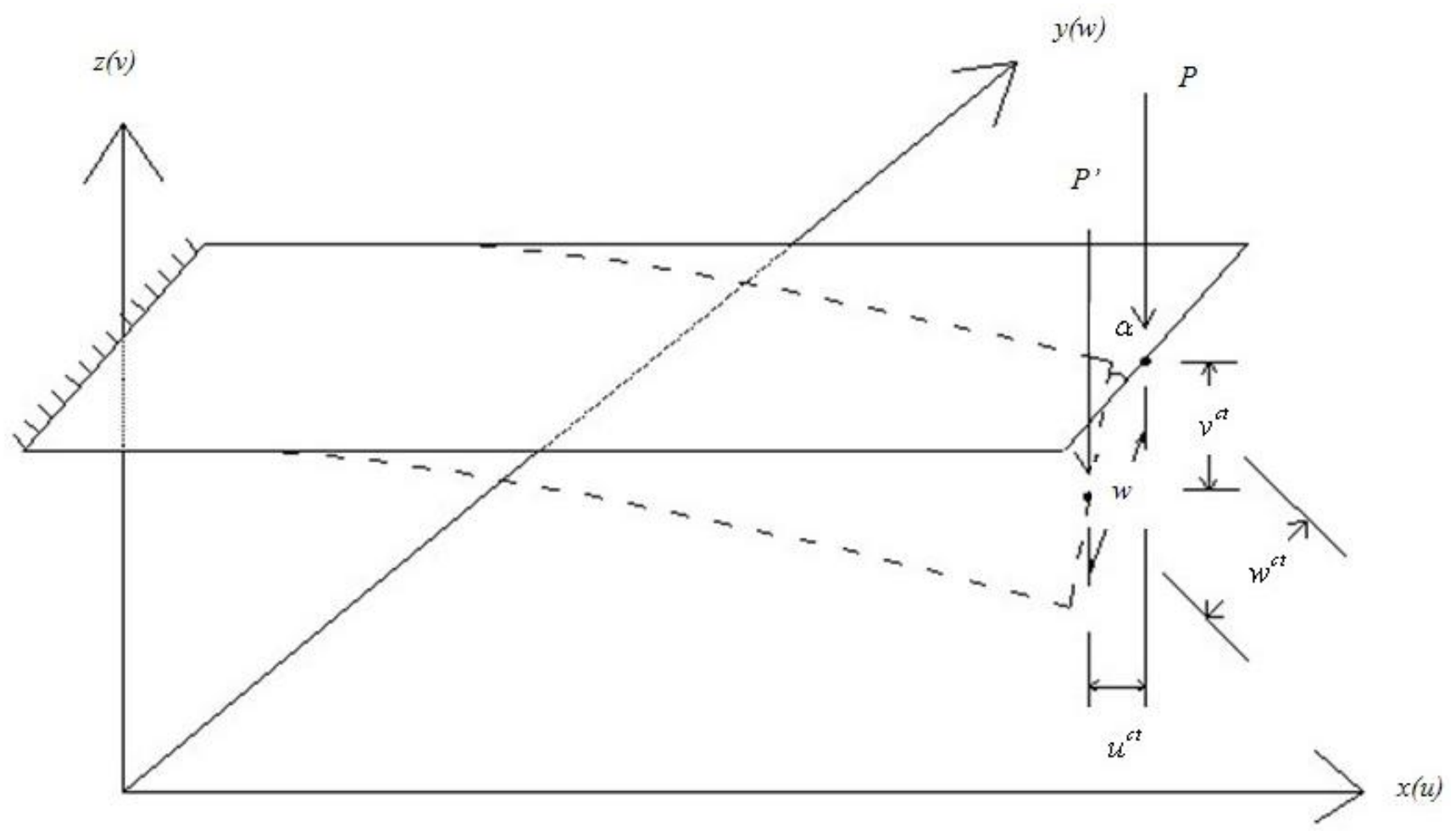

Figure 3.3 Top Flange Deflections under Tip Load $P$

The half of cantilever beam functions are considered as (Qiao 2003),

$$
\left\{\begin{array}{l}
w=C_{1} \sum_{m=1,2,3, \ldots}\left\{1-\cos \left[\frac{(2 m-1) \pi x}{2 L}\right]\right\} \\
\alpha=C_{2} \sum_{m=1,2,3, \ldots}\left\{1-\cos \left[\frac{(2 m-1) \pi x}{2 L}\right]\right\}
\end{array}\right.
$$

Referring to Equations (3.3), the displacements and rotations of the top flange become

$$
\left\{\begin{array}{l}
w^{c t}=w+\frac{h}{2} \alpha=\left(C_{1}+\frac{h}{2} \cdot C_{2}\right) \sum_{m=1,2,3, \cdots}\left\{1-\cos \left[\frac{(2 m-1) \pi x}{2 L}\right]\right\} \\
\alpha^{c t}=\alpha=C_{2} \sum_{m=1,2,3, \cdots}\left\{1-\cos \left[\frac{(2 m-1) \pi x}{2 L}\right]\right\}
\end{array}\right.
$$


Substituting Equations (3.5) into Equations (3.3), the displacements can be calculated as

$$
\left\{\begin{array}{l}
u^{c t}=-\frac{y \pi}{2 L} \cdot\left(C_{1}+\frac{h}{2} \cdot C_{2}\right) \sum_{m=1,2,3, \cdots}(2 m-1) \sin \left[\frac{(2 m-1) \pi x}{2 L}\right] \\
v^{c t}=-y \cdot C_{2} \sum_{m=1,2,3, \ldots}\left\{1-\cos \left[\frac{(2 m-1) \pi x}{2 L}\right]\right\} \\
w^{c t}=\left(C_{1}+\frac{h}{2} \cdot C_{2}\right) \sum_{m=1,2,3, \ldots}\left\{1-\cos \left[\frac{(2 m-1) \pi x}{2 L}\right]\right\}
\end{array}\right.
$$

The strain energy of the top flange plate referred to arbitrary orthogonal coordinates may be written as (Ma 1996)

$$
U^{c t}=\frac{1}{2} \iint_{v}\left(\sigma_{x}^{c t} \varepsilon_{x}^{c t}+\sigma_{y}^{c t} \varepsilon_{y}^{c t}+\sigma_{z}^{c t} \varepsilon_{z}^{c t}+\tau_{x y}^{c t} \gamma_{x y}^{c t}+\tau_{x z}^{c t} \gamma_{x z}^{c t}+\tau_{y z}^{c t} \gamma_{y z}^{c t}\right) d v
$$

Considering the top flange of an I-beam to act as a beam element, $\gamma_{x z}^{c t}, \gamma_{y z}^{c t}$ and $\sigma_{z}^{c t}$ are assumed to be equal to zero. Therefore, in accordance with the basic approximations of thin-plate theory, the strain energy can be simplified as

$$
U^{c t}=\frac{1}{2} \iint_{A}\left(\sigma_{x}^{c t} \varepsilon_{x}^{c t}+\sigma_{y}^{c t} \varepsilon_{y}^{c t}+\tau_{x y}^{c t} \gamma_{x y}^{c t}\right) d A
$$

For the orthotropic plate in the $x-y$ plane, the membrane forces, the bending and twisting moments per unit length in terms of the mid-surface in-plane strains and curvatures are given by

$$
\left(\begin{array}{l}
N_{x}^{c t} \\
N_{y}^{c t} \\
N_{x y}^{c t} \\
M_{x}^{c t} \\
M_{y}^{c t} \\
M_{x y}^{c t}
\end{array}\right)=\left[\begin{array}{cccccc}
A_{11} & A_{12} & 0 & 0 & 0 & 0 \\
A_{12} & A_{22} & 0 & 0 & 0 & 0 \\
0 & 0 & A_{66} & 0 & 0 & 0 \\
0 & 0 & 0 & D_{11} & D_{12} & 0 \\
0 & 0 & 0 & D_{12} & D_{22} & 0 \\
0 & 0 & 0 & 0 & 0 & D_{66}
\end{array}\right]\left(\begin{array}{c}
\varepsilon_{x}^{c t} \\
\varepsilon_{y}^{c t} \\
\gamma_{x y}^{c t} \\
\kappa_{x}^{c t} \\
\kappa_{y}^{c t} \\
\kappa_{x y}^{c t}
\end{array}\right)
$$

where $A_{i j}, D_{i j}(i, j=1,2,6)$ are stiffness matrices.

Since the top flange acts as a beam, the transverse resultant force and moment are assumed to be equal to zero, thus 


$$
N_{y}^{c t}=M_{y}^{c t}=0
$$

Substituting Equations (3.9) into Equation (3.8), the total strain energy of the top flange becomes

$$
U^{c t}=\frac{1}{2} \iint_{A} N_{x}^{c t} \varepsilon_{x}^{c t} d A+\frac{1}{2} \iint_{A} N_{x y}^{c t} \gamma_{x y}^{c t} d A+\frac{1}{2} \iint_{A} M_{x}^{c t} \kappa_{x}^{c t} d A+\frac{1}{2} \iint_{A} M_{x y}^{c t} K_{x y}^{c t} d A
$$

where

$$
\left\{\begin{array}{l}
N_{x}^{c t}=A_{11} \varepsilon_{x}^{c t} \\
N_{x y}^{c t}=A_{66} \gamma_{x y}^{c t} \\
M_{x}^{c t}=D_{11} \kappa_{x}^{c t} \\
M_{x y}^{c t}=D_{66} \kappa_{x y}^{c t}
\end{array}\right.
$$

The strains in an arbitrary location of the top flange ( $x-y$ plane) can be written as

$$
\left\{\begin{array}{l}
\varepsilon_{x}^{c t}=\frac{\partial u^{c t}}{\partial x}+\frac{1}{2}\left[\left(\frac{\partial w^{c t}}{\partial x}\right)^{2}+\frac{1}{2}\left(\frac{\partial v^{c t}}{\partial x}\right)^{2}\right] \\
\varepsilon_{y}^{c t}=\frac{\partial w^{c t}}{\partial y}+\frac{1}{2}\left[\left(\frac{\partial u^{c t}}{\partial y}\right)^{2}+\frac{1}{2}\left(\frac{\partial v^{c t}}{\partial y}\right)^{2}\right] \\
\gamma_{x y}^{c t}=\frac{\partial w^{c t}}{\partial x}+\frac{\partial u^{c t}}{\partial y}+\frac{\partial v^{c t}}{\partial x} \frac{\partial v^{c t}}{\partial y}
\end{array}\right.
$$

Substituting Equations (3.6) and (3.12) into Equation (3.11), ignoring fourthorder terms, the total strain energy of the top flange can be obtained

$$
\begin{aligned}
U^{c t}= & \frac{1}{2} \iint_{A} N_{x}^{c t}\left[\left(\frac{\partial w^{c t}}{\partial x}\right)^{2}+\frac{1}{2}\left(\frac{\partial v^{c t}}{\partial x}\right)^{2}\right] d A+\frac{1}{2} \iint_{A} N_{x y}^{c t} \frac{\partial v^{c t}}{\partial x} \frac{\partial v^{c t}}{\partial y} d A+\frac{1}{2} A_{11} \iint_{A}\left(\frac{\partial u^{c t}}{\partial x}\right)^{2} d A+ \\
& \frac{1}{2} A_{66} \iint_{A}\left(\frac{\partial w^{c t}}{\partial x}+\frac{\partial u^{c t}}{\partial y}\right)^{2} d A+\frac{1}{2} D_{11} \iint_{A}\left(\frac{\partial^{2} v^{c t}}{\partial x^{2}}\right)^{2} d A+\frac{1}{2} D_{66} \iint_{A}\left(\frac{\partial^{2} v^{c t}}{\partial x \partial y}\right)^{2} d A
\end{aligned}
$$

where, 


$$
\left\{\begin{array}{l}
\left(\frac{\partial w^{c t}}{\partial x}\right)^{2}=\frac{\left(2 C_{1}+h C_{2}\right)^{2} \pi^{2}}{16 L^{2}} \sum_{m=1,2,3, \cdots}(2 m-1)^{2} \cdot \sin ^{2}\left[\frac{(2 m-1) \pi x}{2 L}\right] \\
\left(\frac{\partial v^{c t}}{\partial x}\right)^{2}=\frac{y^{2} C_{2}^{2} \pi^{2}}{8 L^{2}} \sum_{m=1,2,3, \cdots}(2 m-1)^{2} \cdot \sin ^{2}\left[\frac{(2 m-1) \pi x}{2 L}\right] \\
\left(\frac{\partial u^{c t}}{\partial x}\right)^{2}=\frac{y^{2} \pi^{4}}{16 L^{4}}\left(C_{1}+\frac{h}{2} C_{2}\right)^{2} \sum_{m=1,2,3, \cdots}(2 m-1)^{4} \cdot \cos ^{2}\left[\frac{(2 m-1) \pi x}{2 L}\right] \\
\left(\frac{\partial^{2} v^{c t}}{\partial x^{2}}\right)^{2}=\frac{y^{2} C_{2}^{2} \pi^{4}}{16 L^{4}} \sum_{m=1,2,3, \cdots}(2 m-1)^{4} \cdot \cos ^{2}\left[\frac{(2 m-1) \pi x}{2 L}\right] \\
\left(\frac{\partial^{2} v^{c t}}{\partial x \partial y}\right)^{2}=\frac{C_{2}^{2} \pi^{2}}{4 L^{2}} \sum_{m=1,2,3, \cdots}(2 m-1)^{2} \cdot \sin ^{2}\left[\frac{(2 m-1) \pi x}{2 L}\right] \\
\left(\frac{\partial w^{c t}}{\partial x}+\frac{\partial u^{c t}}{\partial y}\right)^{2}=0
\end{array}\right.
$$

For a cantilever beam subjected to a tip concentrated vertical load as shown in Figure 3.1, the membrane forces are expressed in terms of the tip applied concentrated load $P$. The expressions for the top flange are

$$
\begin{cases}N_{x}^{c t}=\frac{P h t}{2 I}(L-x) & (0 \leq x \leq L) \\ N_{y}^{c t}=N_{x y}^{c t}=0 & (0 \leq x \leq L)\end{cases}
$$

where $I$ is the moment of inertia. According the definition, the moment of inertia of the sinusoidal web I-beam cross-section is variable. For the sake of simplicity, it is assumed to be constant as flat web I-beam, which can be expression as, as shown in Figure 3.2

$$
I=\left(\frac{1}{2} b h^{2}+\frac{1}{12} h^{3}\right) t
$$

After substituting Equations (3.14) into Equation (3.13), the total strain energy of the top flange of cantilever I-beams can be calculated as

$$
U^{c t}=P \cdot \xi_{1}^{c t}+\xi_{2}^{c t}
$$

where

$$
\left\{\begin{aligned}
\xi_{1}^{c t}= & \frac{h t \pi^{2}}{64 I L^{2}} \sum_{m=1,2,3, \ldots} \int_{-\frac{1}{b} / 2}^{b} \int_{0}^{L}(L-x)\left[\left(2 C_{1}+h C_{2}\right)^{2}+2 y^{2} C_{2}^{2}\right](2 m-1)^{2} \cdot \sin ^{2}\left[\frac{(2 m-1) \pi x}{2 L}\right] d x d y \\
\xi_{2}^{c t}= & \frac{\pi^{4}}{32 L^{4}}\left[\left(A_{11} C_{1}+\frac{A_{11} h}{2} C_{2}\right)^{2}+D_{11} C_{2}^{2}\right] \sum_{m=1,2,3, \cdots} \int_{-b / 2}^{b / 2} \int_{0}^{L} y^{2}(2 m-1)^{4} \cdot \cos ^{2}\left[\frac{(2 m-1) \pi x}{2 L}\right] d x d y+ \\
& D_{66} \frac{C_{2}^{2} \pi^{2}}{8 L^{2}} \sum_{m=1,2,3, \ldots, \ldots} \int_{-b / 2}^{b / 2} \int_{0}^{L}(2 m-1)^{2} \cdot \sin ^{2}\left[\frac{(2 m-1) \pi x}{2 L}\right] d x d y
\end{aligned}\right.
$$




\subsubsection{Web Consideration}

The shape function of the sinusoidal web in the $x$-z plate can be described as

$$
y=A \sin \frac{2 \pi x}{a}
$$

with the parameters $A$ and $a$ defined in Figure 3.4.

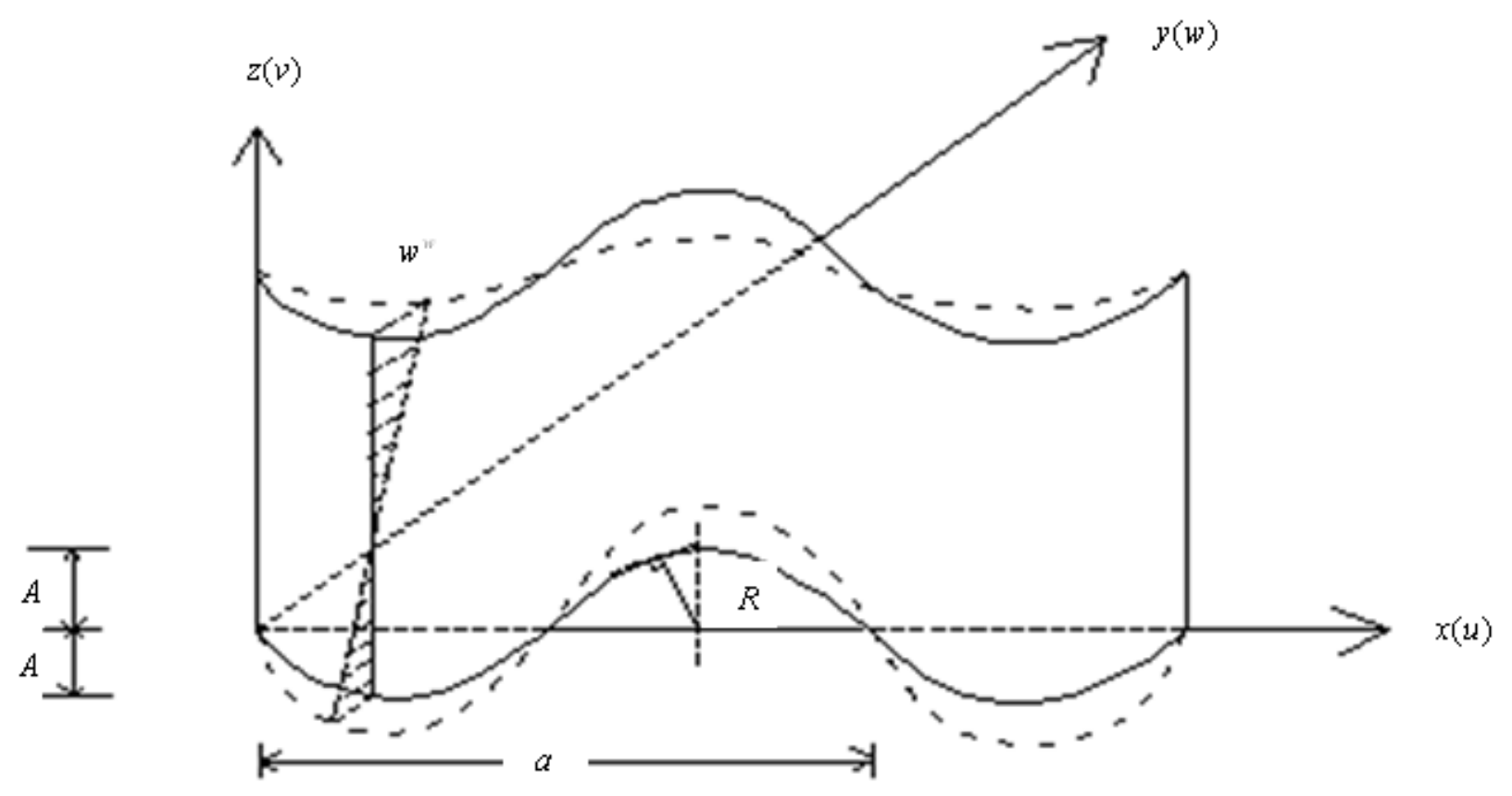

Figure 3.4 Deformed Shape of Sinusoidal Web

Considering a local coordinate system $\left(x^{e}, y^{e}, z^{e}\right)$, the displacements of web in the interior of an element $e$ in three directions can be expressed as

$$
\left\{\begin{array}{l}
u_{e}^{c w}=0 \\
v_{e}^{c w}=0 \\
w_{e}^{c w}=w_{e}^{c w}(x, z)
\end{array}\right.
$$

where 


$$
\left\{\begin{array}{l}
w_{e}=C_{1} \sum_{m=1,2,3, \cdots}\left\{1-\cos \left[\frac{(2 m-1) \pi x}{2 L}\right]\right\} \\
\alpha_{e}=C_{2} \sum_{m=1,2,3, \cdots}\left\{1-\cos \left[\frac{(2 m-1) \pi x}{2 L}\right]\right\}
\end{array}\right.
$$

The local displacement in $y$ direction of the web corresponding to local axis $w$, which yields

$$
\begin{aligned}
w_{e}^{c w} & =w_{e}+z \cdot \alpha_{e} \\
& =\left(C_{1}+z \cdot C_{2}\right) \sum_{m=1,2,3, \cdots}\left\{1-\cos \left[\frac{(2 m-1) \pi x}{2 L}\right]\right\}
\end{aligned}
$$

Assuming the web as a deformed shell, the local potential strain energy of the web consists of the strain energy of the local out-of-plane bending strain energy $U_{e b}^{c w}$ and the local membrane strain energy $U_{e m}^{c w}$, respectively. Hence

$$
U_{e}^{c w}=U_{e m}^{c w}+U_{e b}^{c w}
$$

where

$$
\left\{\begin{array}{l}
U_{e m}^{c w}=\frac{1}{2} \iint_{A}\left[N_{e x}^{c w} \varepsilon_{e x}^{c w}+N_{e z}^{c w} \varepsilon_{e z}^{c w}+N_{e x z}^{c w} \gamma_{e x z}^{c w}\right] d A \\
U_{e b}^{c w}=\frac{1}{2} \iint_{A}\left[D^{e}{ }_{11}\left(\chi_{x}^{c w}\right)^{2}+2 D^{e}{ }_{12} \chi_{x}^{c w} \chi_{z}^{c w}+D^{e}{ }_{22}\left(\chi_{z}^{c w}\right)^{2}+4 D_{66}^{e}\left(\chi_{x z}^{c w}\right)^{2}\right] d A
\end{array}\right.
$$

in which $\chi_{e x}^{c w}=\frac{\partial^{2} w_{e}^{c w}}{\partial x^{2}}, \chi_{e x z}^{c w}=\frac{\partial^{2} w_{e}^{c w}}{\partial x \partial z}, \chi_{e z}^{c w}=\frac{\partial^{2} w_{e}^{c w}}{\partial z^{2}}$ represent the changes of the midsurface curvature of the element $e$ in local coordinate system; $D_{i j}^{e}(i, j=1,6)$ are the element bending stiffness matrices; $v_{i j}(i, j=1,2)$ are Poisson's ratio; $N_{e i}(i=x, z)$ are the element membrane forces in local coordinate $x^{e}$ and $z^{e} ; d A=d s d z$, respectively.

The local membrane strains can be written as (Giles 1998) 


$$
\left\{\begin{array}{l}
\varepsilon_{e x}=\frac{\partial v_{e}^{c w}}{\partial z} \\
\varepsilon_{e z}=\frac{\partial u_{e}^{c w}}{\partial x}-\frac{w_{e}^{c w}}{R} \\
\gamma_{e x z}=\frac{\partial u_{e}^{c w}}{\partial z}+\frac{\partial v_{e}^{c w}}{\partial x}
\end{array}\right.
$$

where $R$ is curvature radius of shell mid-surface in local coordinate system; and $d s$ is the shell length, which is along the local axis $x^{e}$ (see Figure 3.4). Therefore, we have

$$
\left\{\begin{array}{l}
d s=\sum_{m=1,2,3, \cdots} \int_{0}^{L} \sqrt{1+4\left(\frac{A \pi}{a}\right)^{2} \cos ^{2}\left[\frac{(2 m-1) \pi x}{a}\right]} d x \\
R=\sum_{m=1,2,3, \cdots} \frac{1+4\left(\frac{A \pi}{a}\right)^{2} \cos ^{2}\left[\frac{(2 m-1) \pi x}{a}\right]}{4 A\left(\frac{\pi}{a}\right)^{2} \sin \left[\frac{(2 m-1) \pi x}{a}\right]}
\end{array}\right.
$$

Noting that for an I-beam with flat web, the curvature radius is infinite. Meanwhile, shell length $d s$ should be reduced to beam length. Therefore, by assuming $R \rightarrow \infty$ and $d s \rightarrow x$ in Equations (3.24), the flat web geometry will be obtained.

The expressions of the element membrane forces of the web in the local coordinate system $\left(x^{e}, y^{e}, z^{e}\right)$ can be obtained as, as shown in Figure 3.5. The moment of inertia $I$ can be obtained in the same way as Equation (3.16).

$$
\begin{cases}N_{e x}^{c w}=\frac{P^{e} A t}{2 I}(L-x) z \cos \left(\frac{2 \pi x}{a}\right) & (0<x \leq L) \\ N_{e z}^{c w}=0 & (0 \leq x \leq L) \\ N_{e x z}^{c w}=-\frac{P^{e} A t}{2 I}\left[\left(\frac{h}{2}\right)^{2}-z^{2}\right] \sin \left(\frac{2 \pi x}{a}\right) & (0<x \leq L)\end{cases}
$$




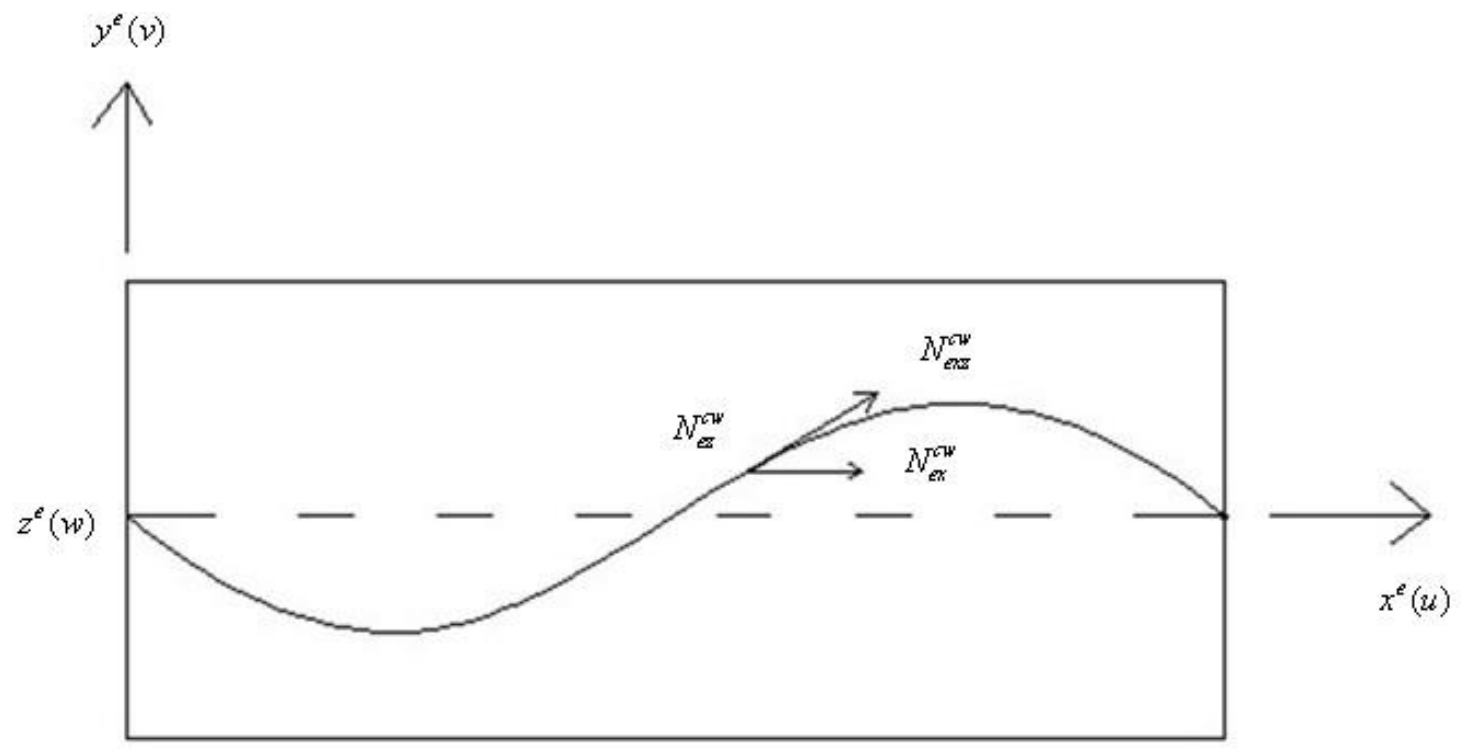

Figure 3.5 Membrane Forces of the Sinusoidal Web in Local $x-y$ Plane

Since these quantities are expressed in the local coordinate system $\left(x^{e}, y^{e}, z^{e}\right)$ of the element $e$, not in the global coordinate system $(x, y, z)$, in order to calculate the corresponding counterparts of the whole sinusoidal web, it is necessary to transform the expressions of the strain energy of the element $e$ from the local coordinate system into the global one.

Assuming $\Gamma$ is the transformation matrix from the local coordinate system to the global coordinate system. Then the local displacement $w_{e}^{c w}$ is related to the displacement in the global coordinate system by the following

$$
w_{e}^{c w}=\Gamma w^{c w}
$$

Noting that $\Gamma$ is a normal matrix $\left(\Gamma^{T}=\Gamma^{-1}\right)$, the element bending stiffness matrices $D_{i j}^{e}(i, j=1,6)$ in the global coordinate system can be expressed as

$$
D_{i j}=\Gamma^{T} D_{i j}^{e} \Gamma
$$

and the equivalent mid-surface curvature in the global coordinate system is solved as 


$$
\chi_{x}^{c w}=\left(\Gamma^{T}\right)^{2} \frac{\partial^{2} w^{c w}}{\partial x^{2}}
$$

In this way, we can obtain all the items in Equation (3.22), (3.23) and (3.24). Substituting Equations (3.22), (3.23) and (3.24) into Equation (3.21), the total strain energy of the sinusoidal web in the global coordinate are calculated as

$$
\begin{aligned}
U^{c w}= & \frac{1}{2} \iint_{A}\left[N_{x}^{c w} \frac{\partial v^{c w}}{\partial z}+N_{z}^{c w}\left(\frac{\partial u^{c w}}{\partial x}-\frac{w^{c w}}{R}\right)+N_{x z}^{c w}\left(\frac{\partial u^{c w}}{\partial z}+\frac{\partial v^{c w}}{\partial x}\right)\right] d s d z+ \\
& \frac{1}{2} \iint_{A}\left[D_{11}\left(\frac{\partial^{2} w^{c w}}{\partial x^{2}}\right)^{2}+2 D_{12} \frac{\partial^{2} w^{c w}}{\partial x^{2}} \frac{\partial^{2} w^{c w}}{\partial z^{2}}+D_{22}\left(\frac{\partial^{2} w^{c w}}{\partial z^{2}}\right)^{2}+4 D_{66}\left(\frac{\partial^{2} w^{c w}}{\partial x \partial z}\right)^{2}\right] d s d z
\end{aligned}
$$

where,

$$
\left\{\begin{array}{l}
\frac{\partial u^{c w}}{\partial x}=\frac{\partial u^{c w}}{\partial z}=\frac{\partial v^{c w}}{\partial x}=\frac{\partial v^{c w}}{\partial z}=\frac{\partial^{2} w^{c w}}{\partial z^{2}}=0 \\
\left(\frac{\partial^{2} w^{c w}}{\partial x^{2}}\right)^{2}=\frac{\pi^{4}}{16 L^{4}}\left(C_{1}+Z C_{2}\right)^{2} \sum_{m=1,2,3, \cdots}(2 m-1)^{4} \cdot \cos ^{2}\left[\frac{(2 m-1) \pi x}{2 L}\right] \\
\left(\frac{\partial^{2} w^{c w}}{\partial x \partial z}\right)^{2}=\frac{\pi^{2}}{4 L^{2}} C_{2}^{2} \sum_{m=1,2,3, \cdots}(2 m-1)^{2} \cdot \cos ^{2}\left[\frac{(2 m-1) \pi x}{2 L}\right]
\end{array}\right.
$$

Therefore, the total strain energy of the sinusoidal web yields

$$
U^{c w}=P \cdot \xi_{1}^{c w}+\xi_{2}^{c w}
$$

where

$$
\left\{\begin{aligned}
\xi_{1}^{c w}= & \int_{-1 / 2}^{1 / 2} \int_{0}^{L}\left[\frac{A t}{4 I}\left(z^{2}-\frac{h^{2}}{4}\right)\right] \sin \left(\frac{2 \pi x}{a}\right) d s d z \\
\xi_{2}^{c w}= & D_{11} \frac{\pi^{4}}{32 L^{4}} \sum_{m=1,2,3, \ldots} \int_{-1 / 2}^{1 / 2} \int_{0}^{L}\left(C_{1}+z C_{2}\right)^{2}(2 m-1)^{4} \cdot \cos ^{2}\left[\frac{(2 m-1) \pi x}{2 L}\right] d s d z+ \\
& D_{66} C_{2}^{2} \frac{\pi^{2}}{2 L^{2}} \sum_{m=1,2,3, \ldots} \int_{-1 / 2}^{1 / 2} \int_{0}^{L}(2 m-1)^{2} \cdot \cos ^{2}\left[\frac{(2 m-1) \pi x}{2 L}\right] d s d z
\end{aligned}\right.
$$

\subsubsection{Bottom Flange Consideration}

Similarly to Chapter 3.2.1.1, the displacements of three directions of the bottom flange are expressed as follows 


$$
\left\{\begin{array}{l}
u^{c b}=u^{c b}(x, y)=-y \cdot \frac{d w}{d x} \\
v^{c b}=v^{c b}(x, y)=-y \cdot \alpha \\
w^{c b}=w^{c b}(x)
\end{array}\right.
$$

Based on the half of cantilever beam functions described in Equations (3.4), the displacements and rotations of the bottom flange become

$$
\left\{\begin{array}{l}
w^{c b}=w+\frac{h}{2} \alpha=\left(C_{1}+\frac{h}{2} \cdot C_{2}\right) \sum_{m=1,2,3, \cdots}\left\{1-\cos \left[\frac{(2 m-1) \pi x}{2 L}\right]\right\} \\
\alpha^{c b}=\alpha=C_{2} \sum_{m=1,2,3, \cdots}\left\{1-\cos \left[\frac{(2 m-1) \pi x}{2 L}\right]\right\}
\end{array}\right.
$$

Substituting Equations (3.30) into Equations (3.29), the displacements can be calculated by

$$
\left\{\begin{array}{l}
u^{c b}=-\frac{y \pi}{2 L} \cdot\left(C_{1}+\frac{h}{2} \cdot C_{2}\right) \sum_{m=1,2,2, \cdots}(2 m-1) \sin \left[\frac{(2 m-1) \pi x}{2 L}\right] \\
v^{c b}=-y \cdot C_{2} \sum_{m=1,2,3, \cdots}\left\{1-\cos \left[\frac{(2 m-1) \pi x}{2 L}\right]\right\} \\
w^{c b}=\left(C_{1}+\frac{h}{2} \cdot C_{2}\right) \sum_{m=1,2,3, \cdots}\left\{1-\cos \left[\frac{(2 m-1) \pi x}{2 L}\right]\right\}
\end{array}\right.
$$

The strain energy of the bottom flange plate referred to arbitrary orthogonal coordinates may be written as

$$
U^{c b}=\frac{1}{2} \iint_{v}\left(\sigma_{x}^{c b} \varepsilon_{x}^{c b}+\sigma_{y}^{c b} \varepsilon_{y}^{c b}+\sigma_{z}^{c b} \varepsilon_{z}^{c b}+\tau_{x y}^{c b} \gamma_{x y}^{c b}+\tau_{x z}^{c b} \gamma_{x z}^{c b}+\tau_{y z}^{c b} \gamma_{y z}^{c b}\right) d v
$$

Similarly, after omitting $\gamma_{x z}^{c b}, \gamma_{y z}^{c b}$ and $\sigma_{z}^{c b}$, the strain energy can be simplified as

$$
U^{c b}=\frac{1}{2} \iint_{A}\left(\sigma_{x}^{c b} \varepsilon_{x}^{c b}+\sigma_{y}^{c b} \varepsilon_{y}^{c b}+\tau_{x y}^{c b} \gamma_{x y}^{c b}\right) d A
$$

The membrane forces, the bending and twisting moments per unit length of the bottom flange are given by 


$$
\left(\begin{array}{l}
N_{x}^{c b} \\
N_{y}^{c b} \\
N_{x y}^{c b} \\
M_{x}^{c b} \\
M_{y}^{c b} \\
M_{x y}^{c b}
\end{array}\right)=\left[\begin{array}{cccccc}
A_{11} & A_{12} & 0 & 0 & 0 & 0 \\
A_{12} & A_{22} & 0 & 0 & 0 & 0 \\
0 & 0 & A_{66} & 0 & 0 & 0 \\
0 & 0 & 0 & D_{11} & D_{12} & 0 \\
0 & 0 & 0 & D_{12} & D_{22} & 0 \\
0 & 0 & 0 & 0 & 0 & D_{66}
\end{array}\right]\left(\begin{array}{c}
\varepsilon_{x}^{c b} \\
\varepsilon_{y}^{c b} \\
\gamma_{x y}^{c b} \\
\kappa_{x}^{c b} \\
\kappa_{y}^{c b} \\
\kappa_{x y}^{c b}
\end{array}\right)
$$

where $A_{i j}, D_{i j}(i, j=1,2,6)$ are stiffness matrices.

The transverse resultant force and moment of the bottom flange are also assumed to be equal to zero, thus

$$
N_{y}^{c b}=M_{y}^{c b}=0
$$

Substituting Equations (3.34) into Equation (3.33), the total strain energy of the bottom flange becomes

$$
U^{c b}=\frac{1}{2} \iint_{A} N_{x}^{c b} \varepsilon_{x}^{c b} d A+\frac{1}{2} \iint_{A} N_{x y}^{c b} \gamma_{x y}^{c b} d A+\frac{1}{2} \iint_{A} M_{x}^{c b} \kappa_{x}^{c b} d A+\frac{1}{2} \iint_{A} M_{x y}^{c b} \kappa_{x y}^{c b} d A
$$

where

$$
\left\{\begin{array}{l}
N_{x}^{c b}=A_{11} \varepsilon_{x}^{c b} \\
N_{x y}^{c b}=A_{66} \gamma_{x y}^{c b} \\
M_{x}^{c b}=D_{11} \kappa_{x}^{c b} \\
M_{x y}^{c b}=D_{66} K_{x y}^{c b}
\end{array}\right.
$$

The strains in an arbitrary location of the bottom flange ( $x-y$ plane) can be written as

$$
\left\{\begin{array}{l}
\varepsilon_{x}^{c b}=\frac{\partial u^{c b}}{\partial x}+\frac{1}{2}\left[\left(\frac{\partial w^{c b}}{\partial x}\right)^{2}+\frac{1}{2}\left(\frac{\partial v^{c b}}{\partial x}\right)^{2}\right] \\
\varepsilon_{y}^{c b}=\frac{\partial w^{c b}}{\partial y}+\frac{1}{2}\left[\left(\frac{\partial u^{c b}}{\partial y}\right)^{2}+\frac{1}{2}\left(\frac{\partial v^{c b}}{\partial y}\right)^{2}\right] \\
\gamma_{x y}^{c b}=\frac{\partial w^{c b}}{\partial x}+\frac{\partial u^{c b}}{\partial y}+\frac{\partial v^{c b}}{\partial x} \frac{\partial v^{c b}}{\partial y}
\end{array}\right.
$$

Substituting Equations (3.38) and (3.31) into Equation (3.36), ignoring fourthorder terms, the total strain energy of the bottom flange can be obtained 


$$
\begin{aligned}
U^{c b}= & \frac{1}{2} \iint_{A} N_{x}^{c b}\left[\left(\frac{\partial w^{c b}}{\partial x}\right)^{2}+\frac{1}{2}\left(\frac{\partial v^{c b}}{\partial x}\right)^{2}\right] d A+\frac{1}{2} \iint_{A} N_{x y}^{c b} \frac{\partial v^{c b}}{\partial x} \frac{\partial v^{c b}}{\partial y} d A+\frac{1}{2} A_{11} \iint_{A}\left(\frac{\partial u^{c b}}{\partial x}\right)^{2} d A+ \\
& \frac{1}{2} A_{66} \iint_{A}\left(\frac{\partial w^{c b}}{\partial x}+\frac{\partial u^{c b}}{\partial y}\right)^{2} d A+\frac{1}{2} D_{11} \iint_{A}\left(\frac{\partial^{2} v^{c b}}{\partial x^{2}}\right)^{2} d A+\frac{1}{2} D_{66} \iint_{A}\left(\frac{\partial^{2} v^{c b}}{\partial x \partial y}\right)^{2} d A
\end{aligned}
$$

where the expressions of the membrane forces are

$$
\begin{cases}N_{x}^{c b}=-\frac{P h t}{2 I}(L-x) & (0 \leq x \leq L) \\ N_{y}^{c b}=N_{x y}^{c b}=0 & (0 \leq x \leq L)\end{cases}
$$

Hence, the totally strain energy of the bottom flange can be written as

$$
U^{c b}=-P \cdot \xi_{1}^{c b}+\xi_{2}^{c b}
$$

where

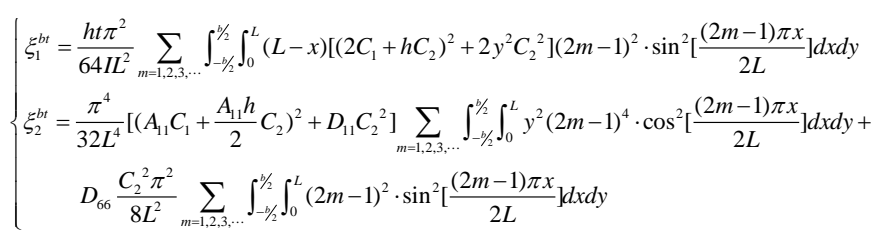

According to basic assumption of Equation (3.2), the total strain energy of the cantilever I-beam can be described as

$$
\Pi=P \cdot\left(\xi_{1}^{c t}+\xi_{1}^{c w}-\xi_{1}^{c b}\right)+\xi_{2}^{c t}+\xi_{2}^{c w}+\xi_{2}^{c b}=0
$$

Since Equation (3.43) is valid for any constants $C_{1}$ and $C_{2}$, the following requirement should be satisfied

$$
P=\frac{\xi_{2}^{c t}+\xi_{2}^{c w}+\xi_{2}^{c b}}{\xi_{1}^{c b}-\xi_{1}^{c t}-\xi_{1}^{c w}}
$$

where $\xi_{1}^{c t}, \xi_{2}^{c t}, \xi_{1}^{c w}, \xi_{2}^{c w}, \xi_{1}^{c b}$ and $\xi_{2}^{c b}$ are given by Equations (3.17), (3.28) and (3.42). 


\subsubsection{Simply-Supported I-Beams}

\subsubsection{Top Flange Consideration}

Similarly to cantilever I-beams case, the deformation before buckling is ignored. Based on the coordinate system and cross-sectional geometry shown in Figure 3.6, the displacements in three directions of the top flange are expressed as follows

$$
\left\{\begin{aligned}
u^{s t} & =u^{s t}(x, y)=-y \cdot \frac{d w}{d x} \\
v^{s t} & =v^{s t}(x, y)=-y \cdot \alpha \\
w^{s t} & =w^{s t}(x)
\end{aligned}\right.
$$

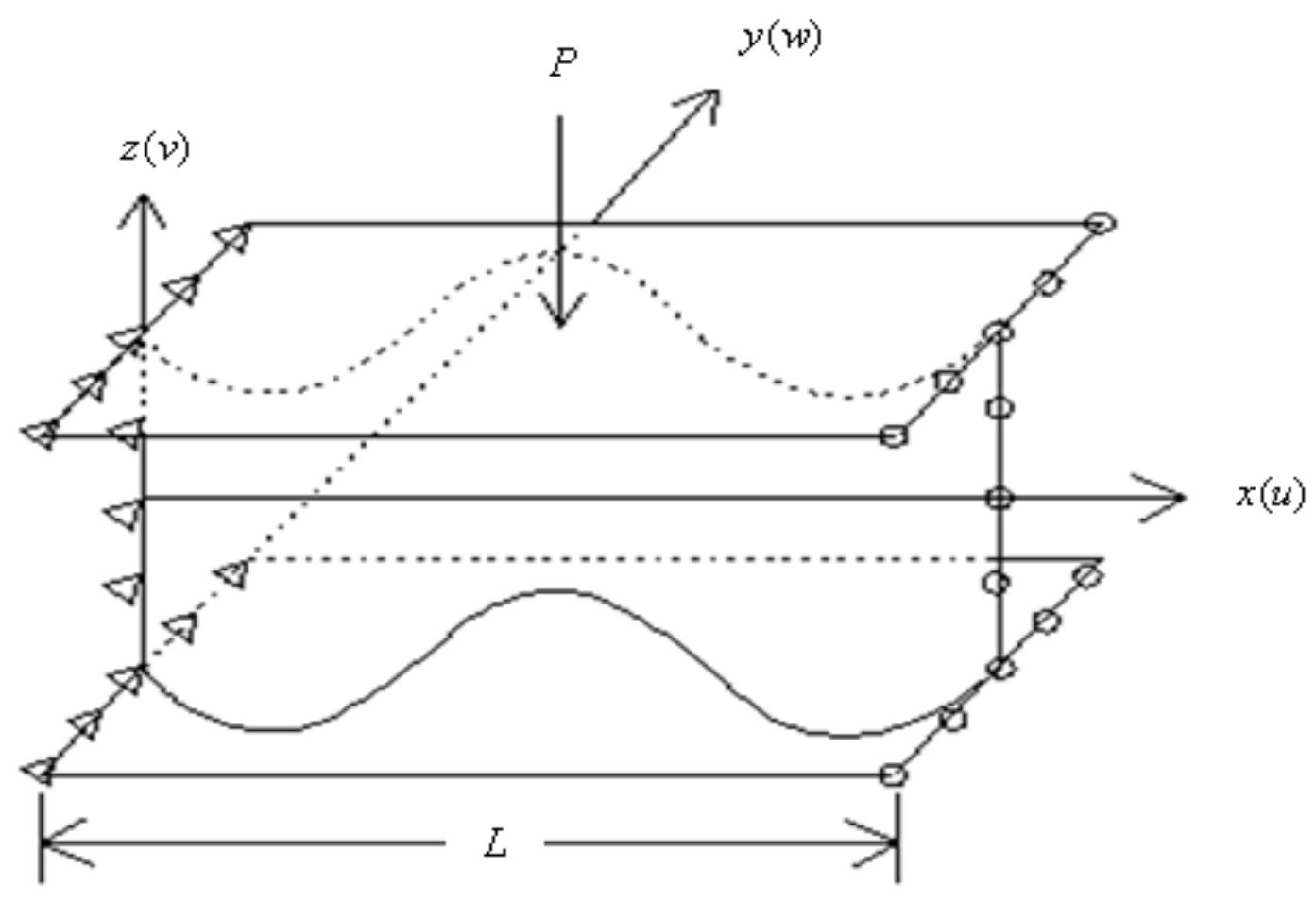

Figure 3.6 Simply-Supported I-Beam under Centric Load $P$

The half of simply-supported beam functions are considered as

$$
\left\{\begin{array}{l}
w=C_{1} \sum_{m=1,2,3, \cdots} \sin \left(\frac{m \pi x}{L}\right) \\
\alpha=C_{2} \sum_{m=1,2,3, \cdots} \sin \left(\frac{m \pi x}{L}\right)
\end{array}\right.
$$


Referring to Equation (3.45), the displacements and rotations of the top flange become

$$
\left\{\begin{array}{l}
w^{s t}=w+\frac{h}{2} \alpha=\left(C_{1}+\frac{h}{2} \cdot C_{2}\right) \sum_{m=1,2,3, \cdots} \sin \left(\frac{m \pi x}{L}\right) \\
\alpha^{t t}=\alpha=C_{2} \sum_{m=1,2,3, \cdots} \sin \left(\frac{m \pi x}{L}\right)
\end{array}\right.
$$

Substituting Equations (3.47) into Equations (3.45), the displacements can be calculated by

$$
\left\{\begin{array}{l}
u^{u}=-\frac{y \pi}{L} \cdot\left(C_{1}+\frac{h}{2} \cdot C_{2}\right) \sum_{m=1,2,3, \cdots} m \cos \left(\frac{m \pi x}{L}\right) \\
v^{s t}=-y \cdot C_{2} \sum_{m=1,2,3, \cdots} \sin \left(\frac{m \pi x}{L}\right) \\
w^{s t}=\left(C_{1}+\frac{h}{2} \cdot C_{2}\right) \sum_{m=1,2,3, \ldots} \sin \left(\frac{m \pi x}{L}\right)
\end{array}\right.
$$

The strain energy of the top flange plate referred to arbitrary orthogonal coordinates may be written as

$$
U^{s t}=\frac{1}{2} \iint_{v}\left(\sigma_{x}^{s t} \varepsilon_{x}^{s t}+\sigma_{y}^{s t} \varepsilon_{y}^{s t}+\sigma_{z}^{s t} \varepsilon_{z}^{s t}+\tau_{x y}^{s t} \gamma_{x y}^{s t}+\tau_{x z}^{s t} \gamma_{x z}^{s t}+\tau_{y z}^{s t} \gamma_{y z}^{s t}\right) d v
$$

Similar to cantilever I-beam, after omitting $\gamma_{x z}^{s t}, \gamma_{y z}^{s t}$ and $\sigma_{z}^{s t}$, the strain energy can be simplified as

$$
U^{s t}=\frac{1}{2} \iint_{A}\left(\sigma_{x}^{s t} \varepsilon_{x}^{s t}+\sigma_{y}^{s t} \varepsilon_{y}^{s t}+\tau_{x y}^{s t} \gamma_{x y}^{s t}\right) d A
$$

The membrane forces, the bending and twisting moments are given by

$$
\left(\begin{array}{l}
N_{x}^{s t} \\
N_{y}^{s t} \\
N_{x y}^{s t} \\
M_{x}^{s t} \\
M_{y}^{s t} \\
M_{x y}^{s t}
\end{array}\right)=\left[\begin{array}{cccccc}
A_{11} & A_{12} & 0 & 0 & 0 & 0 \\
A_{12} & A_{22} & 0 & 0 & 0 & 0 \\
0 & 0 & A_{66} & 0 & 0 & 0 \\
0 & 0 & 0 & D_{11} & D_{12} & 0 \\
0 & 0 & 0 & D_{12} & D_{22} & 0 \\
0 & 0 & 0 & 0 & 0 & D_{66}
\end{array}\right]\left(\begin{array}{l}
\varepsilon_{x}^{s t} \\
\varepsilon_{y}^{s t} \\
\gamma_{x y}^{s t} \\
\kappa_{x}^{s t} \\
\kappa_{y}^{s t} \\
\kappa_{x y}^{s t}
\end{array}\right)
$$

where $A_{i j}, D_{i j}(i, j=1,2,6)$ are stiffness matrices. 
By assuming the transverse resultant force and moment are assumed to be equal to zero

$$
N_{y}^{s t}=M_{y}^{s t}=0
$$

The total strain energy of the top flange becomes

$$
U^{s t}=\frac{1}{2} \iint_{A} N_{x}^{s t} \varepsilon_{x}^{t} d A+\frac{1}{2} \iint_{A} N_{x y}^{s t} \gamma_{x y}^{s t} d A+\frac{1}{2} \iint_{A} M_{x}^{s t} K_{x}^{s t} d A+\frac{1}{2} \iint_{A} M_{y y}^{s t} K_{x y}^{s t} d A
$$

where

$$
\left\{\begin{array}{l}
N_{x}^{s t}=A_{11} \varepsilon_{x}^{s t} \\
N_{x y}^{s t}=A_{66} \gamma_{x y}^{s t} \\
M_{x}^{s t}=D_{11} \kappa_{x}^{s t} \\
M_{x y}^{s t}=D_{66} \kappa_{x y}^{s t}
\end{array}\right.
$$

Similarly, the strains in an arbitrary location of the top flange ( $x-y$ plane) can be written as

$$
\left\{\begin{array}{l}
\varepsilon_{x}^{s t}=\frac{\partial u^{s t}}{\partial x}+\frac{1}{2}\left[\left(\frac{\partial w^{s t}}{\partial x}\right)^{2}+\frac{1}{2}\left(\frac{\partial v^{s t}}{\partial x}\right)^{2}\right] \\
\varepsilon_{y}^{s t}=\frac{\partial w^{s t}}{\partial y}+\frac{1}{2}\left[\left(\frac{\partial u^{s t}}{\partial y}\right)^{2}+\frac{1}{2}\left(\frac{\partial v^{s t}}{\partial y}\right)^{2}\right] \\
\gamma_{x y}^{s t}=\frac{\partial w^{s t}}{\partial x}+\frac{\partial u^{s t}}{\partial y}+\frac{\partial v^{s t}}{\partial x} \frac{\partial v^{s t}}{\partial y}
\end{array}\right.
$$

Substituting Equations (3.55) into Equation (3.53), ignoring fourth-order terms, the total strain energy of the top flange of simply-supported I-beams can be obtained

$$
\begin{aligned}
U^{s t}= & \frac{1}{2} \iint_{A} N_{x}^{s t}\left[\left(\frac{\partial w^{s t}}{\partial x}\right)^{2}+\frac{1}{2}\left(\frac{\partial v^{s t}}{\partial x}\right)^{2}\right] d A+\frac{1}{2} \iint_{A} N_{x y}^{s t} \frac{\partial v^{s t}}{\partial x} \frac{\partial v^{s t}}{\partial y} d A+\frac{1}{2} A_{11} \iint_{A}\left(\frac{\partial u^{s t}}{\partial x}\right)^{2} d A+ \\
& \frac{1}{2} A_{66} \iint_{A}\left(\frac{\partial w^{s t}}{\partial x}+\frac{\partial u^{s t}}{\partial y}\right)^{2} d A+\frac{1}{2} D_{11} \iint_{A}\left(\frac{\partial^{2} v^{s t}}{\partial x^{2}}\right)^{2} d A+\frac{1}{2} D_{66} \iint_{A}\left(\frac{\partial^{2} v^{s t}}{\partial x \partial y}\right)^{2} d A
\end{aligned}
$$

where, 


$$
\left\{\begin{array}{l}
\left(\frac{\partial w^{s t}}{\partial x}\right)^{2}=\frac{\left(2 C_{1}+h C_{2}\right)^{2} \pi^{2}}{4 L^{2}} \sum_{m=1,2,3, \cdots} m^{2} \cdot \cos ^{2}\left(\frac{m \pi x}{L}\right) \\
\left(\frac{\partial v^{s t}}{\partial x}\right)^{2}=\frac{y^{2} C_{2}^{2} \pi^{2}}{2 L^{2}} \sum_{m=1,2,3, \ldots} m^{2} \cdot \cos ^{2}\left(\frac{m \pi x}{L}\right) \\
\left(\frac{\partial u^{s t}}{\partial x}\right)^{2}=\frac{y^{2} \pi^{4}}{4 L^{4}}\left(C_{1}+\frac{h}{2} C_{2}\right)^{2} \sum_{m=1,2,3, \cdots} m^{4} \cdot \sin ^{2}\left(\frac{m \pi x}{L}\right) \\
\left(\frac{\partial^{2} v^{s t}}{\partial x^{2}}\right)^{2}=\frac{y^{2} C_{2}^{2} \pi^{4}}{4 L^{4}} \sum_{m=1,2,3, \cdots} m^{4} \cdot \cos ^{2}\left(\frac{m \pi x}{L}\right) \\
\left(\frac{\partial^{2} v^{s t}}{\partial x \partial y}\right)^{2}=\frac{C_{2}^{2} \pi^{2}}{L^{2}} \sum_{m=1,2,3, \cdots} m^{2} \cdot \sin ^{2}\left(\frac{m \pi x}{L}\right) \\
\left(\frac{\partial w^{s t}}{\partial x}+\frac{\partial u^{u t}}{\partial y}\right)^{2}=0
\end{array}\right.
$$

Considering a simply-supported I-beam subjected to a mid-span concentrated load, the membrane forces are expressed in terms of the mid-span load $P$. The expressions of top flange are

$$
\begin{cases}N_{x}^{s t}=\frac{P b t}{4 I} x & \left(0 \leq x \leq \frac{L}{2}\right) \\ N_{x}^{s t}=\frac{P b t}{4 I}(L-x) & \left(\frac{L}{2}<x \leq L\right) \\ N_{z}^{s t}=N_{x z}^{s t}=0 & \left(\frac{L}{2} \leq x \leq L\right)\end{cases}
$$

Substituting Equations (3.57) into Equation (3.56), the top flange strain energy can be calculated as

$$
U^{s t}=P\left(\xi_{1}^{s t}+\xi_{2}^{s t}\right)+\xi_{3}^{s t}
$$

where,

$$
\left\{\begin{aligned}
\xi_{1}^{s t}= & \frac{b t \pi^{2}}{32 I L^{2}} \sum_{m=1,2,3, \ldots} \int_{-b / 2}^{b / 2} \int_{0}^{L / 2} x\left[\left(2 C_{1}+h C_{2}\right)^{2}+y^{2} C_{2}^{2}\right] m^{2} \cdot \cos ^{2}\left(\frac{m \pi x}{L}\right) d x d y \\
\xi_{2}^{s t}= & \frac{\pi^{2}}{4 L^{2}} \sum_{m=1,2,2, \ldots} \int_{-b / 2}^{b / 2} \int_{L / 2}^{L} \frac{b t}{8 I}(L-x)\left[\left(2 C_{1}+h C_{2}\right)^{2}+y^{2} C_{2}^{2}\right] m^{2} \cdot \sin ^{2}\left(\frac{m \pi x}{L}\right) d x d y \\
\xi_{3}^{s t}= & \frac{\pi^{4}}{8 L^{4}}\left[A_{11}\left(C_{1}+\frac{h}{2} C_{2}\right)^{2}+D_{11} C_{2}^{2}\right] \sum_{m=1,2,3, \ldots} \int_{-b / 2}^{b / 2} \int_{0}^{L} y^{2} m^{4} \cdot \cos ^{2}\left(\frac{m \pi x}{L}\right) d x d y+ \\
& D_{66} \frac{C_{2}^{2} \pi^{2}}{L^{2}} \sum_{m=1,2,3, \ldots} \int_{-b / 2}^{b / 2} \int_{0}^{L} m^{2} \cdot \sin ^{2}\left(\frac{m \pi x}{L}\right) d x d y
\end{aligned}\right.
$$




\subsubsection{Web Consideration}

Based on the same shape function of the sinusoidal web geometry as described in Equation (3.17), the element displacements of the web of simply-supported I-beams in local coordinate system $\left(x^{e}, y^{e}, z^{e}\right)$ might be assumed as

$$
\left\{\begin{array}{l}
u_{e}^{s w}=0 \\
v_{e}^{s w}=0 \\
w_{e}^{s w}=w_{e}^{s w}(x, z)
\end{array}\right.
$$

where,

$$
\left\{\begin{array}{l}
w_{e}=C_{1} \sum_{m=1,2,3, \cdots} \sin \left(\frac{m \pi x}{L}\right) \\
\alpha_{e}=C_{2} \sum_{m=1,2,3, \cdots} \sin \left(\frac{m \pi x}{L}\right)
\end{array}\right.
$$

The element displacement in $y$ direction of the web corresponding to local axis $w$, which yields

$$
\begin{aligned}
w_{e}^{s w} & =w_{e}+z \cdot \alpha_{e} \\
& =\left(C_{1}+z \cdot C_{2}\right) \sum_{m=1,2,3, \cdots} \sin \left(\frac{m \pi x}{L}\right)
\end{aligned}
$$

Assuming the web as a deformed shell, the local potential strain energy of the web consists of the strain energy of the local out-of-plane bending strain energy $U_{e b}^{s w}$ and the local membrane strain energy $U_{e m}^{s w}$, respectively. Hence

$$
U_{e}^{s w}=U_{e m}^{s w}+U_{e b}^{s w}
$$

where

$$
\left\{\begin{array}{l}
U_{e m}^{s w}=\frac{1}{2} \iint_{A}\left[N_{e x}^{s w} \varepsilon_{e x}^{s w}+N_{e z}^{s w} \varepsilon_{e z}^{s w}+N_{e x z}^{s w} \gamma_{e x z}^{s w}\right] d A \\
U_{e b}^{s w}=\frac{1}{2} \iint_{A}\left[D_{11}^{e}\left(\chi_{e x}^{s w}\right)^{2}+2 D^{e}{ }_{12}^{e} \chi_{e x}^{s w} \chi_{e z}^{s w}+D^{e}{ }_{22}^{e}\left(\chi_{e z}^{s w}\right)^{s w}+4 D_{66}^{e}\left(\chi_{e x z}^{s w}\right)^{2}\right] d A
\end{array}\right.
$$


Similar to Equations (3.23), the local membrane strains can be written as

$$
\left\{\begin{array}{l}
\varepsilon_{e x}=\frac{\partial v_{e}^{s w}}{\partial z} \\
\varepsilon_{e z}=\frac{\partial u_{e}^{s w}}{\partial x}-\frac{w_{e}^{s w}}{R_{e}} \\
\gamma_{e x z}=\frac{\partial u_{e}^{s w}}{\partial z}+\frac{\partial v_{e}^{s w}}{\partial x}
\end{array}\right.
$$

where the expressions of $R_{e}$ and $s_{e}$ are the same as Equations (3.24).

The expressions of the membrane forces for web are

$$
\begin{cases}N_{e x}^{s w}=\frac{P^{e} A t}{2 I} x z \cos \left(\frac{2 \pi x}{a}\right) & \left(0 \leq x \leq \frac{L}{2}\right) \\ N_{e x}^{s w}=\frac{P^{e} A t}{2 I}(L-x) z \cos \left(\frac{2 \pi x}{a}\right) & \left(\frac{L}{2}<x \leq L\right) \\ N_{c z}^{s w}=0 & (0 \leq x \leq L) \\ N_{e c z}^{s w}=-\frac{P^{e} A}{2 I} \sin \left(\frac{2 \pi x}{a}\right) & \left(0<x \leq \frac{L}{2}\right) \\ N_{c c z}^{s w}=\frac{P^{e} A}{2 I} \sin \left(\frac{2 \pi x}{a}\right) & \left(\frac{L}{2} \leq x \leq L\right)\end{cases}
$$

According to the same assumptions, the potential strain energy in global coordinate system can be expressed as

$$
\begin{aligned}
U^{s w}= & \frac{1}{2} \iint_{A}\left[N_{x}^{s w} \frac{\partial v^{s w}}{\partial z}+N_{z}^{w}\left(\frac{\partial u^{s w}}{\partial x}+\frac{w^{s w}}{R}\right)+N_{x z}^{s w}\left(\frac{\partial u^{s w}}{\partial z}+\frac{\partial v^{s w}}{\partial x}\right)\right] d A+ \\
& \frac{1}{2} \iint_{A}\left[D_{11}\left(\frac{\partial^{2} w^{s w}}{\partial x^{2}}\right)^{2}+2 D_{12} \frac{\partial^{2} w^{s w}}{\partial x^{2}} \frac{\partial^{2} w^{s w}}{\partial z^{2}}+D_{22}\left(\frac{\partial^{2} w^{w w}}{\partial z^{2}}\right)^{2}+4 D_{66}\left(\frac{\partial^{2} w^{s w}}{\partial x \partial z}\right)^{2}\right] d A
\end{aligned}
$$

where,

$$
\left\{\begin{array}{l}
\frac{\partial u^{s w}}{\partial x}=\frac{\partial u^{s w}}{\partial z}=\frac{\partial v^{s w}}{\partial x}=\frac{\partial v^{s w}}{\partial z}=\frac{\partial^{2} w^{s w}}{\partial z^{2}}=0 \\
\left(\frac{\partial^{2} w^{s w}}{\partial x^{2}}\right)^{2}=\frac{\pi^{4}}{4 L^{4}}\left(C_{1}+Z C_{2}\right)^{2} \sum_{m=1,2,3, \cdots} m^{4} \cdot \sin ^{2}\left(\frac{m \pi x}{L}\right) \\
\left(\frac{\partial^{2} w^{s w}}{\partial x \partial z}\right)^{2}=\frac{\pi^{2}}{L^{2}} C_{2}^{2} \sum_{m=1,2,3, \cdots} m^{2} \cdot \sin ^{2}\left(\frac{m \pi x}{L}\right)
\end{array}\right.
$$

Substituting Equations (3.66) into Equation (3.67) yields

$$
U^{s w}=\xi^{s w}
$$


where

$$
\begin{aligned}
\xi^{s w}= & D_{11} \frac{\pi^{4}}{8 L^{4}} \sum_{m=1,2,3, \ldots} \int_{0}^{h} \int_{0}^{L}\left(C_{1}+Z C_{2}\right)^{2} m^{4} \cdot \sin ^{2}\left(\frac{m \pi x}{L}\right) d s d z+ \\
& D_{66} C_{2}^{2} \frac{2 \pi^{2}}{L^{2}} \sum_{m=1,2,3, \ldots} \int_{0}^{h} \int_{0}^{L} m^{2} \cdot \sin ^{2}\left(\frac{m \pi x}{L}\right) d s d z
\end{aligned}
$$

\subsubsection{Bottom Flange Consideration}

Similarly to Chapter 3.2.2.1, the displacements of three directions of the bottom flange are expressed as follows

$$
\left\{\begin{array}{l}
u^{s b}=u^{s b}(x, y)=-y \cdot \frac{d w}{d x} \\
v^{s b}=v^{s b}(x, y)=-y \cdot \alpha \\
w^{s b}=w^{s b}(x)
\end{array}\right.
$$

Since the half of simply-supported beam functions can be considered as

$$
\left\{\begin{array}{l}
w=C_{1} \sum_{m=1,2,3, \ldots} \sin \left(\frac{m \pi x}{L}\right) \\
\alpha=C_{2} \sum_{m=1,2,3, \ldots} \sin \left(\frac{m \pi x}{L}\right)
\end{array}\right.
$$

Referring to Equation (3.70), the displacements and rotations of the bottom flange become

$$
\left\{\begin{array}{l}
w^{s b}=w+\frac{h}{2} \alpha=\left(C_{1}+\frac{h}{2} \cdot C_{2}\right) \sum_{m=1,2,3, \cdots} \sin \left(\frac{m \pi x}{L}\right) \\
\alpha^{s b}=\alpha=C_{2} \sum_{m=1,2,3, \cdots} \sin \left(\frac{m \pi x}{L}\right)
\end{array}\right.
$$

Substituting Equations (3.68) into Equations (3.66), the displacements can be calculated by

$$
\left\{\begin{array}{l}
u^{s t}=-\frac{y \pi}{L} \cdot\left(C_{1}+\frac{h}{2} \cdot C_{2}\right) \sum_{m=1,2,3, \cdots} m \cos \left(\frac{m \pi x}{L}\right) \\
v^{s t}=-y \cdot C_{2} \sum_{m=1,2,3, \cdots} \sin \left(\frac{m \pi x}{L}\right) \\
w^{s t}=\left(C_{1}+\frac{h}{2} \cdot C_{2}\right) \sum_{m=1,2,3, \cdots} \sin \left(\frac{m \pi x}{L}\right)
\end{array}\right.
$$


Therefore, the strain energy of the top flange plate referred to arbitrary orthogonal coordinates may be written as

$$
U^{s b}=\frac{1}{2} \iint_{v}\left(\sigma_{x}^{s b} \varepsilon_{x}^{s b}+\sigma_{y}^{s b} \varepsilon_{y}^{s b}+\sigma_{z}^{s b} \varepsilon_{z}^{s b}+\tau_{x y}^{s b} \gamma_{x y}^{s b}+\tau_{x z}^{s b} \gamma_{x z}^{s b}+\tau_{y z}^{s b} \gamma_{y z}^{s b}\right) d v
$$

After omitting $\gamma_{x z}^{s b}, \gamma_{y z}^{s b}$ and $\sigma_{z}^{s b}$, the strain energy can be simplified as

$$
U^{s b}=\frac{1}{2} \iint_{A}\left(\sigma_{x}^{s b} \varepsilon_{x}^{s b}+\sigma_{y}^{s b} \varepsilon_{y}^{s b}+\tau_{x y}^{s b} \gamma_{x y}^{s b}\right) d A
$$

Similarly, assuming the membrane forces, the bending and twisting moments are

$$
\left(\begin{array}{l}
N_{x}^{s b} \\
N_{y}^{s b b} \\
N_{x y}^{s b} \\
M_{x}^{s b} \\
M_{y b}^{s b} \\
M_{x y}^{s b}
\end{array}\right)=\left[\begin{array}{cccccc}
A_{11} & A_{12} & 0 & 0 & 0 & 0 \\
A_{12} & A_{22} & 0 & 0 & 0 & 0 \\
0 & 0 & A_{66} & 0 & 0 & 0 \\
0 & 0 & 0 & D_{11} & D_{12} & 0 \\
0 & 0 & 0 & D_{12} & D_{22} & 0 \\
0 & 0 & 0 & 0 & 0 & D_{66}
\end{array}\right]\left(\begin{array}{c}
\varepsilon_{x}^{s b} \\
\varepsilon_{y}^{s b b} \\
\gamma_{s y}^{s b b} \\
\kappa_{x}^{s b b} \\
\kappa_{y}^{s b} \\
\kappa_{x y}^{s b b}
\end{array}\right)
$$

where $A_{i j}, D_{i j}(i, j=1,2,6)$ are stiffness matrices.

Hence, the total strain energy of the bottom flange becomes

$$
U^{s b}=\frac{1}{2} \iint_{A} N_{x}^{s b} \varepsilon_{x}^{s b} d A+\frac{1}{2} \iint_{A} N_{x y}^{s b} \gamma_{x y}^{s b} d A+\frac{1}{2} \iint_{A} M_{x}^{s b} K_{x}^{s b} d A+\frac{1}{2} \iint_{A} M_{x y}^{s b} K_{x y}^{s b} d A
$$

where

$$
\left\{\begin{array}{l}
N_{x}^{s b}=A_{11} \varepsilon_{x}^{s b} \\
N_{x y}^{s b}=A_{66} \gamma_{x y}^{s b} \\
M_{x}^{s b}=D_{11} \kappa_{x}^{s b} \\
M_{x y}^{s b}=D_{66} \kappa_{x y}^{s b}
\end{array}\right.
$$

The strains in an arbitrary location of the bottom flange ( $x-y$ plane) can be written as 


$$
\left\{\begin{array}{l}
\varepsilon_{x}^{s b}=\frac{\partial u^{s b}}{\partial x}+\frac{1}{2}\left[\left(\frac{\partial w^{s b}}{\partial x}\right)^{2}+\frac{1}{2}\left(\frac{\partial v^{s b}}{\partial x}\right)^{2}\right] \\
\varepsilon_{y}^{s b}=\frac{\partial w^{s b}}{\partial y}+\frac{1}{2}\left[\left(\frac{\partial u^{s b}}{\partial y}\right)^{2}+\frac{1}{2}\left(\frac{\partial v^{s b}}{\partial y}\right)^{2}\right] \\
\gamma_{x y}^{s b}=\frac{\partial w^{s b}}{\partial x}+\frac{\partial u^{s b}}{\partial y}+\frac{\partial v^{s b}}{\partial x} \frac{\partial v^{s b}}{\partial y}
\end{array}\right.
$$

Substituting Equations (3.78) into Equation (3.77), ignoring fourth-order terms, the total strain energy of the bottom flange of simply-supported I-beams can be obtained

$$
\begin{aligned}
U^{s b}= & \frac{1}{2} \iint_{A} N_{x}^{s b}\left[\left(\frac{\partial w^{s b}}{\partial x}\right)^{2}+\frac{1}{2}\left(\frac{\partial v^{s b}}{\partial x}\right)^{2}\right] d A+\frac{1}{2} \iint_{A} N_{x y}^{s b} \frac{\partial v^{s b}}{\partial x} \frac{\partial v^{s b}}{\partial y} d A+\frac{1}{2} A_{11} \iint_{A}\left(\frac{\partial u^{s b}}{\partial x}\right)^{2} d A+ \\
& \frac{1}{2} A_{66} \iint_{A}\left(\frac{\partial w^{s b}}{\partial x}+\frac{\partial u^{s b}}{\partial y}\right)^{2} d A+\frac{1}{2} D_{11} \iint_{A}\left(\frac{\partial^{2} v^{s b}}{\partial x^{2}}\right)^{2} d A+\frac{1}{2} D_{66} \iint_{A}\left(\frac{\partial^{2} v^{s b}}{\partial x \partial y}\right)^{2} d A
\end{aligned}
$$

where

$$
\left\{\begin{array}{l}
\left(\frac{\partial w^{s b}}{\partial x}\right)^{2}=\frac{C_{1} \pi^{2}}{L} \sum_{m=1,2,3, \ldots} m^{2} \cdot \cos ^{2}\left(\frac{m \pi x}{L}\right) \\
\left(\frac{\partial v^{s b}}{\partial x}\right)^{2}=\frac{y^{2} C_{2}^{2} \pi^{2}}{L^{2}} \sum_{m=1,2,3, \cdots} m^{2} \cdot \cos ^{2}\left(\frac{m \pi x}{L}\right) \\
\left(\frac{\partial u^{s b}}{\partial x}\right)^{2}=\frac{C_{1}^{2} y^{2} \pi^{4}}{L^{4}} \sum_{m=1,2,3, \cdots} m^{4} \cdot \sin ^{2}\left(\frac{m \pi x}{L}\right) \\
\left(\frac{\partial^{2} v^{s b}}{\partial x^{2}}\right)^{2}=\frac{y^{2} C_{2}^{2} \pi^{4}}{L^{4}} \sum_{m=1,2,3, \cdots} m^{4} \cdot \sin ^{2}\left(\frac{m \pi x}{L}\right) \\
\left(\frac{\partial^{2} v^{s b}}{\partial x \partial y}\right)^{2}=\frac{C_{2}^{2} \pi^{2}}{L^{2}} \sum_{m=1,2,3, \cdots} m^{2} \cdot \cos ^{2}\left(\frac{m \pi x}{L}\right) \\
\left(\frac{\partial w^{s b}}{\partial x}+\frac{\partial u^{s b}}{\partial y}\right)^{2}=0
\end{array}\right.
$$

Considering a simply-supported I-beam subjected to a mid-span concentrated load, the membrane forces are expressed in terms of the mid-span load $P$. The expressions of top flange are

$$
\begin{cases}N_{x}^{s t}=\frac{P b t}{4 I} x & \left(0 \leq x \leq \frac{L}{2}\right) \\ N_{x}^{s t}=\frac{P b t}{4 I}(L-x) & \left(\frac{L}{2}<x \leq L\right) \\ N_{z}^{s t}=N_{x z}^{s t}=0 & \left(\frac{L}{2} \leq x \leq L\right)\end{cases}
$$

Hence, the totally strain energy for bottom flange can be written as 


$$
U^{s b}=P\left(\xi_{1}^{s b}+\xi_{2}^{s b}\right)+\xi_{3}^{s b}
$$

where

$$
\left\{\begin{aligned}
\xi_{1}^{s b}= & \left.\frac{b t \pi^{2}}{16 I L^{2}} \sum_{m=1,2,3, \ldots} \int_{-b / 2}^{b / 2} \int_{0}^{L / 2} x\left(2 C_{1} L+y^{2} C_{2}^{2}\right) m^{2} \cdot \cos ^{2}\left(\frac{m \pi x}{L}\right)\right] d x d y \\
\xi_{2}^{s b}= & \frac{b t \pi^{2}}{16 I L^{2}} \sum_{m=1,2,3, \ldots} \int_{-b / 2}^{b / 2} \int_{L / 2}^{L}(L-x)\left(2 C_{1} L+y^{2} C_{2}^{2}\right) m^{2} \cdot \cos ^{2}\left(\frac{m \pi x}{L}\right) d x d y \\
\xi_{3}^{s b}= & \frac{\left(A_{11} C_{1}^{2}+D_{11} C_{2}^{2}\right) \pi^{4}}{2 L^{4}} \sum_{m=1,2,3, \ldots} \int_{-b / 2}^{b / 2} \int_{0}^{L}\left[y^{2} m^{4} \cdot \sin ^{2}\left(\frac{m \pi x}{L}\right) d x d y+\right. \\
& D_{66} \frac{C_{2}^{2} \pi^{2}}{2 L^{2}} \sum_{m=1,2,3, \ldots} \int_{-b / 2}^{b / 2} \int_{0}^{L} m^{2} \cdot \cos ^{2}\left(\frac{m \pi x}{L}\right) d x d y
\end{aligned}\right.
$$

Therefore, the strain energy of simply-supposed I-beams with sinusoidal web can be calculated as

$$
\Pi=P\left(\xi_{1}^{s t}+\xi_{2}^{s t}+\xi_{1}^{s b}+\xi_{2}^{s b}\right)+\xi_{3}^{s t}+\xi^{s w}+\xi_{3}^{s b}=0
$$

Equation (3.83) is valid for any constants $C$. Therefore, the critical buckling load can be calculated as

$$
P_{c r}=-\frac{\xi_{3}^{s t}+\xi^{s w}+\xi_{3}^{s b}}{\xi_{1}^{s t}+\xi_{2}^{s t}+\xi_{1}^{s b}+\xi_{2}^{s b}}
$$

where $\xi_{1}^{s t}, \xi_{2}^{s t}, \xi^{s w}, \xi_{1}^{s b}, \xi_{2}^{s b}$ and $\xi_{3}^{s b}$ are given by Equations (3.59), (3.69) and (3.82).

\subsection{Verification with Existing Solutions of Flat Web I-Beams}

To verify the accuracy, the analytical model is first reduced to calculate the cantilever I-beams with flat web as shown in Figures 3.7 to 3.9, based on the assumption of Equation 3.24. 

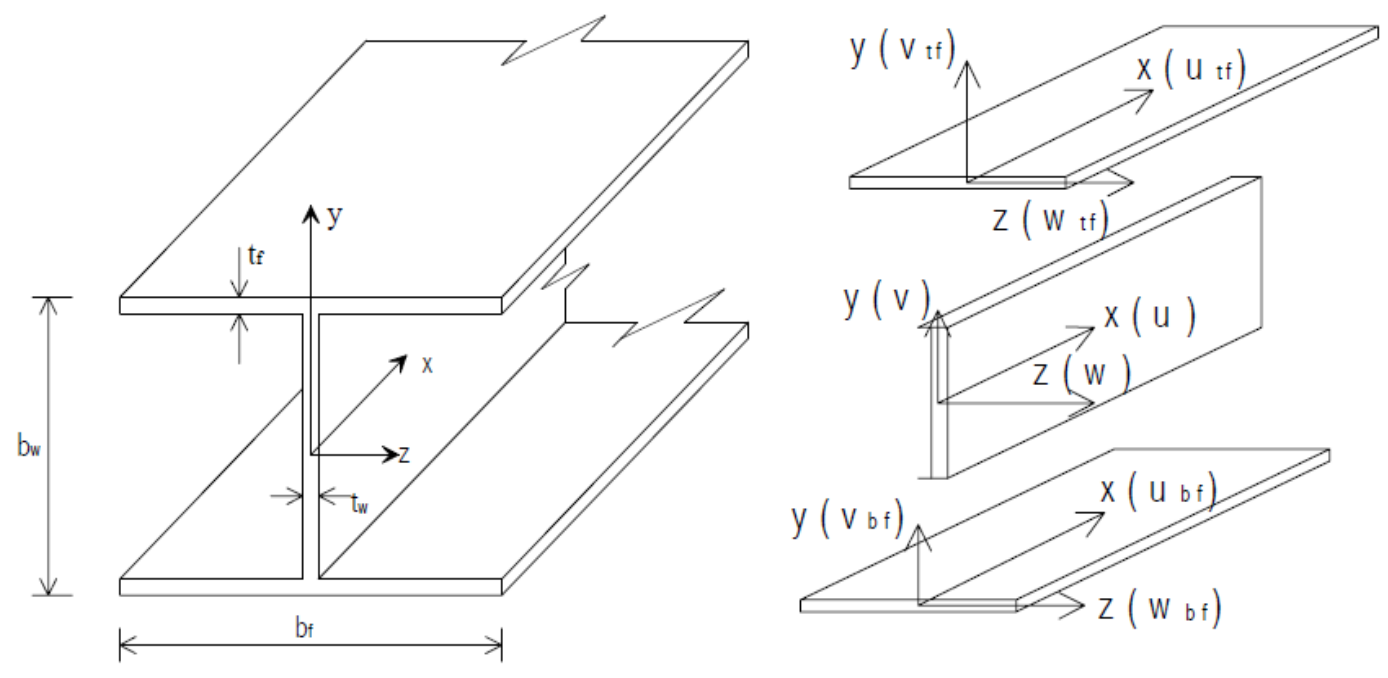

Figure 3.7 Coordinate System and Geometry of Flat Web I-Beam

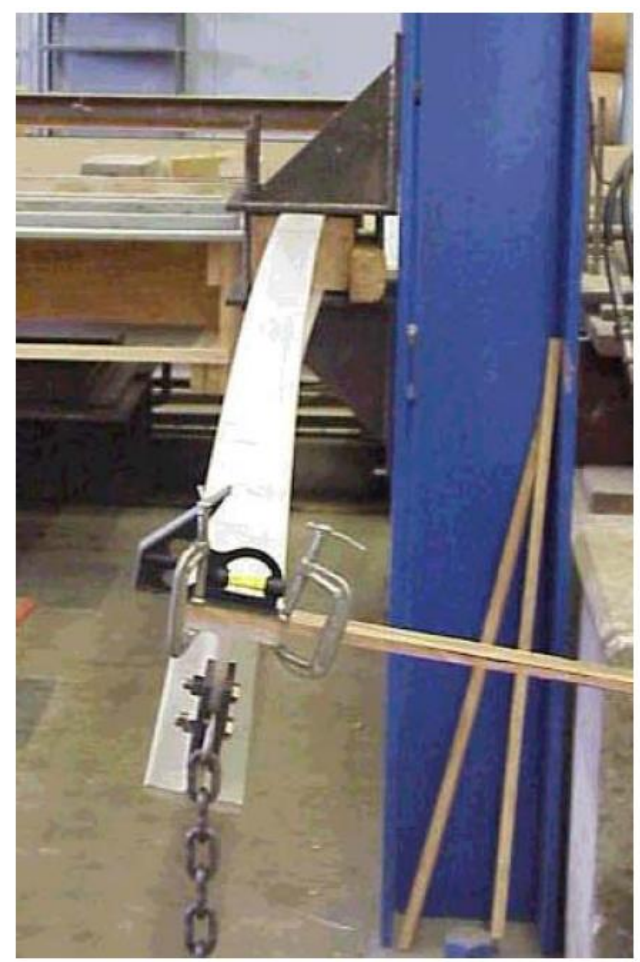

Figure 3.8 Flat Web I-Beam Buckled I3x6 Beam 


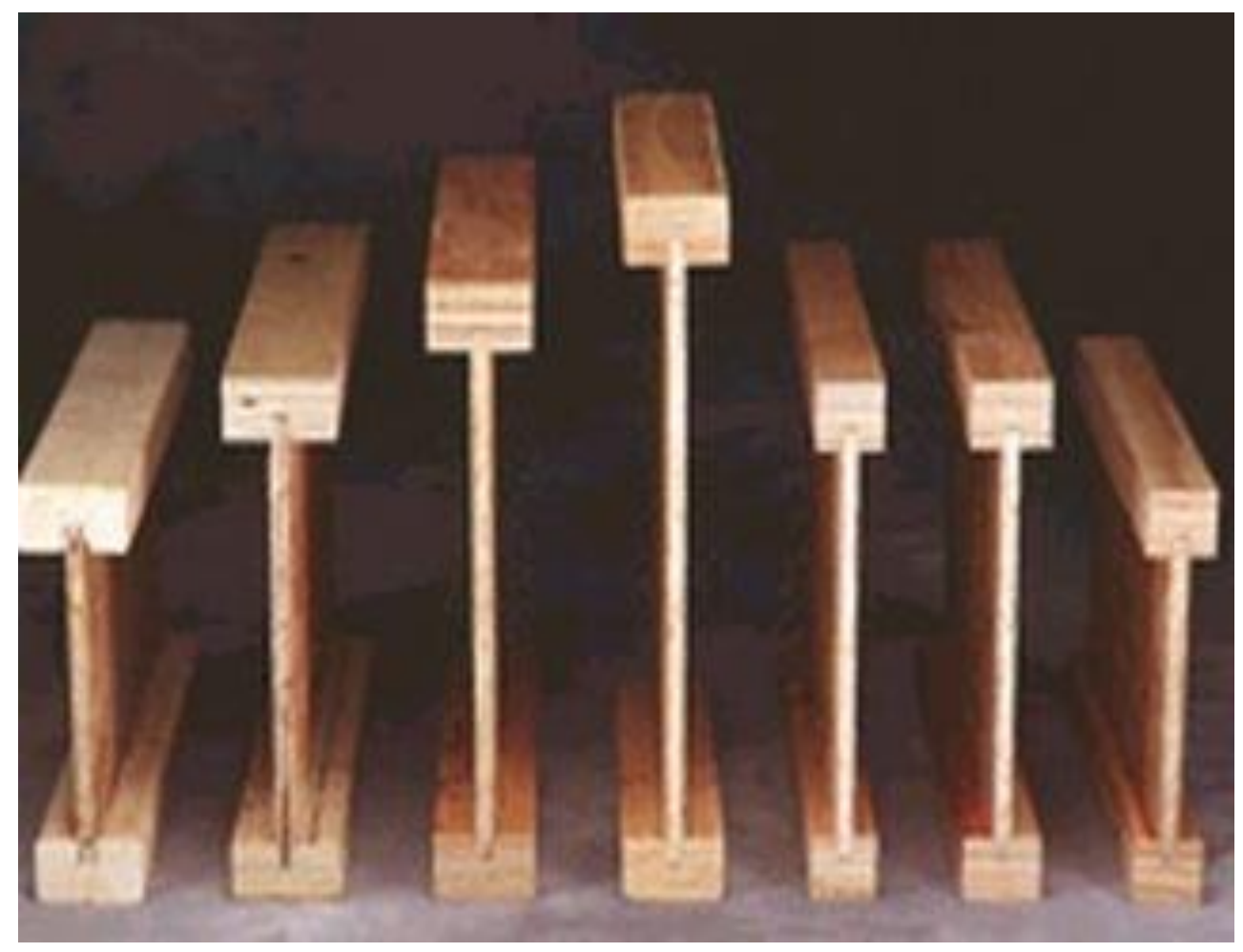

Figure 3.9 Composite Wood I-Beam Samples with Flat Web

The analytical solutions are compared with existing analytical, experimental and numerical solutions (Qiao 2003). The analytical solutions of the existing solutions are based on total potential energy governing instability and derived using the plate theory. By applying the Rayleigh-Ritz method and solving for the eigenvalues of the potential energy equilibrium equation, the lateral buckling load, $P_{c r}$, for a free-end point load applied at the centroid of the cross-section is obtained. For different assumed buckling shape functions, the explicit equations of critical buckling load are achieved.

In the experiment study, four geometries of flat web I-beams were tested to evaluate their lateral buckling responses, as shown in Figure 3.8. The four I-sections

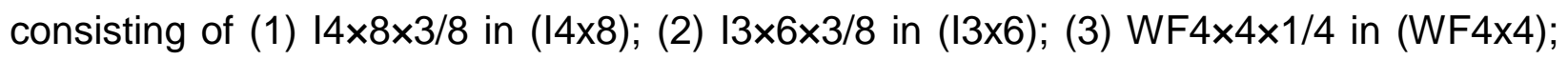
and (4) WF6 $\times 6 \times 3 / 8$ in (WF6 66 ). The clamped-end of the beams was achieved using two steel angles attached to a vertical steel column. Using a loading platform, the loads 
were initially applied by sequentially adding steel angle plates of $25.0 \mathrm{lbs}$, and as the critical loads were being reached, incremental weights of 5.0 lbs were added until the beam buckled. The tip load was applied through a chain attached at the centroid of the cross section. Varying span lengths from $6.0 \mathrm{ft}$ to $13.0 \mathrm{ft}$, two beam samples per geometry were evaluated, and an averaged value for each pair of beam samples was considered as the experimental critical load.

The FE simulation of the existing results is present by the commercial FE program ANSYS, for modeling of the FRP beams using Mindlin eight-node isoparametric layered shell elements (SHELL99).

Table 3.1 lists the material properties of the composite material. Table 3.2 summaries the analytical, experimental and numerical results from existing solutions and the analytical results based on present analytical model. Good correlations can be observed, with a maximum difference of $5.6 \%$ between present analytical solutions and existing numerical results.

Table 3.1 Material Properties of I-Beams

\begin{tabular}{c|c|c|c|c|c}
\hline \hline & $\boldsymbol{E}_{1}(\mathrm{psi})$ & $\boldsymbol{E}_{\boldsymbol{1}}(\mathrm{psi})$ & $\boldsymbol{G}_{12}(\mathrm{psi})$ & $\boldsymbol{G}_{1 \mathbf{z}}(\mathrm{psi})$ & $\boldsymbol{G}_{2 z}(\mathrm{psi})$ \\
\hline Web & 2260000 & 180000 & 152000 & 148000 & 148000 \\
Flanges & 1940000 & 64000 & 61000 & 67000 & 67000 \\
\hline \hline
\end{tabular}


Table 3.2 Comparison of Critical Buckling Loads $\boldsymbol{P}_{c r}$ between Existing Results and Present

\begin{tabular}{|c|c|c|c|c|c|c|c|}
\hline \multicolumn{8}{|c|}{ Flexural-Torsional (Lateral) Buckling } \\
\hline \multicolumn{3}{|c|}{ Section Dimensions } & \multicolumn{5}{|c|}{ Flat Web } \\
\hline $\begin{array}{c}\text { Height } \\
\text { (in) }\end{array}$ & $\begin{array}{l}\text { Flange } \\
\text { Width } \\
\text { (in) }\end{array}$ & $\begin{array}{l}\text { Length } \\
\qquad(\mathrm{ft})\end{array}$ & $\begin{array}{c}\text { Present } \\
\text { Analytical } \\
\text { Solutions } \\
P_{c r} \text { (lbs) }\end{array}$ & 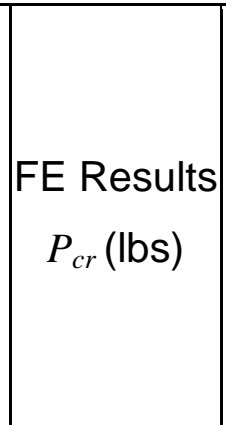 & $\begin{array}{c}\text { Existing } \\
\text { Analytical } \\
\text { Solutions } \\
P_{c r}(\mathrm{lbs})\end{array}$ & $\begin{array}{c}\text { Experimental } \\
\text { Results } \\
P_{c r}(\mathrm{lbs})\end{array}$ & $\begin{array}{l}\text { Differences } \\
\text { between } \\
\text { Present } \\
\text { Analytical } \\
\text { and FE } \\
\text { Results (\%) }\end{array}$ \\
\hline 6 & 3 & 10 & 503.21 & 488.7 & 525.6 & 462.7 & 2.88 \\
\hline 6 & 3 & 12 & 301.55 & 306.9 & 335.9 & 304.8 & -1.77 \\
\hline 8 & 4 & 10 & 1010.8 & 1012.3 & 1071.2 & 901.5 & -0.15 \\
\hline 8 & 4 & 12 & 629.06 & 664.5 & 717.6 & 661.6 & -5.6 \\
\hline
\end{tabular}

\subsection{Verification with Experimental Investigation of Sinusoidal Web I-Beams}

The proposed analytical model is further applied to study I-beams with sinusoidal web. In order to verify the accuracy of present model, tests on wood composite I-beams using hardwood veneer-mill residues with sinusoidal web have been conducted to evaluate flexural-torsional buckling in West Virginia University (McGraw, et al. 2011), as shown in Figures 3.10 a\&b. 

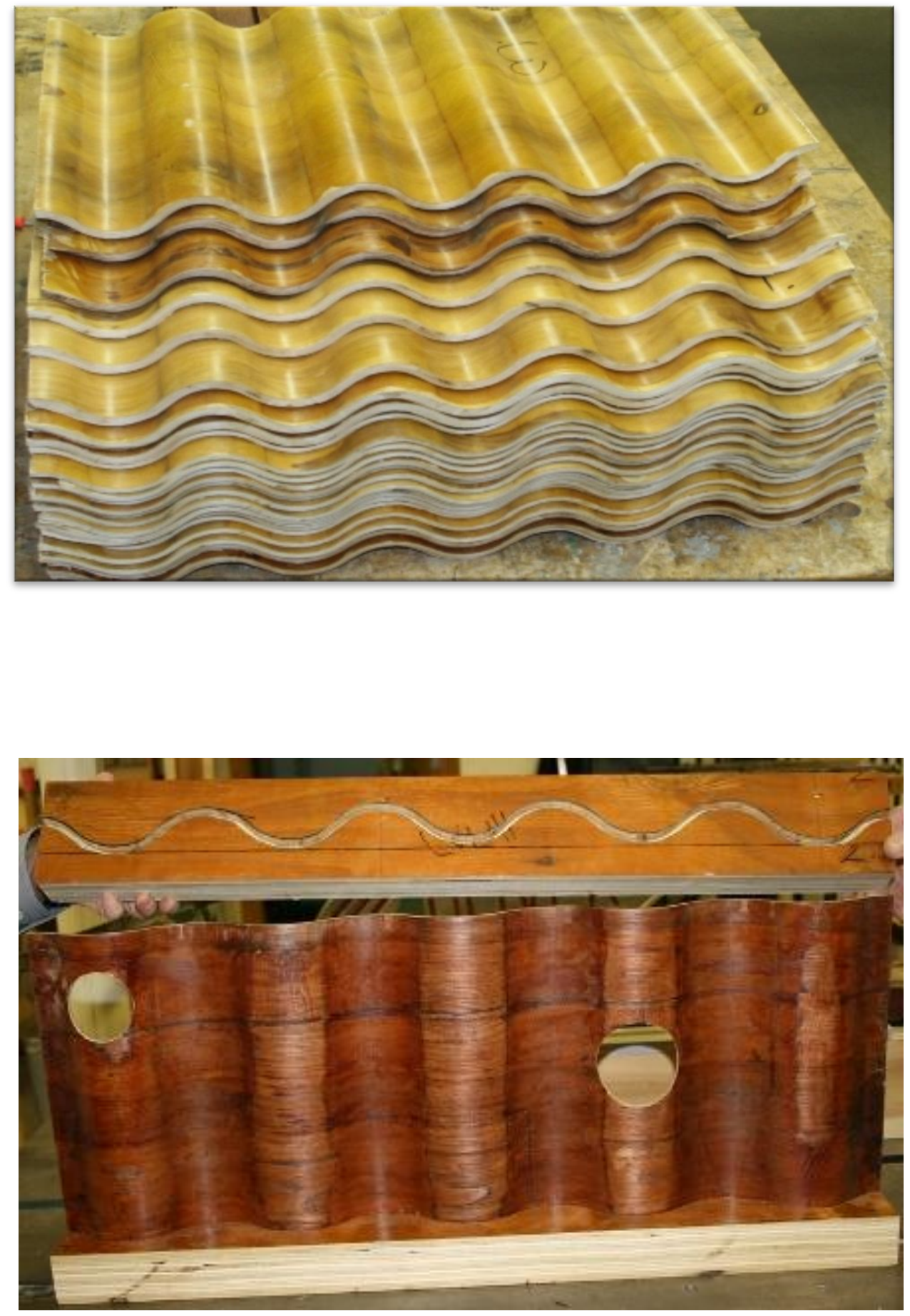

Figure 3.10 a\&b Composite Wood I-Beam Samples with Sinusoidal Web 
Cantilever I-beam testing are carried out. Three beam samples are evaluated for each group, and the average value for each group is shown in Table 3.3, which also lists the analytical results using the model developed in this study. Good correlations can be observed between the analytical and experimental results.

Table 3.3 Comparison of Critical Buckling Loads $\boldsymbol{P}_{c r}$ between Analytical and Experimental Results

\begin{tabular}{c|c|c|c|c|c}
\hline \hline \multicolumn{6}{c}{ Flexural-Torsional (Lateral) Buckling } \\
\hline \multicolumn{2}{c}{ Section Dimensions } & \multicolumn{3}{|c}{ Sinusoidal Web } \\
\hline $\begin{array}{c}\text { Height } \\
\text { (in) }\end{array}$ & $\begin{array}{c}\text { Flange } \\
\text { Width } \\
\text { (in) }\end{array}$ & $\begin{array}{c}\text { Length } \\
\text { (ft) }\end{array}$ & $\begin{array}{c}\text { Analytical } \\
\text { Solutions } P_{c r}(\mathrm{lbs})\end{array}$ & $\begin{array}{c}\text { Ave. } \\
\text { Experimental } \\
\text { Results } P_{c r}(\mathrm{lbs})\end{array}$ & $\begin{array}{c}\text { Differences between } \\
\text { Present Analytical } \\
\text { and Experimental } \\
\text { Results (\%) }\end{array}$ \\
\hline 10 & 2.3 & 10 & $\mathbf{5 8 6 . 9}$ & - & - \\
10 & 2.3 & 12 & $\mathbf{4 1 3 . 5}$ & 346.4 & $\mathbf{9 . 5}$ \\
16 & 2.3 & 10 & $\mathbf{6 6 4 . 1}$ & - & - \\
16 & 2.3 & 12 & $\mathbf{4 8 6 . 4}$ & 409.0 & $\mathbf{1 0}$ \\
\hline \hline
\end{tabular}

\subsection{Verification with Finite Element Simulation of Sinusoidal Web I-Beams}

A FE model is developed to study the cantilever I-beams with the same configurations, considering the length of both 10 and $12 \mathrm{ft}$. Pre and post-processing for the FE analysis is performed using FEMAP v. 8.3 and the analysis is completed using ABAQUS v. 6.7.

In the FE model, the I-beams are analyzed using 8-node shell elements with 60 elements along the beam length and 4 elements along the width of each flange and the web height, as shown in Figures 3.11 and 3.12. The boundary conditions are imposed at the centroid of the beam ends to simulate simply-supported and cantilever spans. The beam ends are laterally restrained at the top-flange nodes. The top flange is 
laterally restrained at the ends to prevent it from out of plane twisting. The critical buckling load $P_{c r}$ is obtained from the FE eigenvalue analysis. The values $P_{c r}$ of cantilever I-beam are compared with present analytical, and summarized in Table 3.4. Good correlations can be observed between the analytical and FE results.

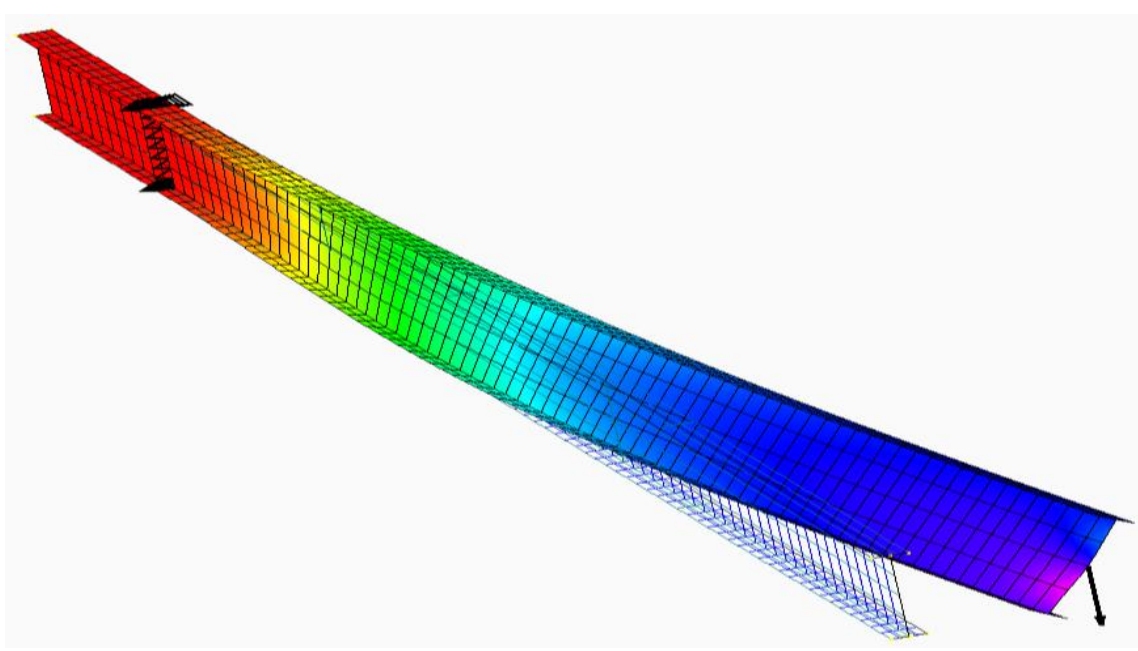

Figure 3.11 Deformed Shape of Sinusoidal Web I-Beam under Cantilever Boundary Conditions for Flexural-Torsional Buckling

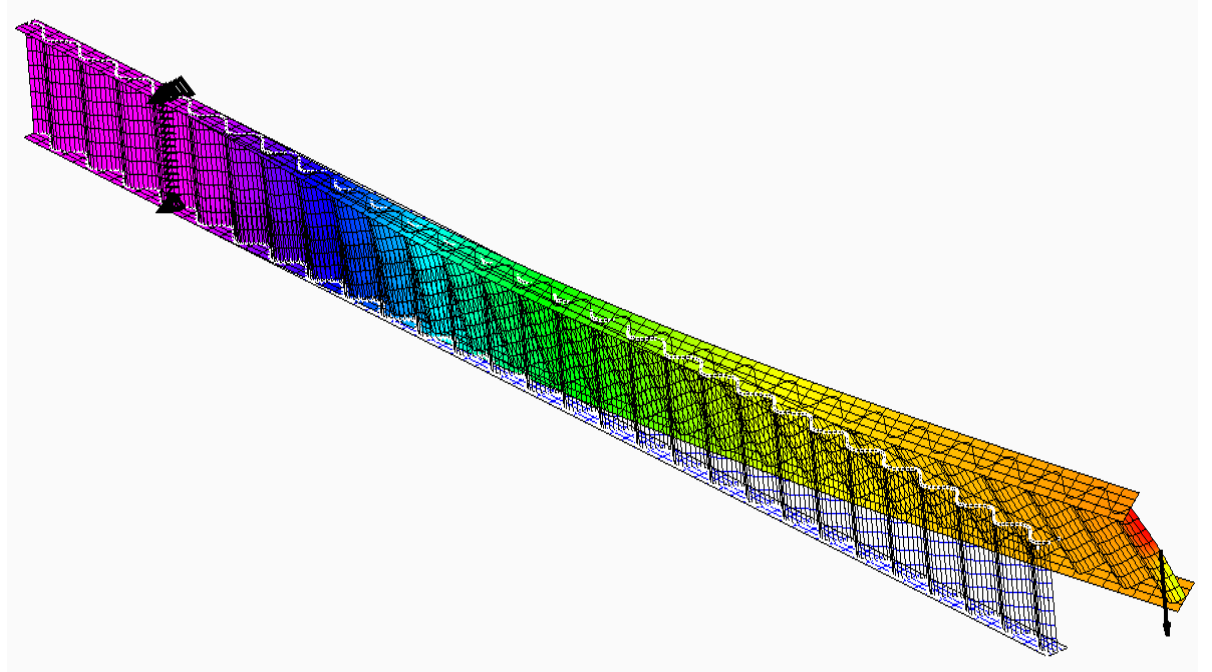

Figure 3.12 Deformed Shape of Sinusoidal Web I-Beam under Cantilever Boundary Conditions for Flexural-Torsional Buckling 
Table 3.4 Comparison of Critical Buckling Loads $\boldsymbol{P}_{c r}$ between Analytical and Numerical Results

\begin{tabular}{|c|c|c|c|c|c|}
\hline \multicolumn{6}{|c|}{ Flexural-Torsional (Lateral) Buckling/ Cantilever I-Beam } \\
\hline \multicolumn{3}{|c|}{ Section Dimensions } & \multicolumn{3}{|c|}{ Sinusoidal Web } \\
\hline $\begin{array}{c}\text { Height } \\
\text { (in) }\end{array}$ & $\begin{array}{l}\text { Flange } \\
\text { Width } \\
\text { (in) }\end{array}$ & $\begin{array}{l}\text { Length } \\
\qquad(\mathrm{ft})\end{array}$ & $\begin{array}{c}\text { Analytical } \\
\text { Solutions } P_{c r} \\
\text { (lbs) }\end{array}$ & $\begin{array}{c}\text { FE Results } \\
P_{c r}(\mathrm{lbs})\end{array}$ & $\begin{array}{l}\text { Differences between } \\
\text { Present Analytical and } \\
\text { FE Results (\%) }\end{array}$ \\
\hline 10 & 2.3 & 10 & 586.9 & 552.52 & 5.86 \\
\hline 10 & 2.3 & 12 & 413.5 & 374.37 & 9.5 \\
\hline 16 & 2.3 & 10 & 664.1 & 628.77 & 5.32 \\
\hline 16 & 2.3 & 12 & 486.4 & 437.78 & 10 \\
\hline
\end{tabular}

\subsection{Parametric Study}

Following the analytical model described above, a parametric study of cantilever I-beam is first carried out by varying the cross sectional geometries, for four different heights, as shown in Figure 3.13. The results are shown in Tables 3.5 and 3.6. Next, sinusoidal web geometry is comparing with flat web geometry, by four different heights, 8", 10", 12" and 16". The results are shown in Tables 3.7 and 3.8.

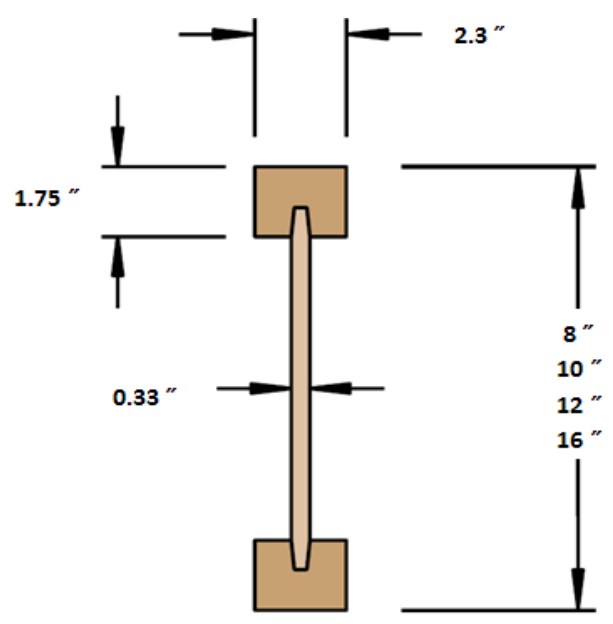

Figure 3.13 Cross-Sectional Geometry of Simply-Supported I-Beam 
Table 3.5 Comparison of Critical Buckling Loads $\boldsymbol{P}_{c r}$ with Different Heights I

\begin{tabular}{|c|c|c|c|}
\hline \multicolumn{4}{|c|}{ Flexural-Torsional (Lateral) Buckling } \\
\hline \multicolumn{4}{|c|}{ Sinusoidal Web } \\
\hline \multicolumn{3}{|c|}{ Section Dimensions } & \multirow[b]{2}{*}{ Critical Buckling Loads $P_{c r}(\mathrm{lbs})$} \\
\hline Height (in) & $\begin{array}{c}\text { Flange Width } \\
\text { (in) }\end{array}$ & Length $(\mathrm{ft})$ & \\
\hline 8 & 2.3 & 10 & 521.7 \\
\hline 10 & 2.3 & 10 & 586.9 \\
\hline 12 & 2.3 & 10 & 623.4 \\
\hline 16 & 2.3 & 10 & 664.1 \\
\hline
\end{tabular}

Table 3.6 Comparison of Critical Buckling Loads $\boldsymbol{P}_{c r}$ with Different Heights II

\begin{tabular}{c|c|c|c}
\hline \hline \multicolumn{4}{c}{ Flexural-Torsional (Lateral) Buckling } \\
\hline \multicolumn{3}{c}{ Sinusoidal Web } \\
\multicolumn{3}{c}{ Section Dimensions } & Critical Buckling Loads $P_{c r}(\mathrm{lbs})$ \\
\hline \multirow{2}{*}{ Height (in) } & Flange Width & Length (ft) & \\
\hline 8 & (in) & 12 & $\mathbf{3 6 7 . 2}$ \\
10 & 2.3 & 12 & $\mathbf{4 1 3 . 5}$ \\
12 & 2.3 & 12 & $\mathbf{4 4 0 . 8}$ \\
16 & 2.3 & 12 & $\mathbf{4 8 6 . 4}$ \\
\hline \hline
\end{tabular}


Table 3.7 Comparison of Critical Buckling Loads $\boldsymbol{P}_{c r}$ with Different Web Geometries I

\begin{tabular}{c|c|c|c|c|c}
\hline \multicolumn{5}{c}{ Flexural-Torsional (Lateral) Buckling } \\
\hline \multicolumn{3}{c}{ Section Dimensions } & \multicolumn{3}{c}{ Critical Buckling Loads } \\
\hline Height & Flange Width & Length & Sinusoidal & Flat Web & Difference \\
(in) & (in) & $(\mathrm{ft})$ & Web & & $(\%)$ \\
\hline 8 & 2.3 & 10 & 521.7 & 395.81 & $\mathbf{2 4 . 1}$ \\
10 & 2.3 & 10 & 586.9 & 442.16 & $\mathbf{2 4 . 7}$ \\
12 & 2.3 & 10 & 623.4 & 480.03 & $\mathbf{2 3 . 0}$ \\
16 & 2.3 & 10 & 664.1 & 513.28 & $\mathbf{2 2 . 7}$ \\
\hline \hline
\end{tabular}

Table 3.8 Comparison of Critical Buckling Loads $\boldsymbol{P}_{c r}$ with Different Web Geometries II

\begin{tabular}{c|c|c|c|c|c}
\hline \hline \multicolumn{4}{c}{ Flexural-Torsional (Lateral) Buckling } \\
\hline \multicolumn{3}{c}{ Section Dimensions } & \multicolumn{3}{c}{ Critical Buckling Loads } \\
\hline \multirow{2}{*}{ Height (in) } & $\begin{array}{c}\text { Flange Width } \\
\text { (in) }\end{array}$ & Length (ft) & $\begin{array}{c}\text { Sinusoidal } \\
\text { Web }\end{array}$ & Flat Web & $\begin{array}{c}\text { Difference } \\
\text { (\%) }\end{array}$ \\
\hline 8 & 2.3 & 12 & 367.2 & 289.17 & $\mathbf{2 1 . 3}$ \\
10 & 2.3 & 12 & 413.5 & 325.24 & $\mathbf{2 1 . 4}$ \\
12 & 2.3 & 12 & 440.8 & 340.25 & $\mathbf{2 2 . 8}$ \\
16 & 2.3 & 12 & 486.4 & 384.26 & $\mathbf{2 1 . 0}$ \\
\hline \hline
\end{tabular}

It can be seen from Figure 3.14 that sinusoidal web critical buckling load becomes larger as web height increases. Meanwhile, as shortening beam length, critical buckling load increases significantly. Figures 3.15 and 3.16 present that the critical buckling load for the I-beams with sinusoidal web are much higher than for those with flat web, with increases of more than $20 \%$. 


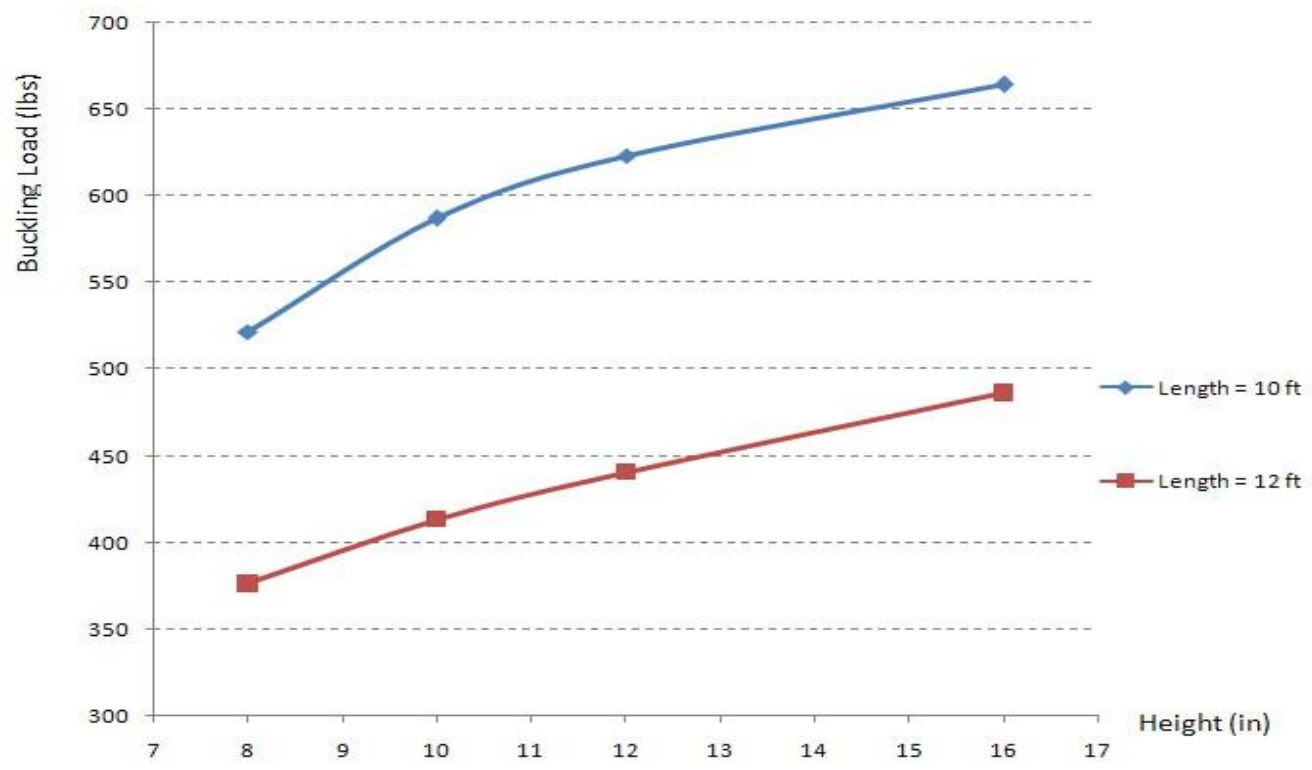

Figure 3.14 Sinusoidal Web Critical Buckling Load vs Web Height

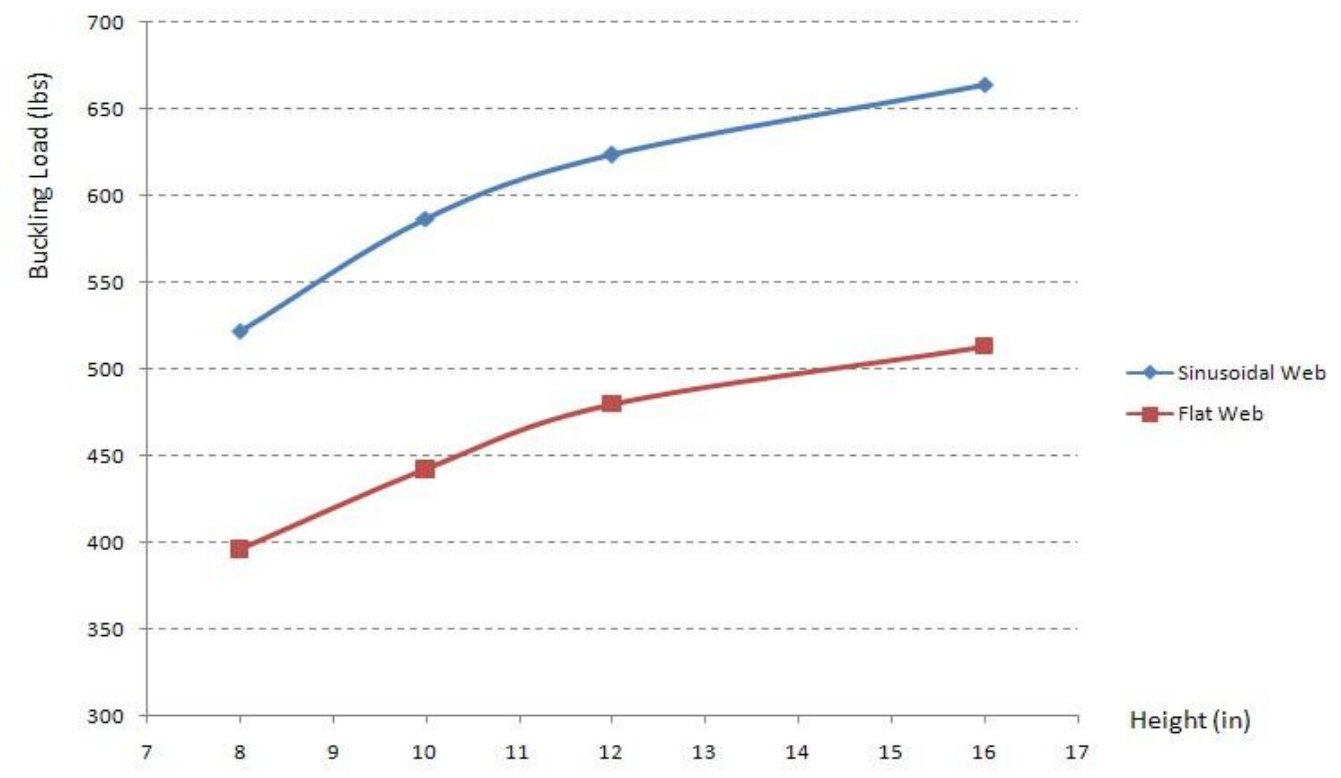

Figure 3.15 Critical Buckling Load $\boldsymbol{P}_{c r}$ Comparisons Between Sinusoidal Web and Flat Web $(L=10 \mathrm{ft})$ 


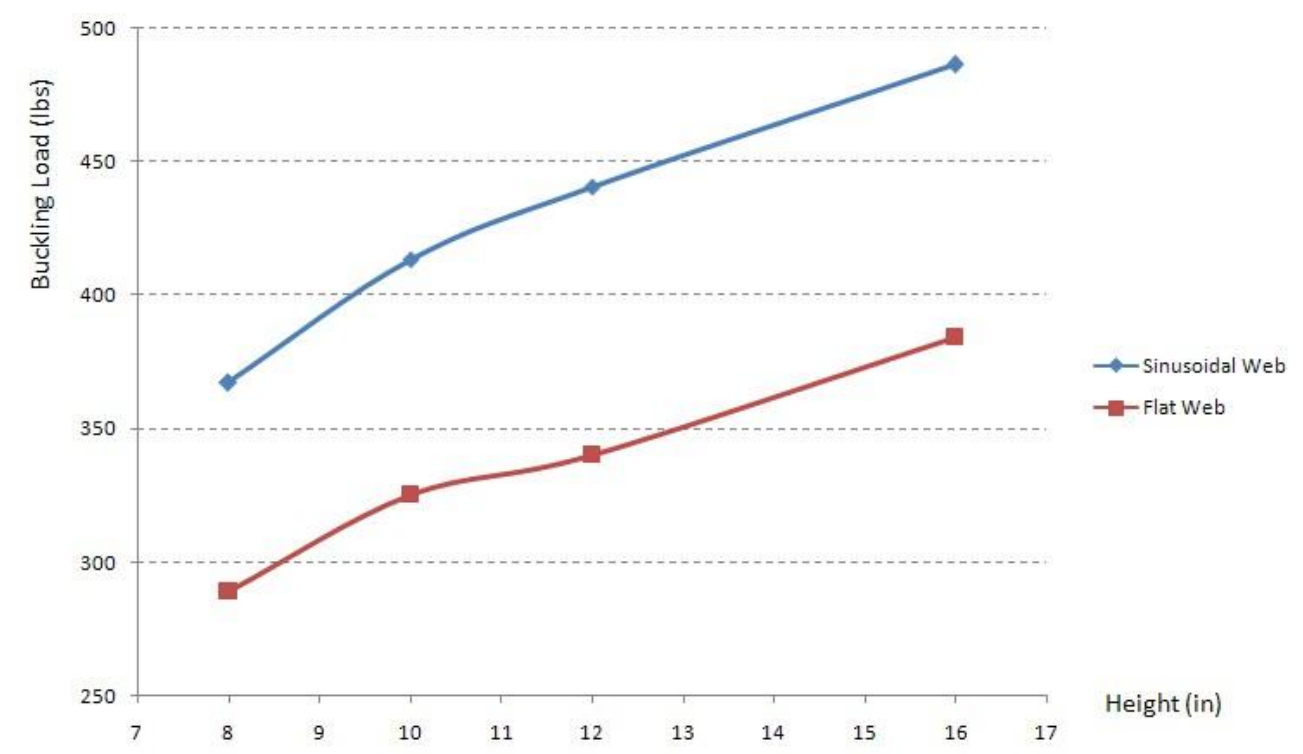

Figure 3.16 Critical Buckling Load $\boldsymbol{P}_{c r}$ Comparisons Between Sinusoidal Web and Flat Web $(L=12 \mathrm{ft})$

\subsection{Conclusions}

In this chapter, an analytical model is presented to evaluate the critical buckling capacities of flexural-torsional (lateral) buckling of composite I-beam. Sinusoidal web geometry is considered, including simply-supported and cantilever boundary conditions. Experimental testing and FE simulation are carried out to verify the analytical solutions.

The analytical solutions are obtained based on energy method, deriving the total potential energy equations governing instability based on plate and shell theory. Good correlations can be obtained between the analytical solutions and experimental and FE results.

Based on the parametric study, the critical buckling load becomes larger as web height increases. Meanwhile, as shortening beam length, critical buckling load increases significantly. Comparing with flat web critical buckling load, sinusoidal web increases more than $20 \%$. The analytical model can be extended to study other types of composite I-beams with curved web and can be used to carry out parametric study to optimize I-beams with curved web. 
CHAPTER FOUR

LOCAL BUCKLING CAPACITIES OF SINUSOIDAL

WEB I-BEAMS UNDER COMPRESSION 


\subsection{Introduction}

Composite I-beams are engineered wood products that consist of two main components. As implied by the name, I-beams have an "l" shaped cross-section with a top and bottom flange separated by a relatively narrow web. These products are manufactured for a variety of lengths and heights, with varying flange and web thicknesses. Flanges are typically made of structural composite lumber (SCL) such as laminated veneer lumber (LVL) or parallel strand lumber (PSL) and occasionally solid lumber. SCL is a composite product formed by combining veneer sheets, strands, or other particles to form long beams with the general orientation of the wood fiber along the longitudinal axis of the member. The web of prefabricated I-beams is typically composed of structural wood panels which are joined along the length of the beam. The two most common used web materials in the industry are oriented strand board (OSB) and plywood, which are manufactured by orienting and laminating layers of veneer sheets, strands, or flakes. Various connection details are used to join the flanges and the web. The joint between the flange and the web is a critical part of beam integrity and is a typical source of patentability (Leichiti et al. 1990).

The long and large lumber members once common for light framing applications are becoming more expensive and harder to find. Researchers have estimated that $50 \%$ of wood fiber can be saved by using wood composite structural shapes (Leichiti et al. 1989). Prefabricated wood I-beams have been commonplace in industry since the late 1960s (Leichti et al. 1990). I-beams are used in both residential and commercial construction primarily as floor beams, but are also used as roof support beams, garage door headers, and framing components as well as other various applications. In fact, it is estimated that $50 \%$ of new residential floors built in North America use this product (Chui et al. 2008). Prefabricated I-beams are becoming popular because of their light weight, dimensional stability, low variability in performance, and ease of construction (Forest Products Laboratory 1999). The I-section provides an efficient structural response where the flanges are designed to provide moment capacity and the web provides the shear capacity. 
However, one significant issue associated with the thin-wall I-beam is that the web is likely to fail due to local compressive or shear buckling. Zhu et al. (2005) found that the greater the height of the beam and the stronger the flanges, the more likely a beam is to experience buckling of the web. Racher et al. (2007) found that as the height of the beam increased the ultimate capacity of the beam is governed by the plate behavior of the web.

To address this issue, a new composite I-beam product with sinusoidal geometry was developed at West Virginia University, using discarded veneer-mill residues as shown in Figure 4.1. Black Cherry (Prunus Serotina) veneer-mill clippings were used to manufacture these composite I-beams. They were manufactured by layering the clippings in a unidirectional mat and using a phenol formaldehyde resin under heat and pressure to bond the strands. Locally supplied 15-layer Yellow Poplar (Liriodendron Tulipifera) LVL was used as flange stock. An investigation into the physical and mechanical properties of the web material as well as the web-to-web and flange-to-web connections was performed earlier (McGraw 2009). This paper focuses on the evaluation of the web local buckling under compression.

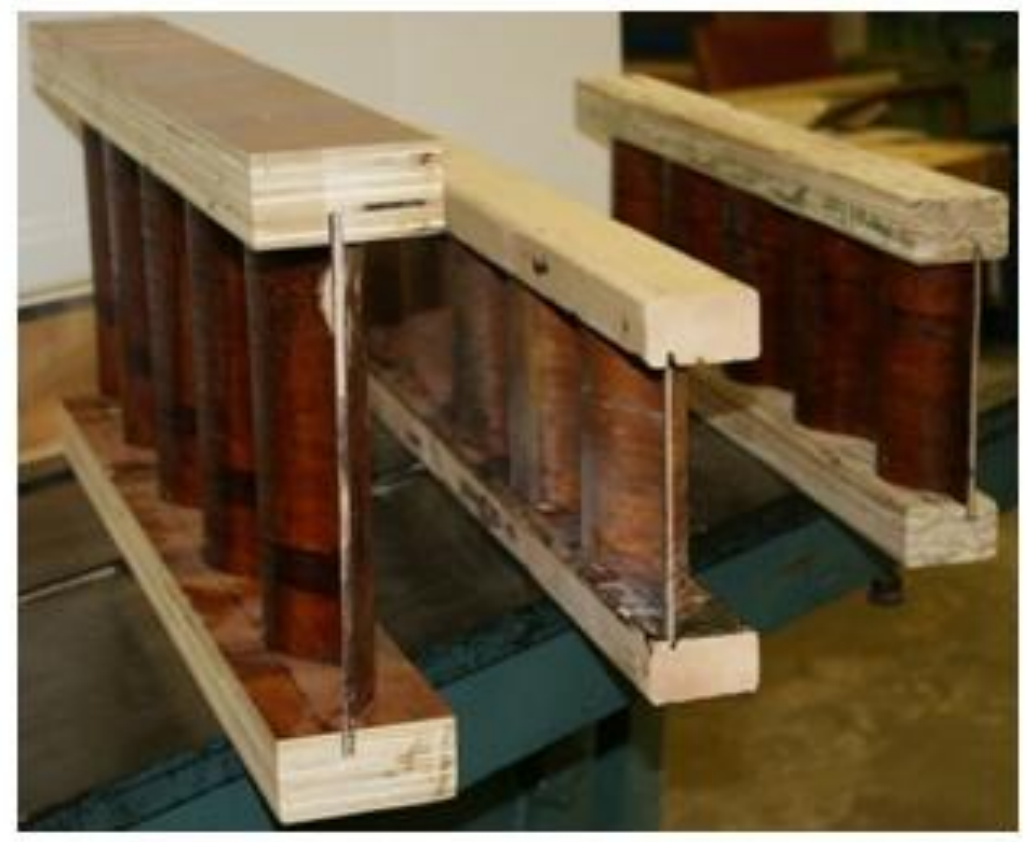

Figure 4.1 Composite I-Beams with Sinusoidal Web 
As pointed out by Bleich (1952), the flange-web joint for I-beam can be viewed as elastically restrained and the web and flange can be treated as plates with elastic restrained edges when considering load buckling. Recent research on the buckling behavior with elastic restrained edges includes, among others, Qiao et al. (2001), Kollar (2002) and Qiao and Zou (2003) on the local buckling of composite FRP shapes by discrete plate analysis; Davalos and Chen (2005) on buckling behavior of honeycomb FRP core with partially elastically restrained loaded edges under out-of-plane compression; Shan and Qiao (2007) on explicit local buckling analysis of rotationally restrained composite plates under uniaxial compression. Therefore, the problem in this study can be described as a curved shell under uniaxial compression with loaded elastic restrained edges.

Research on stability of curved shell can be traced back to the 1930s, when Donnell (1933) proposed a set of equations (Donnell's equation) to study thin-walled tubes under torsion. Batdorf (1947) developed a new method for determining the buckling stresses of cylindrical shells under various loading conditions based on a modified form of Donnell's equation. These equations are still used, which can be found in several books including Ventsel and Krauthammer (2001), where they termed this method as equilibrium method. This method is based on solving differential equations and then considering different loading and boundary conditions, and therefore, it is considered an implicit method. In parallel to the implicit method, previous researchers have carried out work based on the use of energy methods such as the Rayleigh-Ritz method, to determine theoretical buckling loads for panels under pure shear, compression and combinations of these. These cases are summarized in design guides such as those by Timoshenko and Gere (1961), Bruhn (1973), Young (1989), Ugural (1999), and Ventsel and Krauthammer (2001), and Arnold (2008). This approach can be interpreted as an explicit method since it assumes the displacement function and solves for the unknown parameters. Based on the literature review conducted by the authors, these two methods have been applied primarily to cylindrical shells, either considering simply-supported (hinged) or rigid (clamped) boundary conditions. Rosen and Signer (1976) considered elastic restraining effect in their study, which was focused on vibrations and buckling of stiffened cylindrical shells. 


\subsection{Theoretical Formulation}

The local buckling of a sinusoidal core panel under a uniformly distributed compression load is analyzed here based on thin shell theory. Figure 4.2 displays the web in the $x-y$ plane, which can be described as

$$
y=A \sin \frac{2 \pi x}{a}
$$

with parameters $A$ and $a$ defined in Figure 4.2. We can consider a representative section of the web, which is shown as a solid in Figure 4.2, between $x=a_{1}$ and $x=a_{2}$.

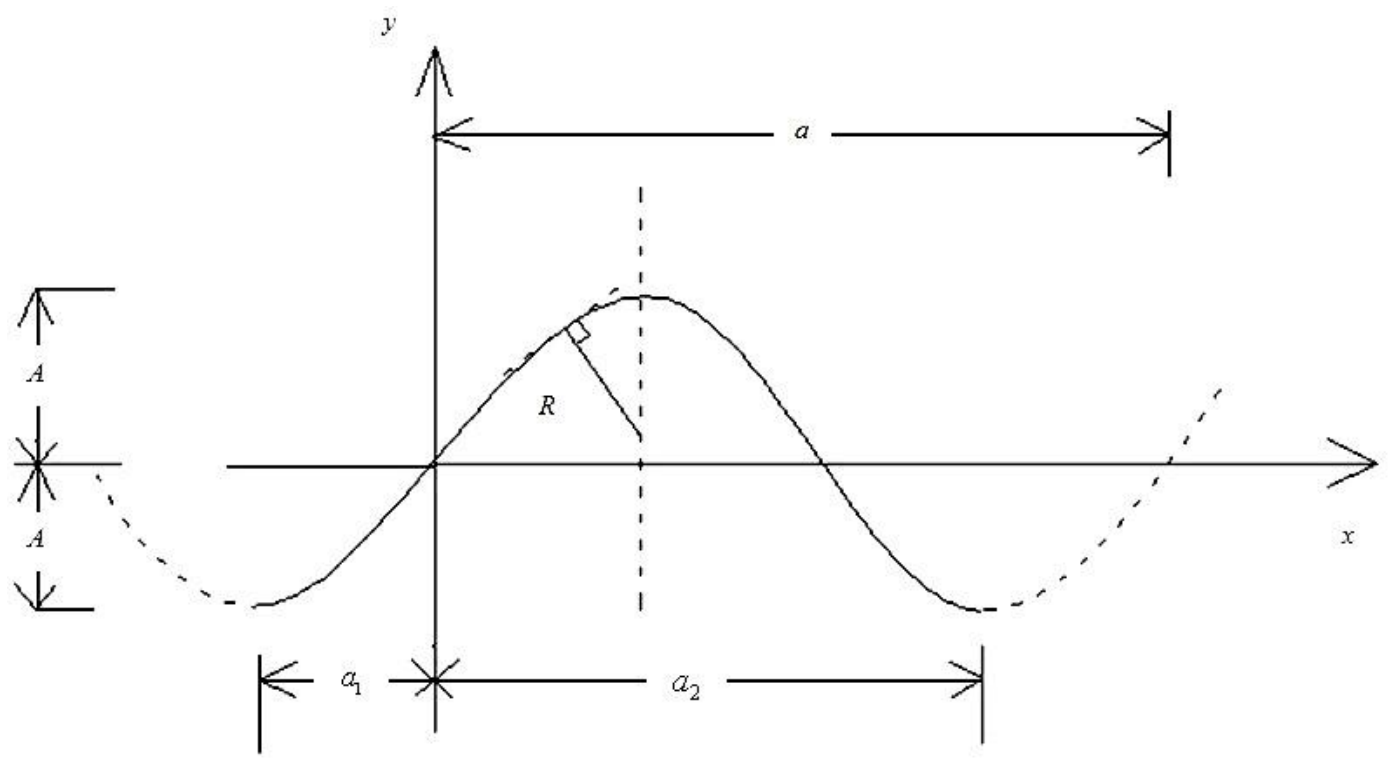

Figure 4.2 Mid-Surface of Sinusoidal Web in $x-y$ Plane

A 3-D view of the model is shown in Figure 4.3. As pointed out by Davalos and Chen (2005), and Shan and Qiao (2007), the joints between the web and flanges can be described as elastically restrained, to define the boundary conditions accordingly. Free edges are assumed for the other two edges because they represent the worst loading scenario and are easy to simulate in the compression test, as will be described later. 


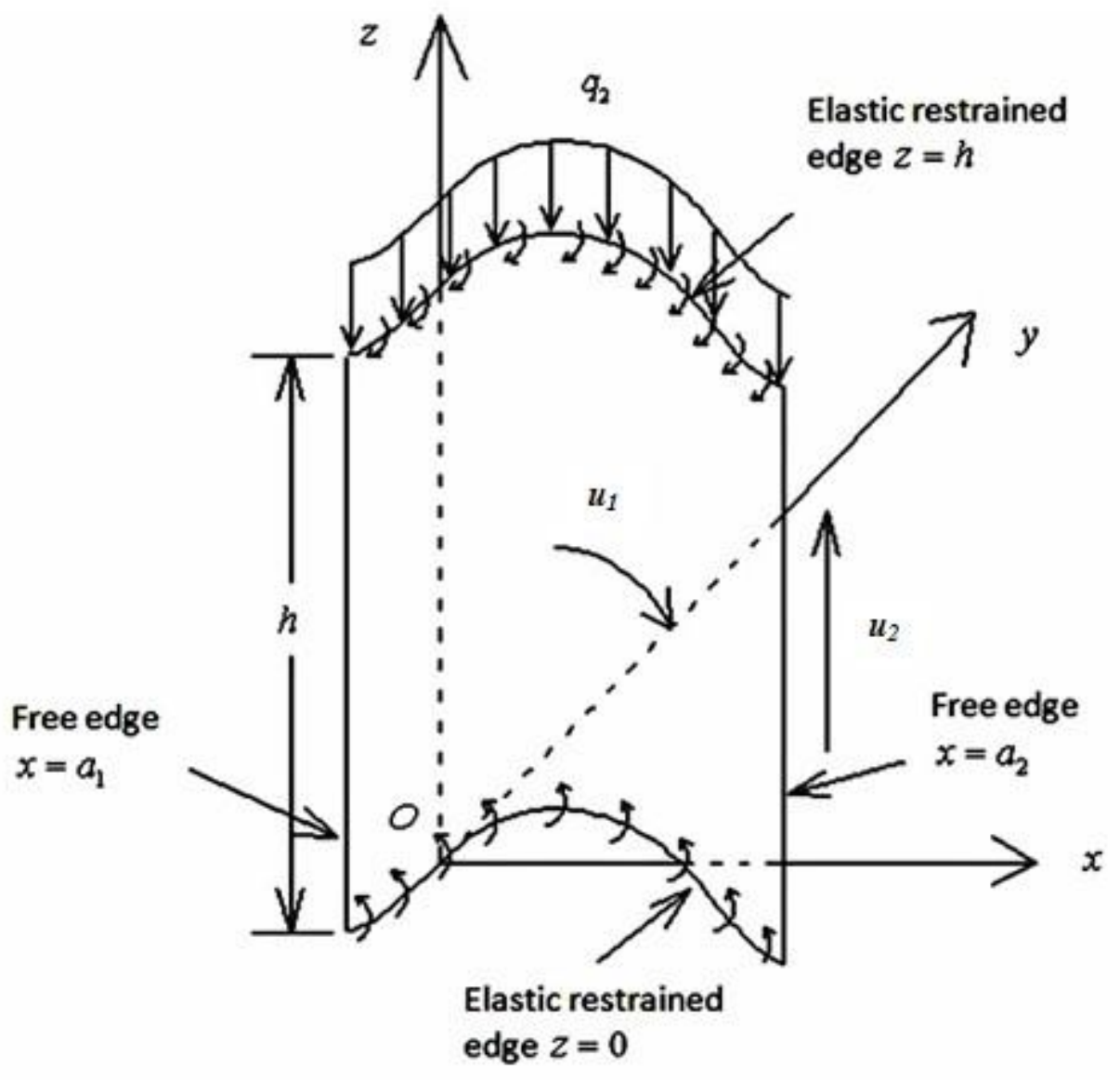

Figure 4.3 Sinusoidal Shells under Axial Compression

The boundary conditions along the four edges as shown in Figure 4.3 can be written as

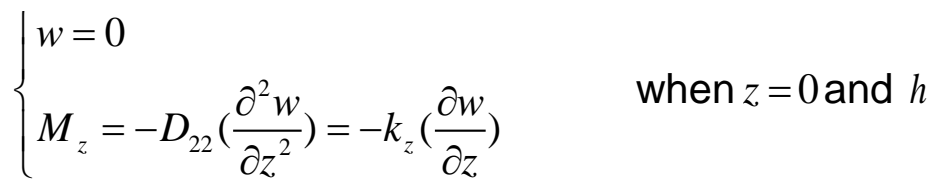

and 


$$
\left\{\begin{array}{l}
M_{x}=D_{12}\left(\frac{\partial^{2} w}{\partial z^{2}}\right)+D_{22}\left(\frac{\partial^{2} w}{\partial x^{2}}\right)=0 \\
V_{x}=\frac{\partial M_{x}}{\partial x}+4 D_{66} \frac{\partial^{3} w}{\partial z^{2} \partial x}=0
\end{array} \quad \text { when } x=a_{1} \text { and } a_{2}\right.
$$

where $w$ is the displacement in the $y$ direction, $k_{z}$ is the elastic rotational restraint stiffness along the two loaded edges, and $D_{i j}(i, j=1,2,6)$ are bending stiffness for the orthotropic shell.

A combined sinusoidal function along $x$ and $z$ directions can be chosen as the buckling displacement function (Shan and Qiao, 2007)

$$
w(z)=C\left\{(1-\omega) \sin \left(\frac{m \pi z}{h}\right)+\omega\left[1-\cos \left(\frac{2 m \pi z}{h}\right)\right]\right\}
$$

where the unique combination of weighted sine and cosine functions is conformable to the buckling shape function as described in Figure 4.3 and Equations (4.2) and (4.3). By properly choosing the weight constant $\omega$, Equation (4.4) can account for the elastic restraining effect along the two loaded edges. When $\omega=0$, it equals the shape function of the shell with simply-supported boundaries; and $\omega=1$ corresponds to the deformation of the shell with clamped boundary conditions. $C$ is a constant to be determined based on energy method.

It is noted that the displacement in Equation (4.4) does not exactly satisfy the free edge conditions as defined in Equation (4.3). However, based on a previous study (Shan, 2007), this approximate displacement function can provide adequate accuracy. Since, it satisfies the conditions of $\left.\frac{\partial^{2} w}{\partial x^{2}}\right|_{x=a_{1}, a_{2}}=0$, which are the dominant terms of the moment and shear force at the free edges of $x=a_{1}$ and $a_{2}$.

Substituting the displacement function shown in Equation (4.4) into boundary conditions shown in Equations (4.2) and (4.3), $\omega$ can be obtained in terms of the elastic rotational restraint stiffness $k_{z}$ as 


$$
\omega=\frac{k_{z} h}{4 \pi m D_{22}+k_{z} h}
$$

The energy criterion can be presented as

$$
\delta U+\delta \Omega=0
$$

where $\delta U$ is the change of the shell strain energy during buckling, and $\delta \Omega$ is the increment in the potential of the external loading owing to stretching of the middle surface and bending as the shell deflects due to the buckling action. Therefore, we need to find the strain state prior to and after buckling.

First, the change of the local shell strain energy $\delta U^{e}$ in local coordinate system is evaluated, by determining the strain component prior to buckling, i.e. in the pre-buckling membrane state. Considering the element axial strain in the $z$ direction of the local coordinate system corresponding to local axis $u_{2}$ as shown in Figure 4.3, or the element meridian strain before buckling $\varepsilon_{20}^{e}$ can be calculated as

$$
\varepsilon_{20}^{e}=-\frac{q_{2}^{e}}{E_{2} t}
$$

where $q_{2}^{e}$ is the element compression force acting on the shell element $e$ in the $z$ direction, $E_{2}$ is the Young's modulus, and $t$ is the thickness of the shell. The corresponding local circumferential strain can be calculated as

$$
\varepsilon_{10}^{e}=-v_{12} \varepsilon_{20}^{e}
$$

where $v_{12}$ is the Poisson's ratio for the orthotropic materials.

As a result of buckling, the local deflection $w^{e}$ induces the circumferential strain $\varepsilon^{e}{ }_{11}$ as 


$$
\varepsilon^{e}{ }_{11}=-\frac{w^{e}}{R}
$$

where $R$ is the mid-surface curvature radius of the sinusoidal curve in the local coordinate system as shown in Figure 4.2. Therefore, the total local circumferential strain after buckling occurs is

$$
\begin{aligned}
\varepsilon_{1}^{e} & =\varepsilon_{10}^{e}+\varepsilon^{e}{ }_{11} \\
& =-v_{21} \varepsilon^{e}{ }_{20}-\frac{w^{e}}{R}
\end{aligned}
$$

To find the corresponding total local meridian $\operatorname{strain} \varepsilon_{2}^{e}$, we can use Hook's law as

$$
-q_{2}^{e}=\frac{E_{2} t}{1-v_{12} v_{21}}\left(\varepsilon_{2}^{e}+v_{12} \varepsilon_{1}^{e}\right)
$$

which gives

$$
\varepsilon_{2}^{e}=-\frac{\left(1-v_{12} v_{21}\right) q_{2}^{e}}{E_{2} t}-v_{12} \varepsilon_{1}^{e}
$$

Therefore, the change of local meridian strain can be calculated as

$$
\varepsilon_{21}^{e}=\varepsilon_{2}^{e}-\varepsilon_{20}^{e}
$$

Next, we can evaluate local $\delta \Omega^{e}$ as

$$
\delta \Omega^{e}=-\delta W^{e}{ }_{e x t}
$$

where $\delta W^{e}{ }_{e x t}$ is the work done by local external loading $q_{2}^{e}$. As explained before, $\delta \Omega^{e}$ is associated with the local meridian strain $\varepsilon^{e}{ }_{21}$ and local bending deflection $w^{e}$, and correspondingly, we define $\delta \Omega^{e}{ }_{1}$, and $\delta \Omega^{e}{ }_{2}$, which can be calculate as 


$$
\begin{gathered}
\delta \Omega^{e}{ }_{21}=-t \iint_{A} q_{2}^{e} \varepsilon_{21}^{e} d A \\
\delta \Omega_{2}^{e}=-t \iint_{A} q_{2}^{e} \chi_{2}^{e} w^{e} d A
\end{gathered}
$$

where $\chi_{2}^{e}=\frac{\partial^{2} w^{e}}{\partial z^{2}}$. Therefore

$$
\begin{aligned}
\delta \Omega^{e} & =\delta \Omega_{1}^{e}+\delta \Omega^{e} \\
& =-t \iint_{A} v_{12}\left(\frac{w^{e}}{R^{e}}\right)^{2} d A-t \iint_{A} q_{2}^{e}{ }_{2} w^{e} \frac{\partial^{2} w^{e}}{\partial z^{2}} d A
\end{aligned}
$$

The variation in local strain energy $\delta U^{e}$ was three components

$$
\delta U^{e}=\delta U_{e}^{m}+\delta U_{e}^{b}+\delta U_{e}^{\Gamma}
$$

where $\delta U_{e}^{b}, \delta U_{e}{ }^{m}$, and $\delta U_{e}^{\Gamma}$ are local strain energies from local bending, membrane, and elastic restrain at the loading edges, respectively. Therefore, we have

$$
\begin{aligned}
\delta U_{e}^{b}= & \frac{1}{2} \iint_{A}\left[D_{11}^{e}\left(\chi_{1}^{e}\right)^{2}+2 D_{12}^{e} \chi_{1}^{e} \chi_{2}^{e}+D_{22}^{e}\left(\chi_{2}^{e}\right)^{2}+4 D_{66}^{e}\left(\chi_{12}^{e}\right)^{2}\right] d A \\
\delta U_{e}^{m}= & \frac{E_{2} t}{2\left(1-v_{12} v_{21}\right)}\left\{\iint_{A}\left[\left(\varepsilon^{e}\right)^{2}+\left(\varepsilon_{2}^{e}\right)^{2}+\left(v_{12}+v_{21}\right) \varepsilon_{1}^{e} \varepsilon_{2}^{e}+\frac{1-v_{12}}{2}\left(\gamma_{12}^{e}\right)^{2}\right] d A-\right. \\
& \left.\iint_{A}\left[\left(\varepsilon_{10}^{e}\right)^{2}+\left(\varepsilon_{20}^{e}\right)^{2}+\left(v_{12}+v_{21}\right) \varepsilon_{10}^{e} \varepsilon_{20}^{e}+\frac{1-v_{12}}{2}\left(\gamma_{12}^{e 0}\right)^{2}\right] d A\right\} \\
\delta U_{e}^{\Gamma}= & \frac{1}{2} \int_{\Gamma} k_{z}\left[\left(\left.\frac{\partial w^{e}}{\partial z}\right|_{z=0}\right)^{2}+\left(\left.\frac{\partial w^{e}}{\partial z}\right|_{z=h}\right)^{2}\right] d s
\end{aligned}
$$

where $\chi_{1}^{e}=\frac{\partial^{2} w^{e}}{\partial x^{2}}, \chi_{12}^{e}=\frac{\partial^{2} w^{e}}{\partial x \partial y}, \chi_{2}^{e}=\frac{\partial^{2} w^{e}}{\partial z^{2}}$ represent changes of the mid-surface curvature of the element $e$ in local coordinate; $D_{i j}(i, j=1,6)$ are element bending stiffness matrices; 
$v_{i j}(i, j=1,2)$ are Poisson's ratio; $\varepsilon_{i}^{e}(i=1,2)$ are axial strains in local coordinate $u_{i}$; $d A=d s d z$, where $s^{e}$ is shell length along the local axis $u_{1}$ (see Figure4.3); $\gamma_{12}^{e}$ and $\gamma_{12}^{e 0}$ are post- and pre-local buckling shear strains, respectively.

Owing to the symmetrical deformation, we have $\gamma_{12}^{e}=\chi_{1}^{e}=\chi_{12}^{e}=0$. Therefore, Equation (4.19) can be reduced to

$$
\begin{aligned}
& \delta U_{e}^{b}=\frac{1}{2} \iint_{A} D_{22}^{e}\left(\frac{\partial^{2} w^{e}}{\partial z^{2}}\right)^{2} d A \\
& \delta U_{e}^{m}=\frac{E_{2} t}{2} \iint_{A}\left[\left(\frac{w^{e}}{R^{e}}\right)^{2}\right] d A+\frac{\left(v_{12}{ }^{2} v_{21}+v_{12} v_{21}{ }^{2}-3 v_{12}-3 v_{21}\right)}{2\left(1-v_{12} v_{21}\right)} \iint_{A} q_{2}^{e}\left(\frac{w^{e}}{R^{e}}\right)^{2} d A \\
& \delta U_{e}^{\Gamma}=\frac{1}{2} \int_{\Gamma} k_{z}\left[\left(\left.\frac{\partial w^{e}}{\partial z}\right|_{z=0}\right)^{2}+\left(\left.\frac{\partial w^{e}}{\partial z}\right|_{z=h}\right)^{2}\right] d s
\end{aligned}
$$

Substituting Equation (4.20) into Equation (4.18), and then using Equations (4.17) and (4.18) into Equation (4.6), we have

$$
\delta \Omega^{e}+\delta U^{e}=0
$$

Similar to Chapter 3.2.1.2, in order to evaluate the corresponding counterparts of $\delta \Omega^{e}$ and $\delta U^{e}$ in global coordinate system, it is necessary to transform Equation (4.21) from the local coordinate system into the global one.

Based on the same calculation as Chapter 3.2.1.2, and after some of mathematic manipulations, we achieved

$$
\delta \Omega+\delta U=\xi_{1}-q_{2} \xi_{2}+\xi_{3}+\xi_{4}+\xi_{5}+q_{2} \xi_{6}=0
$$

where 


$$
\left\{\begin{array}{l}
\xi_{1}=\int_{0}^{h} \int_{a_{1}}^{a_{2}} v_{12} t\left[\frac{f(z)}{R}\right]^{2} d s d z \\
\xi_{2}=\int_{0}^{h} \int_{a_{1}}^{a_{2}} t f(z) \frac{\partial^{2} f(z)}{\partial z^{2}} d s d z \\
\xi_{3}=\int_{0}^{h} \int_{a_{1}}^{a_{2}} \frac{D_{22}}{2}\left[\frac{\partial^{2} f(z)}{\partial z^{2}}\right]^{2} d s d z \\
\xi_{4}=\int_{0}^{h} \int_{a_{1}}^{a_{2}} \frac{E_{2} t}{2}\left[\frac{f(z)}{R}\right]^{2} d s d z \\
\left.\xi_{5}=\int_{a_{1}}^{a_{2}} \frac{k_{z}}{2}\left[\left.\frac{\partial f(z)}{\partial z}\right|_{z=0}\right)^{2}+\left(\left.\frac{\partial f(z)}{\partial z}\right|_{z=h}\right)^{2}\right] d s \\
\xi_{6}=\int_{0}^{h} \int_{a_{1}}^{a_{2}} \frac{\left(v_{12}^{2} v_{21}+v_{12} v_{21}^{2}-3 v_{12}-3 v_{21}\right)}{2\left(1-v_{12} v_{21}\right)}\left[\frac{f(z)}{R}\right]^{2} d s d z
\end{array}\right.
$$

in which

$$
\left\{\begin{array}{l}
d s=\int_{a_{1}}^{a_{2}} \sqrt{1+4\left(\frac{A \pi}{a}\right)^{2} \cos ^{2}\left(\frac{2 \pi x}{a}\right)} d x \\
R=\frac{1+4\left(\frac{A \pi}{a}\right)^{2} \cos ^{2}\left(\frac{2 \pi x}{a}\right)}{4 A\left(\frac{\pi}{a}\right)^{2} \sin \left(\frac{2 \pi x}{a}\right)} \\
f(z)=(1-\omega) \sin \left(\frac{m \pi z}{h}\right)+\omega\left[1-\cos \left(\frac{2 m \pi z}{h}\right)\right]
\end{array}\right.
$$

Equation (4.22) is valid for any $C$ in Equation (4.4). The following requirement should be satisfied

$$
q_{2}=\frac{\xi_{1}+\xi_{3}+\xi_{4}+\xi_{5}}{\xi_{2}-\xi_{6}}
$$

Substituting Equations (4.23) and (4.24) into (4.25) yields

$$
q_{2}=\frac{\eta_{1} \int_{a_{1}}^{a_{2}} \frac{1}{R^{2}} d s+\eta_{4} \int_{a_{1}}^{a_{2}} d s}{\eta_{2} \int_{a_{1}}^{a_{2}} d s-\eta_{3} \int_{a_{1}}^{a_{2}} \frac{1}{R^{2}} d s}
$$

where 


$$
\left\{\begin{aligned}
\eta_{1}= & \left(2 v_{12}+E_{2}\right) \frac{t}{2} \cdot\left\{3 \sin \left(\frac{4 m \pi a}{h}\right)+(6 \omega-15) \sin \left(\frac{2 m \pi a}{h}\right)-24(\omega-2) m \pi a+\right. \\
& \left.8(\omega-1)\left[8 \cos \left(\frac{3 m \pi a}{h}\right)-9 \cos \left(\frac{m \pi a}{h}\right)+8 h\right]\right\} \\
\eta_{2}= & t\left[1-\omega+m \pi \omega-\frac{\omega}{2} \sin \left(\frac{2 m \pi a}{h}\right)\right] \cdot\left\{(\omega-1)\left[1-\cos \left(\frac{m \pi a}{h}\right)\right]+2 \omega \sin \left(\frac{2 m \pi a}{h}\right)\right\} \\
\eta_{3}= & \frac{\left(v_{12}{ }^{2} v_{21}+v_{12} v_{21}^{2}-3 v_{12}-3 v_{21}\right)}{\left(1-v_{12} v_{21}\right)\left(2 v_{12}+E_{2}\right) t} \cdot \eta_{1} \\
\eta_{4}= & \frac{m \pi D_{22}}{2 h}\left\{\left[\omega-\cos \left(\frac{m \pi a}{h}\right)+1\right](\omega-1)+2 \omega \sin \left(\frac{2 m \pi a}{h}\right)\right\}+ \\
& \frac{m^{2} \pi^{2} k_{z}}{2 h^{2}}\left\{[(1-\omega) \cos (m \pi a)+2 \omega \sin (2 m \pi a)]^{2}+(1-\omega)^{2}\right\}
\end{aligned}\right.
$$

In Equation (4.27), for each value of $m$ there is a unique buckling-mode shape and a unique buckling load. In global coordinate system, the lowest critical load can be determined by equating the first derivative of $q_{2}$ to zero with respect to $\mathrm{m}$. It is noted that for a flat plate, we have $R \rightarrow \infty$. Therefore, the terms associated with in-plane stretching, i.e., $\delta \Omega_{1}$ in Equation (4.17) and $\delta U^{m}$ in Equation (4.18), become zero, and the solutions represent the traditional buckling of a flat plate.

\subsection{Verification with Finite Element Simulation}

To verify the model presented in the previous section, both the analytical model and the FE method are used to predict the buckling strength of a web panel under compression. The shape of the web is shown in Figure 3.2, with $a=6$ ", $a_{1}=1.5$ ", $a_{2}=$ 4.5", and $A=0.75 "$. The geometry of the cross section of the beam is shown in Figure 4.4. Both the flanges and the web are modeled as $2 \mathrm{D}$ orthotropic materials with the material properties shown in Table 4.1from material testing. 


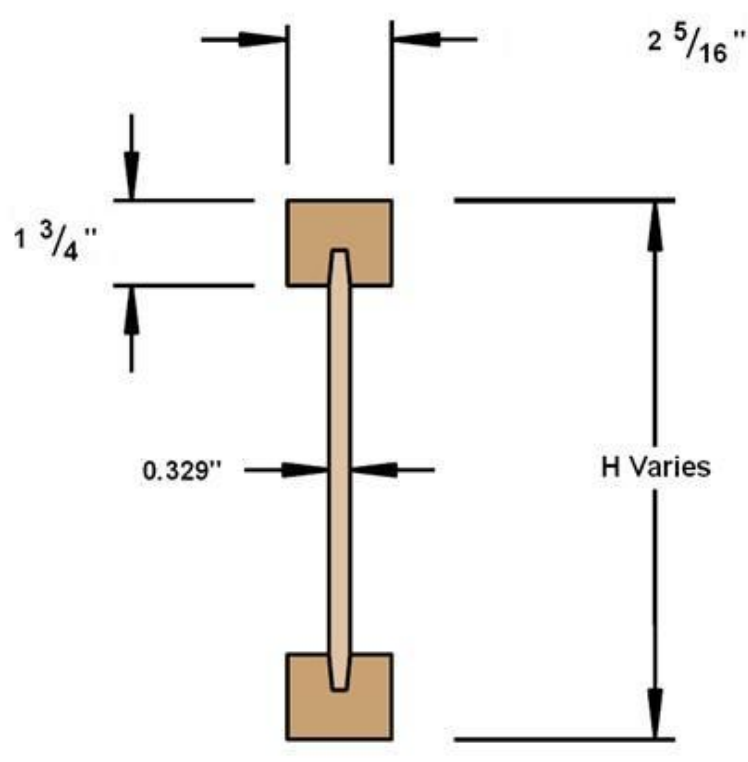

Figure 4.4 Cross-Sectional Geometry of the I-Beam

Table 4.1 Material Properties of Composite I-Beams

\begin{tabular}{c|c|c|c|c|c|c|c}
\hline \hline & $E_{1}(\mathrm{psi})$ & $\boldsymbol{E}_{\boldsymbol{1}}(\mathrm{psi})$ & $\boldsymbol{G}_{12}(\mathrm{psi})$ & $\boldsymbol{G}_{1 \mathbf{1}}(\mathrm{psi})$ & $\boldsymbol{G}_{\mathbf{2 z}}(\mathrm{psi})$ & $\boldsymbol{V}_{\boldsymbol{1 2}}$ & $\boldsymbol{V}_{\mathbf{2 1}}$ \\
\hline Web & 2260000 & 180000 & 152000 & 148000 & 148000 & 57000 & 2755 \\
Flanges & 1940000 & 64000 & 61000 & 67000 & 67000 & - & - \\
\hline \hline
\end{tabular}

ABAQUS (2007) is used for the FE analysis, while FEMAP (2003) is used for pre-and-post processing. The modeling of the sinusoidal web is accomplished in AUTOCAD and the geometry is then exported into FEMAP. The flanges and the web are modeled with eight-node shell elements, S8R. A global mesh size of 0.4275 " is chosen based on a convergence study resulting in 128 elements (16 along the sinusoidal curve and 8 elements along the height) for web, and 164 elements for both flanges. 
Spring element is used to simulate elastic restraints between the flanges and the web. Nodes are created on the flanges that mirrored nodes on the top and bottom of the web a very short distance away. To simulate the elastic restraint between the two flanges and the web, six spring elements are used to connect each of these nodes to represent constraints for each global $x, y$, and $z$ displacements and rotations. The normal spring stiffness is set to a very large value. This value prevents the flanges detaching from the web. The rotational stiffness is varied to represent the relative constraining condition. An eigenvalue analysis is then performed, where the first buckling mode is taken as the critical buckling load. The first buckling mode of a 10 " deep sinusoidal web I-beam is shown in Figure 4.5.

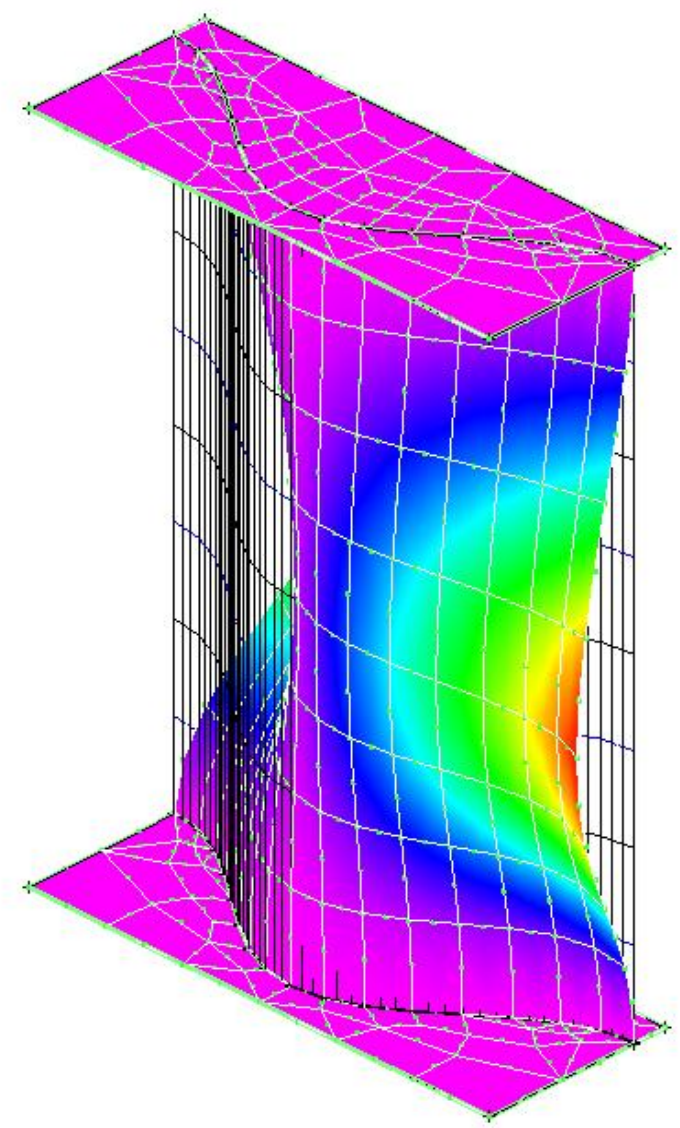

Figure 4.5 First Buckling Mode for 10" Sinusoidal Web I-Beam 
To compare the FE analysis with the analytical solutions, a study is performed in which the height of the web is varied and the spring stiffness is kept constant $\left(k_{z}=\frac{4 \pi m \omega D_{22}}{(1-\omega) h}\right)$. The results of this study are shown in Figure 4.6, where the FE analysis and theoretical solutions show good correlation. Next, the height of the beam is fixed, and the spring stiffness for FE analysis or the elastic rotational restraint stiffness $k_{z}$ is varied to study the restraining effect from the flanges on the buckling load of the beam. Two cases are shown in Figure 4.7, with the beam heights to be 10" and 16", where good correlations can be observed, with a maximum difference of $7 \%$.

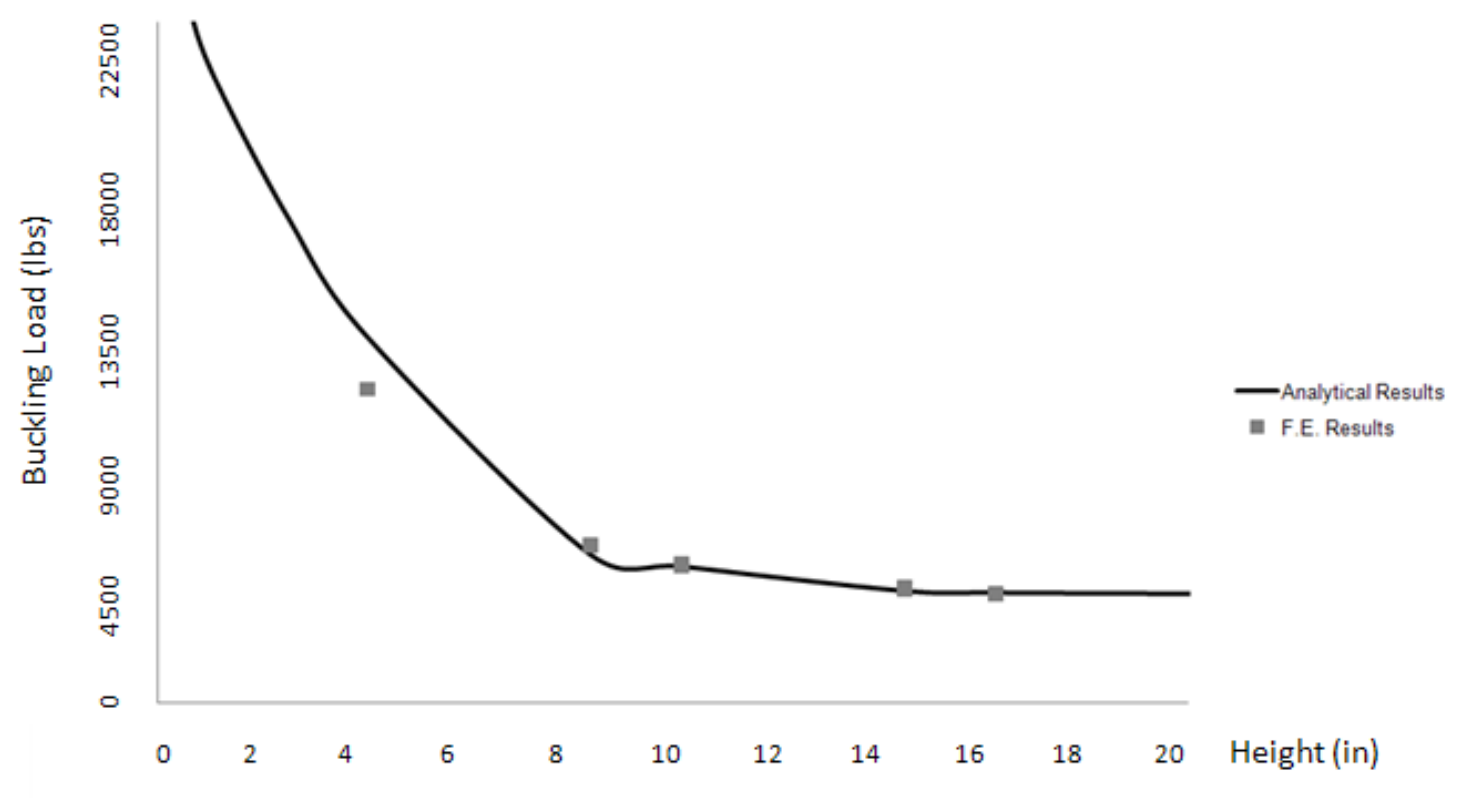

Figure 4.6 Critical Buckling Load vs Web Height $\left(k_{z}=234 \mathrm{lbs}\right.$-in/in) 


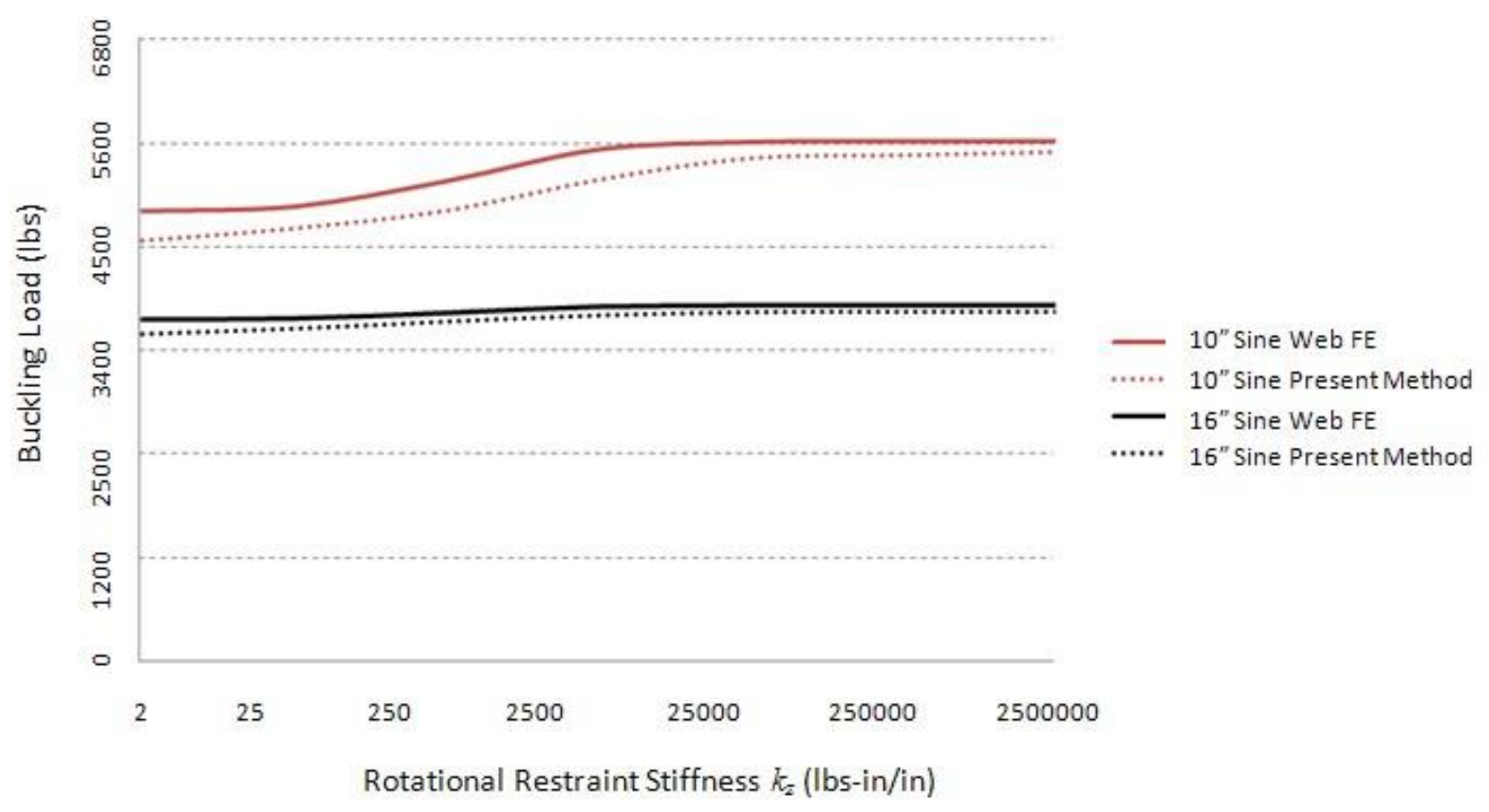

Figure 4.7 Buckling Load vs Spring Stiffness Coefficient for Elastic Restraints

\subsection{Experimental Investigation}

Compression tests were performed to further investigate the behavior of the veneer strand composite I-beams under out-of-plane compression loading. The specimens were cut from full-size l-beams at lengths of 6 " to attain a representative sample of a full beam. Two different heights of 10" and 16" were tested for flat and sinusoidal web geometries. Figure 4.4 shows the cross-sectional geometry of the test specimens, except that the web thickness for the flat beam was 0.375 " to achieve an equivalent volume per unit length between the flat and sinusoidal web.

All tests were carried out according to ASTM D5055-05 (2005) standards, and testing was performed using a hydraulic testing machine. A load cell was placed between the sample and the loading block to record the load in real time, and two LVDTs were placed symmetrically on either side of the sample to record displacement. Also two strain gauges were bonded at the mid height, with one on each side of the web 
to record compressive strains. The test setup is shown in Figure 4.8 where the load was applied uniformly over the top flange. The loading rate was controlled such that failure was reached within $10 \mathrm{~min}$.

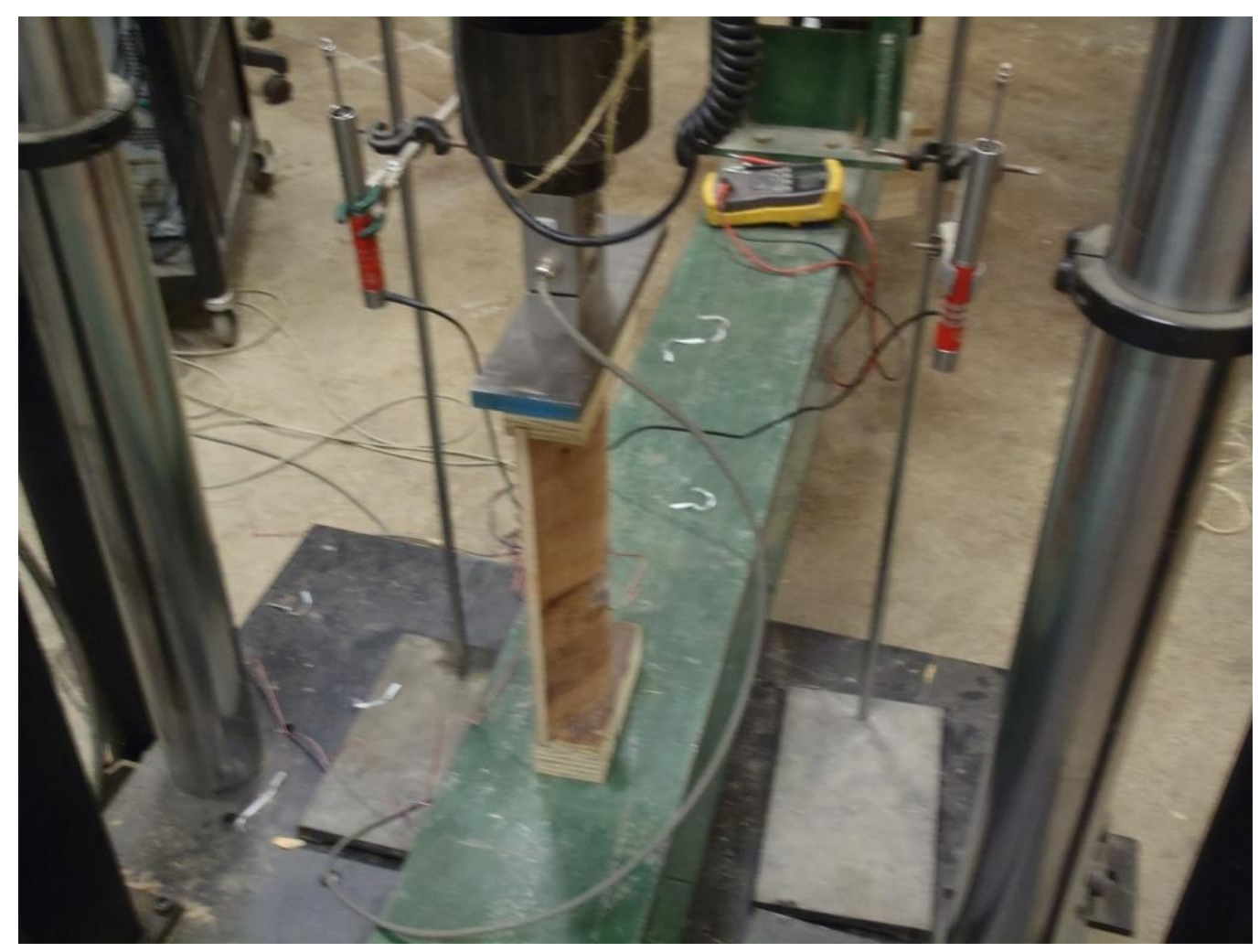

Figure 4.8 Sinusoidal I-Beam Compression Test

Three specimens for each geometry were evaluated under out-of-plane compression. The test results are shown in Table 4.2. Results from the analytical model and FE analysis considering hinged and clamped conditions are also provided in Table 4.2 . 
Table4.2 Estimated Value of Buckling Load for Compression Tests, FE Analysis, and Theoretical Formulation

\begin{tabular}{c|c|c|c|c}
\hline \hline & \multicolumn{2}{|c|}{ Flat Web Beam } & Sinusoidal Web Beam \\
\hline Beam Height (in) & 10 & 16 & 10 & 16 \\
\hline $\begin{array}{c}\text { Experimental Results (Ibs) } \\
\text { Range (Ibs) }\end{array}$ & 1389.32 & 876.75 & 4399.5 & $\begin{array}{c}3736.3 \\
3069- \\
4217\end{array}$ \\
\hline $\begin{array}{c}1243-1619 \\
\text { Finged Boundary Conditions } \\
\text { (Ibs) }\end{array}$ & 701.4 & 238.3 & 4891.8 & 3700.4 \\
$\begin{array}{c}\text { Fixed Boundary Conditions } \\
\text { (Ibs) }\end{array}$ & 2724.7 & 919.5 & 5635.96 & 3857.7 \\
\hline \multicolumn{4}{c}{ Theoretical Formulation $P_{c r}$} \\
\hline $\begin{array}{c}\text { Hinged Boundary Condition } \\
\text { (Ibs) }\end{array}$ \\
\begin{tabular}{c} 
Fixed Boundary Condition (Ibs) \\
\hline \hline
\end{tabular}
\end{tabular}

It can be observed that the buckling load for the beams with sinusoidal web are much higher than for those with flat web, with increases of $217 \%$ and $326 \%$ for 10 " and 16 " beams, respectively. It is also interesting to find out that all the buckling loads from the test for all beams expect the 10" sinusoidal core, are within the predicted values for hinged and clamped boundaries at the web-flange interface, which indicated that the web-flange joints are elastically restrained, as pointed out by Davalos and Chen (2005) and Shan and Qiao (2007). Once the elastic restrain stiffness $k_{z}$ can be experimentally determined for the tested beam, Equation (5.25) can be used to accordingly calculate the buckling load. The predicted value is much higher for the 10" beam with sinusoidal webs, with 4559.13lbs and 5525.8lbs for hinged and clamped boundary conditions, respectively. Based on the compressive strength for coupon tests 
from a previous study (McGraw, 2008), the compressive load for the beam can be calculated as:

$$
P_{c r}=\sigma_{u l t} \cdot A=\left(2300 \mathrm{lbs} / \mathrm{in}^{2}\right)\left(2.25 \mathrm{in}^{2}\right)=5175.65 \mathrm{lbs}
$$

which indicated that the failure can be either buckling or material compression failure depending on the elastic restraining effect of the web-flange joints. Since the test result was $P_{c r}=4399.51 \mathrm{lbs}$, which was close to $4559.13 \mathrm{lbs}$, the failure mode was also buckling.

Another interesting finding is that the difference between the buckling loads for hinged and clamped conditions for the sinusoidal web are less than those for the flat web, indicating that the effect of flange-web joints is less critical for beams with sinusoidal web. This is another advantage for beams with sinusoidal web, since a rigid or clamped connection between flange and web is difficult to achieve during manufacturing.

\subsection{Parametric Study}

Using the analytical model derived above, a parametric study is first carried out by varying the elastic rotational restraint stiffness, $k_{z}$, for seven different heights, as shown in Figure 4.6. Next, the rotational restraint stiffness is fixed and the web height is varied, with results shown in Figure 4.7. It can be seen from Figures 4.9 and 4.10 that the restraining effect from flange-web joint becomes less significant as core height increases. When the beam height reaches 14.25 ", the buckling capacity of the beam remains approximately constant, independently of the height. 


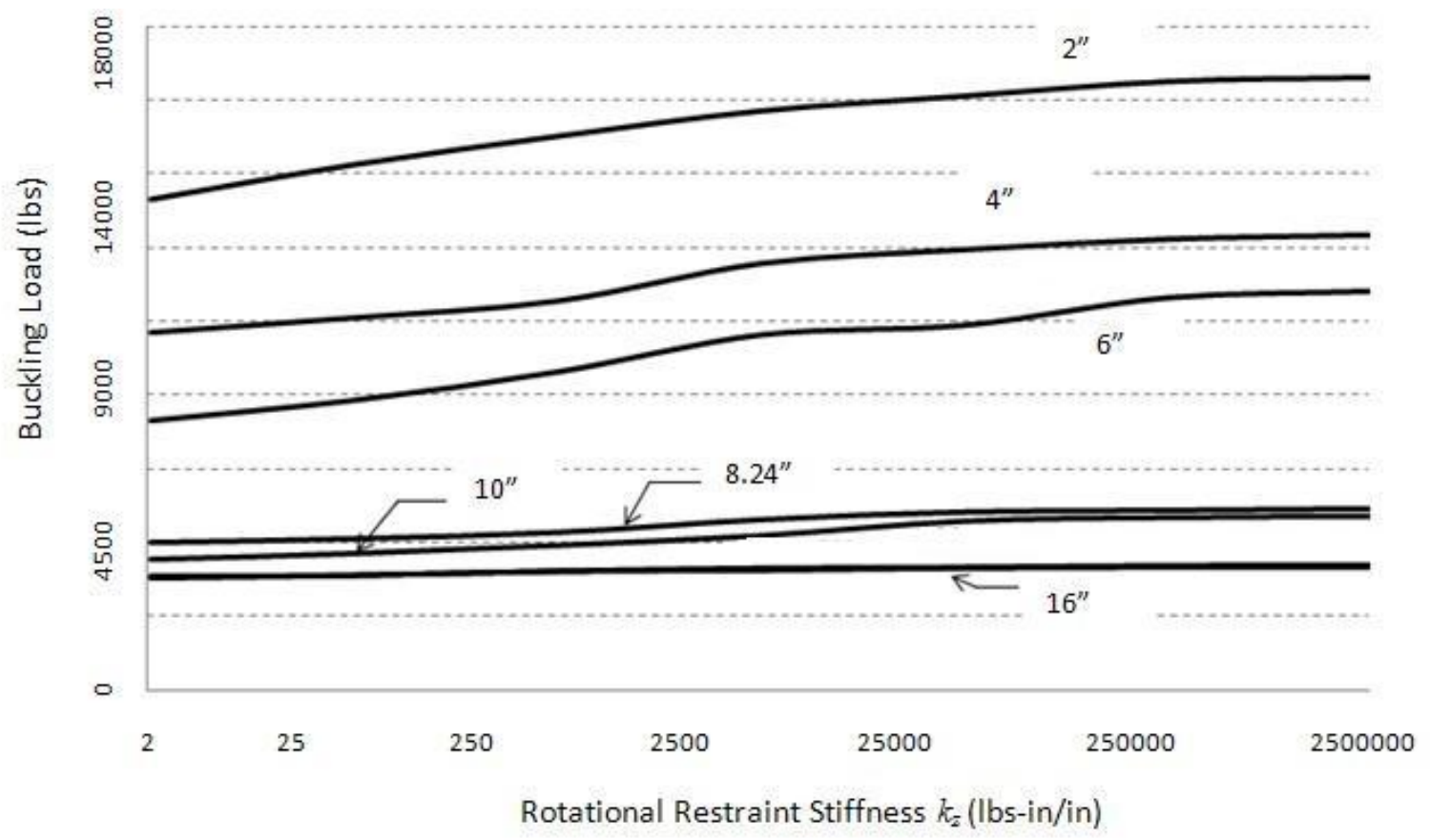

Figure 4.9 Critical Buckling Load vs Spring Stiffness for Various Heights

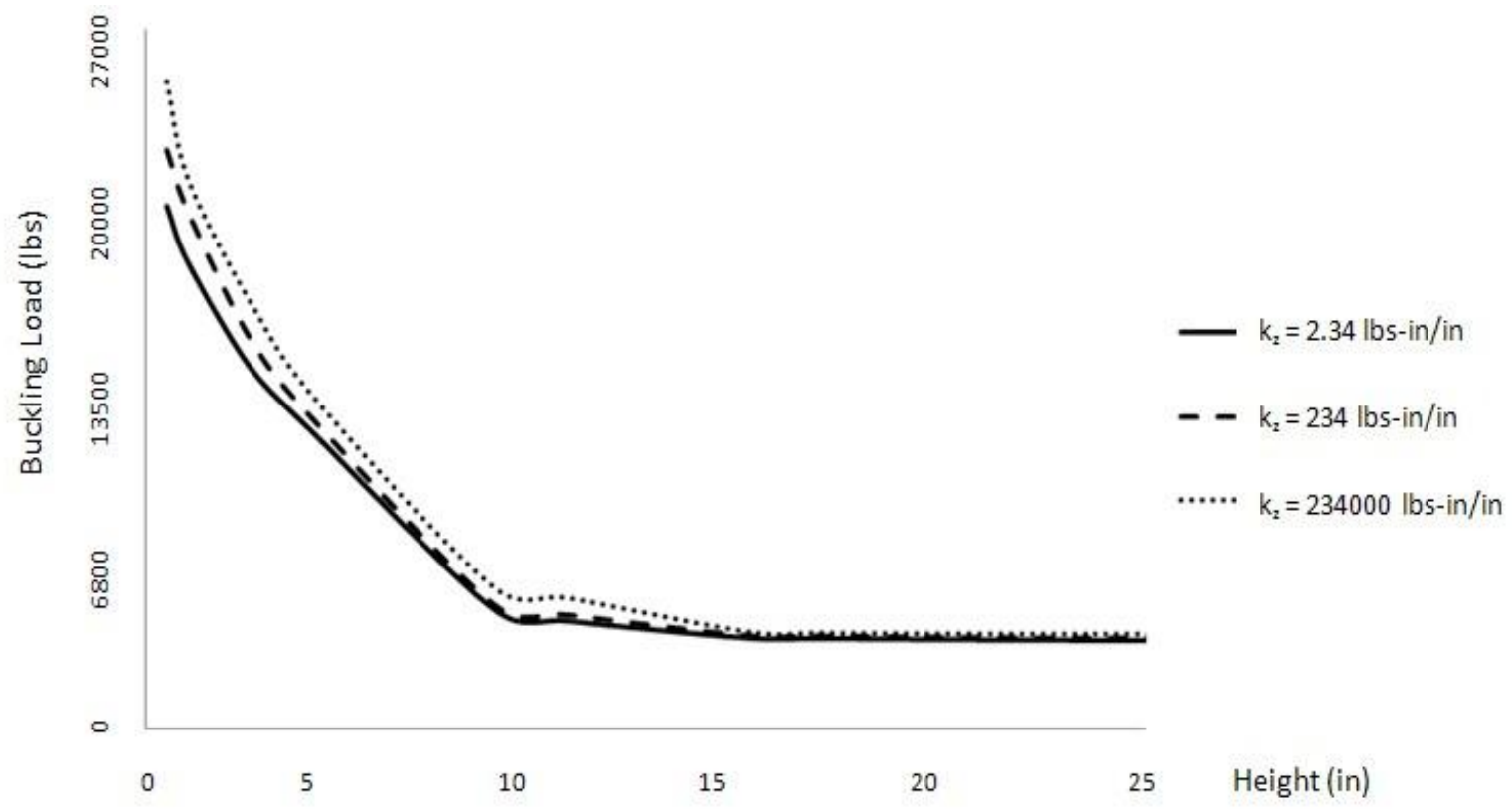

Figure 4.10 Critical Buckling Load vs Web Height for Various Rotational Restraint Stiffnesses 


\subsection{Conclusions}

A combined analytical and experimental study of elastic buckling analysis is given for composite wood I-beams with sinusoidal web geometry under out-of-plane compression. The theoretical predictions were verified through a FE analysis. An experimental study was conducted to evaluate representative I-beam samples under out-of-plane compression loading. Both the analytical solutions and FE analysis were used to predict the buckling load for the tested samples. Finally, a parametric study was carried out to study the effect of the flange-web restraining effects and heights. Based on the results of this study, the following conclusions can be drawn:

1) The explicit solutions derived in this chapter can predict the buckling strength of curved shells with partially elastically restrained loaded edges. The accuracy was verified with FE analysis. Although only the solutions for sinusoidal shell are provided in this study, the model can be easily extended to study other shapes.

2) The typical failure mode for I-beams with veneer-mill clipping composite web panels observed in the compression test was buckling.

3) Based on testing and analytical results, the beams with sinusoidal webs greatly outperformed those with flat webs of the same volume in terms of buckling load. Material compression failure rather than buckling failure was achieved for the 10" sinusoidal web I-beam. For samples that failed due to buckling, the buckling load was in between the values predicted assuming hinged and clamped boundary conditions, verifying the assumption that the flange-web joint is elastically restrained.

4) A parametric study was carried out by varying the elastic restrain stiffness and core height. The restraining effect becomes negligible as the height of the beam increases and the buckling load begins to plateau for a height of approximately 14.25". 
CHAPTER FIVE

\section{CONCLUSIONS AND}

\section{RECOMMENDATIONS}


The goal of this study aims to develop explicit buckling solutions for composite Ibeams, so that design analysis and optimization of such the structures can be greatly facilitated. A comprehensive study on stability analyses (i.e., flexural-torsional buckling, local buckling) of composite I-beams is presented. Major conclusions are presented, followed by recommendations for future work.

\subsection{Conclusions}

\subsubsection{Flexural-Torsional Buckling of Composite I-Beams with Sinusoidal Web}

In this thesis, an analytical model is presented to evaluate the critical buckling capacities of flexural-torsional (lateral) buckling of composite I-beams. Sinusoidal web geometry is considered, including simply-supported and cantilever boundary conditions. Experimental testing and FE simulation are carried out to verify the analytical solutions.

The analytical solutions are obtained based on energy method, deriving the total potential energy equations governing instability based on plate and shell theory. Good correlations can be obtained between the analytical solutions and experimental and FE results. Based on the parametric study,

1) The critical buckling load becomes larger as web height increases;

2) As shortening beam lengths, critical buckling load increases significantly;

3) Comparing with flat web critical buckling load, sinusoidal web increases more than $20 \%$;

4) The analytical model can be extended to study other types of composite I-beams with curved web and can be used to carry out parametric study to optimize Ibeams with curved web.

\subsubsection{Local Buckling of Sinusoidal Web I-Beams}

An analytical study of elastic buckling analysis is given for composite I-beams with sinusoidal web geometry under out-of-plane compression. The theoretical predictions were verified through a FE analysis. An experimental study was conducted 
to evaluate representative I-beam samples under out-of-plane compression loading. Both the analytical solutions and FE analysis were used to predict the buckling load for the tested samples. Finally, a parametric study was carried out to study the effect of the flange-web restraining effects and heights. Based on the results of this study, the following conclusions can be drawn,

1) The explicit solutions derived in this chapter can predict the buckling strength of curved shells with partially elastically restrained loaded edges. The accuracy was verified with FE analysis. Although only the solutions for sinusoidal shell are provided in this study, the model can be easily extended to study other shapes.

2) The typical failure mode for I-beams with veneer-mill clipping composite web panels observed in the compression test was buckling.

3) Based on testing and analytical results, the beams with sinusoidal webs greatly outperformed those with flat webs of the same volume in terms of buckling load. Material compression failure rather than buckling failure was achieved for the 10" sinusoidal web I-beam. For samples that failed due to buckling, the buckling load was in between the values predicted assuming hinged and clamped boundary conditions, verifying the assumption that the flange-web joint is elastically restrained.

4) A parametric study was carried out by varying the elastic restrain stiffness and core height. The restraining effect becomes negligible as the height of the beam increases and the buckling load begins to plateau for a height of approximately 14.25".

\subsection{Recommendations for Future Work}

Though extensive study on flexural-torsional and local buckling for composite structures is presented, there is still a need to develop more generic formulations for stability of composite structures. The following recommendations should be provided for future endeavors: 
1) More buckling models of I-beams with different web geometries, loading and boundary conditions should be further considered (e.g., lateral-distorsional buckling);

2) Only some special cases are studied, and their flexural-torsional buckling explicit solutions are derived. More generic solutions for various composite structural shapes with different loading and boundary conditions should be further developed;

3) A comprehensive study on local buckling of rotationally restrained composite panel primarily under compression is provided;

4) More detailed study on the explicit solutions under other types of loads (e.g., shear, pullout or distributed) as well as their limitations should be investigated. 


\section{REFERENCES}


ABAQUS User's Manual (2007). SIMULIA, Dassault Systems S. A., RI.

Anderson, J. M. and Trahair, N. S..(1972). "Stability of Monosymmetric Beams and Cantilevers."J. Struct. Division, ASCE, 98(1), 269-285.

Arnold, M. A. van der Heijden Ed.. (2008). "W. T. Koiter's Elastic Stability of Solids and Structures." Cambridge University Press.

ASTM Designation: D5055-05, "Standard Specification for Establishing and Monitoring Structural Capacities of Prefabricated Wood I-Beams" (2005). ASTM, PA, USA.

Barbero, E.J., Raftoyiannis, I.G..(1994). "Lateral and Distortional Buckling of Pultruded I-Beams". Comp. Struct., 27(3), 261-8.

Barenblatt, G. I.. (1962). "The Mathematical Theory of Equilibrium Cracks in Brittle Fracture", Adv. Appl. Mech., 7, 55-129.

Batdorf, S. B. (1947)..."A Simplified Method of Elastic-Stability Analysis for Thin Cylindrical Shells." NACA-report 874.

Bejo, L. (2001).. "Simulation Based Modeling of the Elastic Properties of Structural Composite Lumber." Dissertation, West Virginia University.

Bleich, F. (1952)..."Buckling Strength of Metal Structures." McGraw-Hill, New York, USA.

Booth, L. G.. (1974).. "The Effect of Flange-Web Joint Design on the Design of Plywood I-Beams." J. Inst. Wood Sci. 6 (6): 13-24.

Bruhn, E. F (1973).."Analysis and Design of Flight Vehicle Structures."Jacobs Publishing Inc., Indianapolis, IN.

Chajes, A. (1993).."Principles of Structural Stability Theory." Englewood Cliffs, New Jersey: Prentice-Hall. 
Chui, Ying H., Komatsu, K., Jung, K., Noda, Y., Ohashi, Y., and Toda, M.. (2008). "Reinforcement of Wood I- Beams with Natural Fibers." Proceedings of the World Conf. Timber Engrg. 2008. Miyazaki, Japan.

Davalos, J. F., and Chen, A.. (2005). "Buckling Behavior of Honeycomb FRP Core with Partially Restrained Loaded Edges under Out-of-plane Compression." J. Comp. Materials, 39(16), 1465-1484.

Davalos, J. F., Qiao, P. and Salim, H.. (1997). "Flexural-torsional buckling of pultruded fiber reinforced plastic composite I-beams: experimental and analytical evaluations." J. Comp. Struct., 38, 241-250.

Davalos, J. F., Qiao, P., and Barbero, E. J..(1996). "Multi-Objective Material Architecture Optimization of Pultruded FRP I-Beams." Comp. Struct., 35(3), 271-281.

Donnell, L. H..(1933). "Stability of Thin-Wailed Tubes under Torsion."NACA Rep. No. 479.

Dugdale, D. S..(1960). "Yielding of Steel Sheets Containing Slits", J. Mech. Phys. Solids, 8, 100-4.

FEMAP user's Manual (2003). EDS PLM Solutions, Exton, PA.

Fergus, D. A..(1979). "Effect of Web Voids and Stiffness on Structural Performance of Composite I-Beams." Ph.D. Dissertation, Purdue University, West Lafayette, IN.

Forest Products Laboratory.. (1999). "Wood Handbook: Wood as an Engineering Material." FPL-GTR-113.USDA Forest Products Laboratory, Madison, WI.

Fraternali, F., Feo,L.. (2000). "On a Moderate Rotation Theory of Thin-Walled Composite Beams." J. Comp. Part B, 31, 141-58.

Galambos, T. V.. (1963). "Inelastic Lateral Buckling of Beams."J. Struct. Division, ASCE, 89(ST5), 217-242. 
Germer, J.. (1986). “Designer Beams.” Prog. Build. 11(9): 21-23.

Hilson, B. O. and Rodd, P. D..(1979). "The Ultimate Shearing Strength of Timber I-Beams with Hardboard Webs." Struct. Engrg. 57B (2): 25-36.

Hutchinson, J.. (1992). "Mixed Mode Cracking in Layered Materials", Adv. Appl. Mech., 29, 163-199.

Johnson, J. A. and et al.. (1975). "The Performance of Composite Wood/Particleboard Beams under Two-Point Loading." Wood Fiber 8 (2): 85-97.

Jokerst, R. W.. (1981). "Finger-Jointed Wood Products." USDA Forest Serv.. Res. Pap.FPL 382. Forest Prod. Lab., Madison, WI.

Keil, B.. (1977). "Plywood Lumber are Joined for Wood, Energy Saving at Wood I-Beams" Plywood Panel Mag., 18(2): 14-15.

Kitipornchai, S. and Trahair, N. S.. (1975). "Elastic Behavior of Tapered Monosymmetric I-Beams Under Moment Gradient." J. Struct. Division, ASCE, 101(8), 1661-1678.

Koehl, S.. (1976). "Composite I-Beams: Effect of Adhesive or Faster Rigidity." USDA Forest Serv. Res. Pap. FPL. 152.

Kollar, L.P.. (2002). "Buckling of Unidirectional Loaded Composite Plates with One Free and One Rotationally Restrained Unloaded Edge" J. Struct. Engrg, 128(9): 1202-1211.

Laufenberg, T. L.. (1982). "Exposure Effects upon Performance of Laminated Veneer Lumber and Glulam Materials." Forest Prod. J. 32 (5): 42-48.

Leichiti, R. J., Falk, R. H., and Laufenberg, T. L.. (1989). "Prefabricated Wood IBeams: A Literature Review."Wood Fiber Sci., 2(1): 62-79.

Leichiti, R. J., Falk, R. H., and Laufenberg, T. L.. (1990). "Prefabricated Wood IBeams: An Industry Overview." Forest Products J., 40(3): 15-20. 
Leichti, R. J. and Tang, R. C.. (1983). "Analysis of Wood Composite I-Beams with Glued Flange-Web Joints." Spring Meeting, SESA. Brookfield Center, MA.

Leichti, R. J.. (1986). "Assessing the Reliability of Wood Composte I-Beams." Ph. D. Dissertation. Auburn University, AL.

Lewis, W. C., and et al.. (1960). "Design of Plywood Webs in Box Beams: Buckling in Shear Webs of Box and I-Beams and the Effect upon Design Criteria" USDA Forest Serv., No. 1318-B.

Lin, Z.M., Polyzois,D.. (1996). "Stability of Thin-Walled Pultruded Structural Members by Finite Element Method." J. Thin-Walled Struct., 24(1), 1-18.

Ma, M. and Hughes, O.. (1996). "Lateral Distortional Buckling of Monosymmetric I-Beams under Distributed Vertical Load." J. Thin-Walled Struct., 26, 123-145.

Maley, J. D.. (1987). "Wood I-Beams: A Closer Look." Building Struct.. ASCE. NY. 221-235.

Mallick, P. K.. (1988). "Fiber-Reinforced Composites: Materials, Manufacturing, and Design", Marcel Dekker Inc., NY,

McGraw, B., Chen, A., Davalos, J.F., and Ray, I.. (2011). "Evaluation of Wood Composite I-Beam with Sinusoidal Web," submitted to the 13th ASCE Aerospace Division Conference on Engrg, Construction, and Operations in Challenging Environments (Earth and Space 2012 Conference), Pasadena, CA, April 15-18, 2012.

McGraw, B., Roy, M., Jiao, P. and et al.. "Evaluation of Lateral and Distortional Buckling of Wood I-Beam with Sinusoidal Web Geometry. " (in press)

McGraw, B.. (2009). "Recycling Veneer-Mill Residues into Engineered Products with Improved Torsional Rigidity," Master Thesis, West Virginia University. 
McNatt, J. D.. (1980). "Hardboard-Webbed Beams: Research and Application." J. Forest Prod, 30 (10): 57-64.

Michell, A. G. M.. (1899). "Elastic Stability of Long Beams under Transverse Forces." Philosophical M., 48, 298-309.

Murakami, H., Yamakawa,J.. (1996). "On Approximate Solutions for the Deformation of Plane Anisotropic Beams." Comp. Part B, 27B, 493-504.

Nethercot, D.A., Rockey, K.C.. (1971). "An Unified Approach to the Elastic Lateral Buckling of Beams." Struct. Engrg.,49(7), 321-30.

Norlin, B.. (1988). "Buckling of Hardboard-Webbed I-Beams." ICTE, Washington State University, Pullman. WA. 213-215.

Pandey, M.D., Kabir, M.Z., Sherbourne,A.N.. (1995). "Flexural-Torsional Stability of Thin-Walled Composite I-Section Beams." Comp. Engrg., 5(3), 321-42.

Percival, D. H. and et al.. (1977). "Pilot Test of Four 16-Foot, Wood-Based Composite Garage Headers." Forest Prod. J. 27 (9): 45-48.

Pi, Y. L., Trahair, N. S., and Rajasekaran, S.. (1992). "Energy Equation for Beam Lateral Buckling." J. Struct. Engrg., ASCE, 118(6), 1462-1479.

Qiao, P. and Zou, G.. (2003). "Local Buckling of Composite Fiber-reinforced Plastic Wide-flange Sections.” J. Struct. Engrg., 129(1): 125-129.

Qiao, P., Davalos, J.F. and Wang, J.. (2001). "Local Buckling of Composite FRP Shapes by Discrete Plate Analysis." J. Struct. Engrg., 127(3): 245-255.

Qiao, P., Zou, G. and Davalos, J. F.. (2003). "Flexural-Torsional Buckling of Fiber-Reinforced Plastic Composite Cantilever I-Beams." J. Comp. Struct., 60, 205-217.

Racher, P., Bocquet, J.F., and Bouchair, A.. (2007). "Effect of Web Stiffness on the Bending Behaviourof Timber Composite I-Beams." Materials and Design. 28(3): 844-849. 
Rice, J.. (1988). "Elastic Fracture Mechanics Concepts for Interfacial Cracks", ASME J. Appl. Mech., 55, 98-103.

Roberts, T. M. and Azizian, Z. G.. (1983). "Influence of Pre-Buckling Displacements on the Elastic Critical Loads of Thin-walled Bars of Open Cross Section." Int. J. Mech. Sci., 25(2), 93-104.

Roberts, T.M., Jhita,P.S.. (1983). "Lateral, Local and Distorsional Buckling of IBeams." Thin-Walled Struct., 1(4), 289-308.

Rosen, A. and Singer, J.. (1976), "Vibrations and Buckling of Axially Loaded Stiffened Cylindrical Shells with Elastic Restraints." Int. J. Solids Struct. 12(8), 577-588.

Shan, L. Y.. (2007). "Explicit Buckling Analysis of Fiber-Reinforce Plastic (FRP) Composite Structures." Ph.D. Disseration. Washington State University.

Shan, L.Y., and Qiao, P.. (2008). "Explicit local buckling analysis of rotationally restrained composite plates under uniaxial compression." Engrg. Struct., 30(1): 126140

Solli, K. H. and Lackuer, R.. (1986). "Strength Properties, Timber Quality and Grading of Structural Timber of Small Cross Section." Norsk Treteknisk Inst., Oslo, Norway.

Suhir, E.. (2009). "Thermal Stress in a Bi-Material Assembly with a 'PiecewiseContinuous' Bonding Layer: Theorem of Three Axial Forces", J. Appl. Phys., 42, 1-8.

Superfesky, M. J. and Ramaker, T. J.. (1976). "Hardboard-Webbed I-Beams Subjected to Short-Term Loading." USDA Forest Serv. Res. Pap. FPL 264.Forest Prod.Lab., Madison, WI.

Timoshenko, S. P. and Gere, J. M.. (1961). "Theory of Elastic Stability" $2^{\text {ed }}$. New York: McGraw-Hill. 
Tong, G. and Zhang, L.. (2003a). "A General Theory for the Flexural-Torsional Buckling of Thin-Walled Members I: Energy Method." Adv. in Struct. Engrg., 6(4), 293298.

Tong, G. and Zhang, L.. (2003b). "A General Theory for the Flexural-Torsional Buckling of Thin-Walled Members I: Fictitious Load Method." Adv. in Struct. Engrg., 6(4), 299-308.

Trahair, N. S.. (1993). "Flexural-Torsional Buckling of Structures." Boca Raton, Florida: CRC Press.

Ugural, A. C.. (1999). "Stresses in Plates and Shells." $2^{\text {nd }}$ Edition, McGraw-Hill, NY.

Vacharajittiphan, P. and Trahair, N. S..(1973). "Elastic Lateral Buckling of Portal Frames." J. Struct. Division, ASCE, 99(ST5), 821-835.

Vacharajittiphan, P. and Trahair, N. S.. (1975). "Analysis of Lateral Buckling in Plane Frames." J. Struct. Division, ASCE, 101(ST7), 1497-1516.

Ventsel E. and Krauthammer, T.. (2001). "Thin Plates and Shells." Marcel Dekker, Inc., New York, NY.

Wang, C. M., Wang, L., and Ang, K. K.. (1994). "Beam-Buckling Analysis via Automated Rayleigh-Ritz Method." J. Struct. Engrg., ASCE, 120(1), 200-211.

Wang, J.. (2006). "Cohesive Zone Model of Intermediate Crack-Induced Debonding of FRP-Plated Concrete Beam", Int. J. Solids \&Struct., 43, 6630-6648.

Wang, J.. (2007). "Cohesive Zone Model of FRP-Concrete Interface Debonding under Mixed-Model Loading", Int. J. Solids \& sturct., 44, 6551-6568.

Wang, J.. (2007). "Cohesive-Bridging Zone Model of FRP-Concrete Interface Debonding", Engrg.. Frac. Mech., 74, 2643-2658. 
Wang, Q. and Li, W. Y.. (1997). "A closed-form approximate solution of lateral buckling of doubly symmetric thin-walled members considering shear lag." Int. J. Mech. Sci., 32(16), 523-535.

White, M. W..(1956). "The Lateral Torsional Buckling of Yielded Structural Steel Members." Bethlehem, Pennsylvania: PhD Dissertation, Lehigh University.

Young, W. C.. (1989). "Roark's Formulas for Stress and Strain."McGraw-Hill, London, England.

Youngquist, J. Y. and et al.. (1984). "End-Jointing of LVL for Structural Use." Forest Prod. J. 34 (11/12): 25-32.

Zhu, E.C., Guan, Z.W., Rodd, P.D., and Pope, D.J.. (2005). "Buckling of Oriented Strand Board Webbed Wood I-Beams." J. Struct. Engrg., 131(10): 1629-1636.

Zou, G.. (1998). "An exact symplectic geometry solution for the static and dynamic analysis of Reissner plates." Comput. Methods Appl. Mech. Engrg., 156, 171 178. 
APPENDIX 


\section{BRIEF INTRODUCTION OF ENERGY METHOD}

\section{B.1 Principle of Virtual Work}

Suppose that an elastic body undergoes an arbitrary incremental displacement or so-called virtual displacement. This displacement need not actually occur and need not be infinitesimal. When the displacement is taken to be infinitesimal, as is often done, it is reasonable to consider the system of forces acting on the body as constant. The virtual work done by surface forces $P$ per unit area on the body in the process of bringing the body from the initial state to the equilibrium state is expressed as

$$
\delta W=\int_{A}\left(P_{x} \delta u+P_{y} \delta v+P_{z} \delta w\right) d A
$$

here $A$ is the boundary surface and $\delta u, \delta v, \delta w$ are the $x$-, $y$-, $z$ - directed virtual displacements.

The notation $\delta$ denotes the variation of a quantity. The strain energy $\delta u$ acquired by a body of volume $V$ as a result of virtual straining is

$$
\delta U=\int_{V}\left(\sigma_{x} \delta \varepsilon_{x}+\sigma_{y} \delta \varepsilon_{y}+\sigma_{z} \delta \varepsilon_{z}+\tau_{x y} \delta \gamma_{x y}+\tau_{x z} \delta \gamma_{x z}+\tau_{y z} \delta \gamma_{y z}\right) d V
$$

The total work done during the virtual displacement is zero: $\delta W-\delta U=0$. The principle of virtual work for an elastic body is thus represented

$$
\delta W=\delta U
$$

\section{B.2 Principle of Minimum Potential Energy}

In as much as the virtual displacements do not alter the shape of the body and the surface forces are regarded as constants, Equation B-3 can be written as follows

$$
\delta \Pi=\delta(U-W)=0
$$

In this expression 


$$
\Pi=U-W
$$

denotes the potential energy of the body. Equation B-4 represents the condition of stationary potential energy of the system. It can be shown that, for stable equilibrium, the potential energy is a minimum. For all displacements satisfying given boundary conditions and the equilibrium conditions, the potential energy will assume a minimum value. This is referred to as the principle of minimum potential energy.

The potential energy stored in a plate under a distributed lateral load $P(x, y)$ is

$$
\Pi=\frac{1}{2} \iiint_{V}\left(\sigma_{x} \delta \varepsilon_{x}+\sigma_{y} \delta \varepsilon_{y}+\tau_{x y} \delta \gamma_{x y}\right) d x d y d z-\iint_{A}(P w) d x d y
$$

For the case of constant plate thickness, the above may be written

$$
\Pi=-\frac{1}{2} \iint_{A}\left(M_{x} \kappa_{x}+M_{y} \kappa_{y}+2 M_{x y} \kappa_{x y}\right) d x d y-\iint_{A}(P w) d x d y
$$

A physical explanation of the terms of $U$ in this expression is as follows. As $\frac{\partial^{2} w}{\partial x^{2}}=\kappa_{x}$ represents the curvature of the plate in the $x-z$ plane, the angle corresponding to the moment $M_{x} d y$ equals $-\frac{\partial^{2} w}{\partial x^{2}} d x$. The strain energy or work done by the moments $M_{x} d y$ is thus $-\frac{1}{2} M_{x} \kappa_{x} d x d y$. The strain energy owing to $M_{y} d x$ and $M_{x y} d y$ are interpreted similarly. The principle of potential energy, referring to Equation B-7, is expressed in the form

$$
\Pi=-\iint_{A}\left(M_{x} \kappa_{x}+M_{y} \kappa_{y}+2 M_{x y} \kappa_{x y}\right) d x d y-\int_{A}(P \delta w) d x d y=0
$$

\section{B.3 Ritz Method}

The so-called Ritz method is a convenient procedure for determine solutions by the principle of minimum potential energy. The essence of this approach is described for the case of elastic bending of plates as follows 
First choose a solution for the deflection $w$ in the form of a series containing undetermined parameters $a_{m n}(m, n=1,2, \ldots)$. The deflection so selected must satisfy the geometric boundary conditions. The static boundary conditions need not be fulfilled. Clearly, a proper choice of the deflection expression is important to ensure good accuracy for the final solution. Thus, it is desirable to assume an expression for $w$ which is nearly identical with the true bent surface of the plate. Next, employing the selected solution, determine the potential energy $\Pi$ in terms of $a_{m n}$.

In order that the potential energy be a minimum at equilibrium

$$
\frac{\partial \Pi}{\partial a_{11}}=0, \ldots, \frac{\partial \Pi}{\partial a_{m n}}=0
$$

The foregoing represents a system of algebraic equations which are solved to yield the parameters $a_{m n}$. Introducing these values into the assumed expression for deflection, one obtains the solution for a given problem. In general, $a_{m n}$ includes only a finite number of parameters, and the final results are therefore only approximate. Of course, if the assumed $w$ should happen to be the "exact" one, the solution will then be "exact".

Advantages of the Ritz method lie in the relative ease with which mixed edge conditions can be handled. This method is among the simplest for solving plate and shell deflections by means of a hand calculation.

The applications of the stain-energy techniques in the treatment of bending, stretching, as well as buckling problems of plates and shells, will be discussed throughout the text. 